\title{
CONSPECTUS OF VEGETATION SYNTAXA IN SLOVENIA
}

\author{
Urban ŠILG ${ }^{1} \&$ Andraž ČARNI ${ }^{1,2}$
}

\begin{abstract}
For the first time, an overview of plant communities in Slovenia is presented according to the Braun-Blanquet approach. In total 588 associations (and some communities classified into higher syntaxa) belonging to 51 classes have been registered in Slovenia. Additionally 149 syntaxa are mentioned as registered in the field or in, the literature, but not documented with relevé material. Syntaxonomical classification is based on the "EuroChecklist" and includes also the Slovenian written definition of the high-rank syntaxa.
\end{abstract}

Key words: phytosociology, syntaxonomy, vegetation database.

\section{Izvleček}

Prvič je predstavljen pregled vseh rastlinskih združb v Sloveniji razvrščenih po Braun-Blanquetovem principu. Ugotovili smo 577 asociacij (in nekaj združb uvrščenih v višje sintaksone), ki pripadajo 47 vegetacijskim razredom registriranim v Sloveniji. Dodatno smo izpostavili 126 sintaksonov, ki smo jih opazili v naravi ali pa so jih omenili v literaturi, niso pa dokumentirani s popisnim gradivom. Sintaksonomska klasifikacija sledi seznamu "EuroChecklist", zato obenem predstavljamo tudi slovenske definicije višjih sintaksonov.

Ključne besede: fitocenologija, sintaksonomija, vegetacijska podatkovna baza.

\section{INTRODUCTION}

Vegetation science in Slovenia has a long and fruitful tradition beginning with the first studies by Gabrijel Tomažič in 1928 (Robič \& Wraber 2001, Zupančič 2003). All major vegetation types have been targeted so far, yet there is a clear bias towards forest communities. The major reason is because phytosociology (in its narrow sense - devoted mainly to classification of plant communities) was traditionally linked to forestry, mapping, planning and management of forest resources. While forests had therefore been well researched, other vegetation types had not been paid attention to or had been completely neglected. This has changed only in the recent decade.

There were some attempts to compile a catalogue of vegetation syntaxa in Slovenia, yet again - these were very much biased towards forests.
Wraber (1960) made the first attempt in this direction. Smole (1988) published a catalogue of forest communities used in mapping projects in various research institutions in Slovenia. Robič \& Accetto (2001) prepared a more extensive list of forest plant communities, comprising also some non-forest syntaxa used for education at the Department of Forestry and Renewable Forest Resources of the University of Ljubljana. Other plant community accounts featured "red lists" of endangered vegetation (Gregori et al. 1996) or, occasionally, syntaxonomic or nomenclatural revision of a single high-rank syntaxon (Marinček et al. 1993, Zupančič 1999, 2007, Surina et al. 2004, Šilc \& Čarni 2007, Poldini 2009).

The vegetation database of Slovenia using Turboveg (Hennekens \& Schaminée 2001) software enabled first a less biased insight into the vegetation research in Slovenia (Šilc 2006). Nu-

\footnotetext{
${ }^{1}$ Institute of Biology ZRG SAZU, Novi trg 2, SI - 1000 Ljubljana, Urban@zrc-sazu.si, Carni@zrc-sazu.si

${ }^{2}$ University of Nova Gorica, Vipavska 13, SI - 5000 Nova Gorica
} 
merical analyses of the collected relevés revealed which plant communities were well studied (and represented in the data set) and where there were obvious gaps.

Surely, some ideas of placement of the syntaxa presented in this paper will be controversial because of lack of field data and divergence of opinions about their classification. Yet, being the first comprehensive list of all syntaxa documented or presumed to occur (on the basis of observed vegetation stands which might be classified within the latter) in Slovenia, this is a stepping stone towards a detailed, critical and comprehensive national vegetation survey as already finalized (or underway) in many European countries such as the Netherlands, Germany, Austria, Czech Republic, Slovakia, and elsewhere.

The aims of this paper study are: (1) to compile a list of syntaxa known from (or presumed to occur in) Slovenia, (2) to classify them within a system of European high-rank syntaxa as presented in the so-called "EuroChecklist" (Mucina et al., in prep.) (3) to point out the obvious problems and gaps in our knowledge of syntaxonomy of the Slovenian vegetation, and (4) to introduce Slovenian written definitions of the high-rank syntaxa.

\section{METHODS}

Vegetation database of Slovenia (Šilc 2006, 2012), where the majority of accessible (published and from grey literature) relevés from the territory of Slovenia are stored, was a starting point for compilation of the list. Therefore for syntaxa stored in the database, a number of relevés classified are presented. For certain syntaxa (e.g. macrophytic vegetation) that were not researched according to the Braun-Blanquet approach (van der Maarel 2005) in Slovenia we used floristic data to evaluate the possible presence of these vegetation communities. Some communities that were noticed in the field but are not documented by published relevés were added as unpublished. For these data we are grateful to several researchers who contributed their knowledge to earlier versions of the list, and are mentioned next to these unpublished data.

The hierarchy of syntaxa is also shown by codes. The first number indicates class, first letter order, second letter alliance and second number association. These codes are also used in the Turboveg database.

\section{RESULTS AND DISCUSSION}

The syntaxonomical scheme in general follows the synsystem of the so-called "EuroChecklist" of Mucina et al. (in prep.) down to alliance level and with modifications in some syntaxa that were already elaborated for the territory of Slovenia.

The present list of vegetation units follows the rules of the Code of Phytosociological Nomenclature, but some exceptions should be made to obtain information on the existence of some vegetation units that are not validly published. In Slovenia the idea of geographical division of vegetation communities was very alive, with three nominal classification and geographical races according to the modified system of Matuszkiewicz \& Matuszkiewicz (1981). Some authors also neglected the rules of the Code and many names were kept in use, therefore we deliberately preserved those syntaxon names that will enable us to establish a starting point for syntaxonomical revisions of separate classes and vegetation as a whole on the basis of large database of relevés. We must take into consideration that in the Vegetation database of Slovenia (Šilc 2006, 2012) 86 $\%$ of relevés were classified into the synsystem by their authors and the rest also bear some information on the classification of plant communities.

The vegetation of Slovenia comprises $51 \mathrm{veg}$ etation classes indicating great diversity (Figure 1). Classes with the largest number of syntaxa are Molinio-Arrhenatheretea and Carpino-Fagetea. In both classes there are also a significant number of syntaxa that are not documented with relevés as they were only mentioned in some references. Another similar problem is represented by the vegetation of freshwater bodies that had been rarely investigated by the Braun-Blanquet method and the majority of syntaxa were introduced on the basis of floristic data. Three types of vegetation show also a high diversity of syntaxa and collected material: anthropogenic vegetation (classes Stellarietea mediae, Artemisietea and Galio-Urticetea), vegetation of rock crevices and rocks (classes Asplenietea trichomanes and Thlaspietea rotundifoliae) and vegetation of bogs and fens (classes Scheuchzerio-Caricetea fuscae and Oxycocco-Sphagnetea).

The number of vegetation classes shows the high diversity of vegetation. The same is confirmed by the high number of associations and communities (588), nevertheless rather a high number of communities not documented (and 


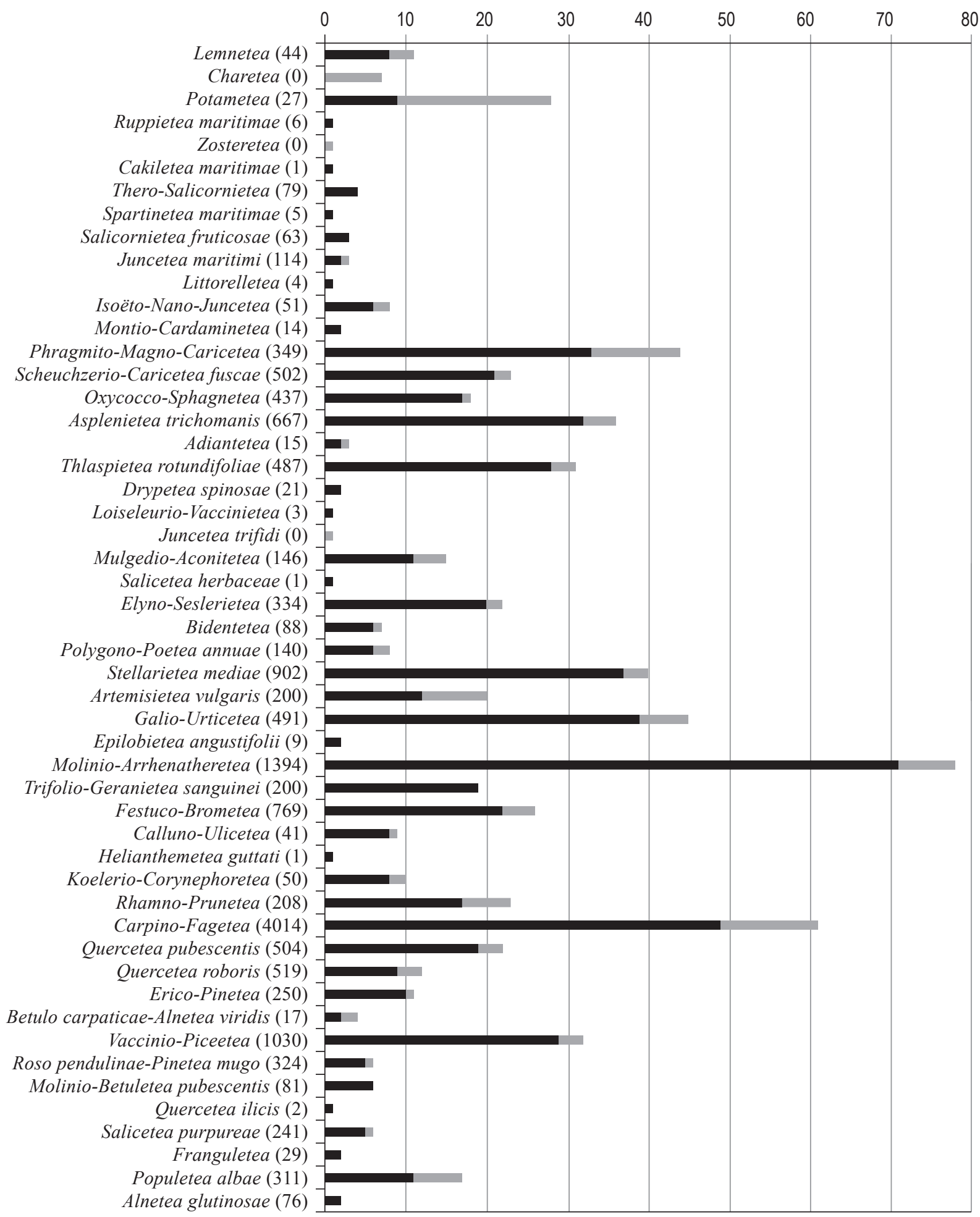

Figure 1: The number of syntaxa (associations and syntaxa on the rank of association) in different vegetation classes. The dark bar represents number of syntaxa supported by relevés and the grey bar the number of syntaxa mentioned as unpublished. The number of releves is shown by the name of class in brackets.

Slika 1: Število sintaksonov (asociacij in sintaksonov na nivoju asociacije) v različnih vegetacijskih razredih. Temen del stolpca predstavlja število sintaksonov za katere obstaja popisno gradivo, sivi del pa število sintaksonov, ki jih v tekstu omenjamo kot neobjavljene. Število popisov je prikazano v oklepajih ob imenu razreda. 
published) in the field by relevés (149) still points out the need for data collection and detailed, monographic treatments of some classes.

The list has been harmonized with the European checklist (Mucina et al. in prep) in order that the Slovenian classification would meet the common European standards and the syntaxa could be integrated into a wider framework. Therefore we amalgamated alliances Carpinon orientalis (Ostryo-Carpinion orientalis) and Fraxino orni-Ostryion that were traditionally treated as two alliances (Čarni et al. 2009). The classification of altimontane and subalpine spruce forests on the southern edge of their distribution in northern Slovenia is not clear, because the proportion of species from deciduous forests increases towards the south (Wallnöfer 1993). As this diversity is in major cases treated on the level of geographical races (Zupančič 1999) and according to numerical analysis of material originating from Slovenia (Čarni et al. in prep.), the classification of these associations i.e. Adenostylo glabae-Picceteum and Seslerio-Piceetum within the Chysanthemo-Piceion was accepted (Wallnöfer 1993). The floodplain riparian forests on nutrient-rich alluvial soils $\mathrm{Al}$ no-Fraxinetalia are subdivided into two alliances: Alnion incanae and Alno-Quercion that appears only in the (north)-eastern part of the country.

As already stated, the classification of vegetation could be done using different approaches and this system of classification is only one view over this subject. But it gives a kick off for future syntaxonomical analyses that will result in complete elaboration of the Vegetation of Slovenia based on relevé databases and modern numerical techniques.

\section{ACKNOWLEDGEMENTS}

We thank Igor Dakskobler, Mateja Germ, Petra Košir, Andrej Martinčič, Livio Poldini and many others for supplying us with valuable data on some communities and many comments on previous versions of the manuscript. Ladislav Mucina substantially improved our manuscript, and also allowed us to use the unpublished EuroChecklist. Tomaž Sajovic kindly checked the Slovenian translations. This project was funded from ARRS L1-6517.

\section{REFERENCES}

Čarni, A., Košir, P., Karadžić, B., Matevski, V., Redžić, S. \& Škvorc, Ž. 2009: Thermophilous deciduous forests in Southeastern Europe. Plant Biosystems 143: 1-13.

Exner, A. 2007: Piceetalia Pawł. 1928. In: Willner, W. \& Grabherr, G. (ed.): Die Wälder und Gebüsche Österreichs. 1. Textband. Elsevier, München, pp. 184-208.

Gregori, J., Martinčič, A., Tarman, K., Urbanc-Berčič, O., Tome, D. \& Zupančič, M. 1996: Narava Slovenije, stanje in perspektive: zbornik prispevkov o naravni dediščini Slovenije. Društvo ekologov Slovenije, Ljubljana, $424 \mathrm{p}$.

Hennekens, S. M. \& Schaminée, J. H. J. 2001: TURBOVEG, a comprehensive data base management system for vegetation data. Journal of Vegetation Science 12: 589-591.

Kopecký, K. 1992: Syntaxonomische Klassifizierung von Pflanzengesellschaften unter Anwendung der deduktiven Methode. Tuexenia 12: $13-24$.

Maarel van der, E. 2005: Vegetation ecology. Blackwell, Malden, $359 \mathrm{p}$.

Marinček, L., Mucina, L., Poldini, L., Zupančič, M., Dakskobler, I. \& Accetto, M. 1993: Nomenklatorische Revision der Illyrischen Buchenwälder (Verband Aremonio-Fagion). Studia geobotanica 12: 121-135.

Matuszkiewicz, W. \& Matuszkiewicz, A. 1981: Das Prinzip der mehrdimensionalen Gliederung der Vegetationseinheiten, erlaeutet am Beispiel der Eichen-Hainbuchenwaelder in Polen. Vaduz, Rinteln, 123-148 p.

Mucina, L. et al. 2012: EuroChecklist, in prep.

Poldini, L. 2009: La diversità vegetale del Carso fra Trieste e Gorizia. Lo stato dell'ambiente. Edizione Goliardiche, Trieste, 732 pp.

Robič, D. \& Accetto, M. 2001: Pregled sintaksonomskega sistema gozdnega in obgozdnega rastlinja Slovenije: gradivo za pouk fitocenologije. Biotehniška fakulteta, Oddelek za gozdarstvo in obnovljive gozdne vire, Ljubljana, $18 \mathrm{p}$.

Robič, D. \& Wraber, T. 2001: Življenje in delo botanika Gabrijela Tomažiča (1899-1977). Hladnikia 12: 7-21.

Šilc, U. \& Čarni, A. 2007: Formalized classification of weed vegetation of arable land in Slovenia. Preslia 79: 283-302. 
Šilc, U. 2006: Slovenian Phytosociology in a Database: state of the art, basic statistics and perspecitves. Hladnikia 19: 27-34.

Šilc, U. 2012: Vegetation database of Slovenia. Biodiversity \& Ecology 4 (in print)

Smole, I. 1988: Katalog gozdnih združb: pregled gozdnovegetacijskih raziskav po srednjeevropski fitocenološki metodi v Sloveniji s seznamom vseh doslej opisanih gozdnih združb ter njihova razvrstitev po medsebojni sorodnosti. Inštitut za gozdno in lesno gospodarstvo, Ljubljana, $154 \mathrm{p}$.

Surina, B., Dakskobler, I., Kaligarič, M. \& Seliškar, A. 2004: Seznam sintaksonov. In: Čušin, B. (ur.) \& al.: Natura 2000 v Sloveniji. Rastline. Založba ZRG, Ljubljana, pp. 168-172.

Wallnöffer, S. 1993: Vaccinio-Piceetea. In: Mucina, L., Grabherr, G. \& Wallnöffer, S. (ed.): Pflanzengesellschaften Österreichs-Wälder und Gebüsche. Gustav Fisher Verlag, Jena, Stuttgart, New York, pp. 283-337.

Wraber, M. 1960: Fitocenološka razčlenitev gozdne vegetacije v Sloveniji. In: Lazar, J. (ed.): Ad annuum horti botanici Labacensis solemnem. Ljubljana, pp. 49-98.

Zupančič, M. 1999: Smrekovi gozdovi Slovenije. Slovenska akademija znanosti in umetnosti, Ljubljana, $222 \mathrm{p}$.

Zupančič, M. 2003: Vegetacijska raziskovanja in kartiranje v Sloveniji. Zbornik gozdarstva in lesarstva 72: 5-18.

Zupančič, M. 2007: Syntaxonomic problems of the classes Vaccinio-Piceetea and Erico-Pinetea in Slovenia. Fitosociologia 44 (2): 3-13.

\section{APPENDIX REFERENCES}

Accetto, M. 1999: Floristična in vegetacijska opazovanja v ostenjih severovzhodne Kostelske. Gozdarski vestnik 57: 3-22.

Accetto, M. 2006: Nomenklaturna notica k sintaksonomskemu uvrščanju vlažnih dobovo-gabrovih gozdov. Samozaložba, Ljubljana, 6 p.

Čarni A. et al. (in prep.) Smrekovi in jelovi gozdovi v Sloveniji.

Čarni, A., Košir, P., Marinček, L., Marinšek, A., Šilc, U. \& Zelnik, I. 2008: Komentar k vegetacijski karti gozdnih združb Slovenije v merilu 1:50.000 - list Murska Sobota. Pomurska akademsko znanstvena unija - PAZU, Murska Sobota, 64 p.
Dakskobler, I. \& Čušin, B. 2003: Rastlinstvo in rastje Dolenje Trebuše in njene okolice. Trebuški zbornik, Tolminski muzej, Tolmin, s. 99-132.

Dakskobler, I. \& Marinšek, A. 2009: Pregled jelovih rastišč v Sloveniji. Zbornik gozdarstva in lesarstva (Ljubljana) 89: 43-54.

Dakskobler, I. 2004: Gozdna vegetacija Bovškega (Julijske Alpe, severozahodna Slovenija). Hladnikia 17: 25-38.

Dakskobler, I. 2005: Rastlinstvo in rastje (flora in vegetacija) Baške doline (zahodna Slovenija). Razprave 4. razreda SAZU (Ljubljana) 46-2: 5-59.

Exner, A. 2007: Vaccinio-Piccetea Br.-Bl. et al. 1939. In: Willner W. \& Grabherr, G.: Die Wälder und Gebüsche Österreichs. Spektrum, München, pp.183-218.

Franz, W. R. 2002: Die Hopfenbuche (Ostrya carpinifolia Scop.) in Österreich und NordSlowenien: (Morphologie, Anatomie, Verbreitung, Standort und Soziologie). Carinthia II, $1-256$.

Kaligarič, M. 2004: Podmorski travniki s pozejdonovko (Posidonion oceanicae) (EU_1120*). In: Jogan, N., Kotarac, M. \& Lešnik, A. (ed.) 2004: Opredelitev območij evropsko pomembnih negozdnih habitatnih tipov s pomočjo razširjenosti značilnih rastlinskih vrst. Center za kartografijo favne in flore, Ljubljana, pp. 34-39.

Košir, Ž. 1994: Ekološke in fitocenološke razmere $\mathrm{v}$ gorskem in hribovitem jugozahodnem obrobju Panonije. Ministrstvo za kmetijstvo in gozdarstvo, Ljubljana, 149 p.

Košir, Ž. 2000. Upoštevanje lastnosti gozdnih združb pri gospodarjenju s sečnimi ostanki. Gozdarski vestnik 58 (10): 439-445.

Košir, Ž. 2007: Položaj gorskih bukovih gozdov v Sloveniji. Gozdarski vestnik 65: 365-392, 409-421.

Košir, Ž. 2010: Lastnosti gozdnih združb kot osnova za gospodarjenje po meri narave. Zveza gozdarskih društev Slovenije, Gozdarska založba, Ljubljana, 288 p.

Marinček, L. 1994: Zur Nomenklatur der Hainbuchenwälder des Erythronio-Carpinion. In: (ed.): Simpozij-Pevalek Flora i vegetacija $\mathrm{Hr}$ vatske. Čakovec, pp. 57-62.

Marković, L. 1982: Ruderalna vegetacija ter vegetacija posek in gozdnih robov. In: Mayer, E. (ed.): Vegetacijska karta Postojna L33-77. Tolmač k vegetacijskim kartam. SAZU, Razred za naravoslovne vede, Biološki inštitut Jovana Hadžija, Ljubljana, pp. 96-112. 
Martinčič, A. \& Leskovar, I. 2002: Vegetacija. In: Gaberščik, A. (ed.): Jezero, ki izginja: monografija o Cerkniškem jezeru. Društvo ekologov Slovenije, Ljubljana, pp. 81-94.

Petkovšek, V. \& Seliškar, A. 1979: Vegetacija na Planinskem polju in njeno varstvo. Varstvo narave 12: 13-32.

Poldini, L. 1985: Note ai margini della vegetazione carsica. Studia geobotanica 5: 39-48.

Seliškar, A., 1996: Traviščna in močvirna vegetacija. In: Gregori, J., Martinčič, A., Tarman, K., Urbanc-Berčič, O., Tome, D. \& Zupančič, M. (eds.): Narava Slovenije, stanje in perspektive. Društvo ekologov Slovenije, Ljubljana, pp. 99-106.
Seljak, G. 1974: Travniška vegetacija Porezna. Univerza $\mathrm{v}$ Ljubljani,Biotehniška fakulteta, Ljubljana, 103 p.

Wallnöfer, S. 1993: Vaccinio-Piceetea. In: Mucina, L., Grabherr, G. \& Wallnöfer, S. Die Pflanzengesellschaten Österreichs, Teil III, Wälder und Gebüsche, Gustav Fischer Verlag, Jena, pp. 283-337.

Wraber, T. 1971: Contributo alla conoscenza della vegetazione pioniere (Asplenietea rupestria e Thlaspietea rotundifolii) delle Alpi Giulie. Università degli Studi di Trieste, Trieste, $81 \mathrm{p}$. 

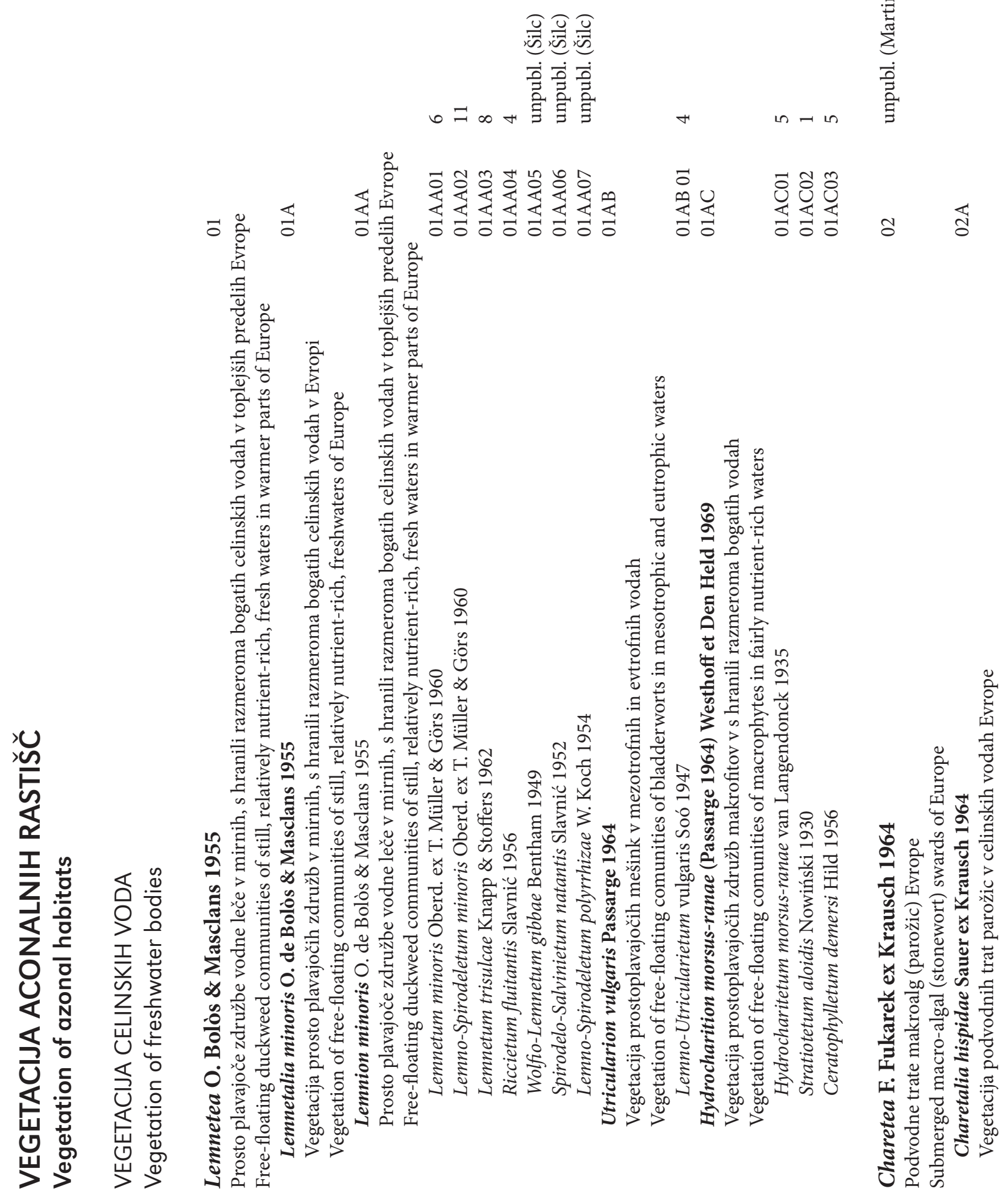


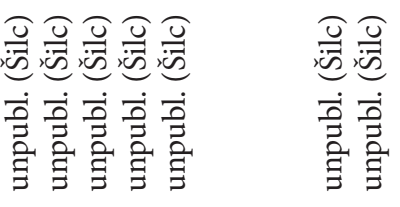

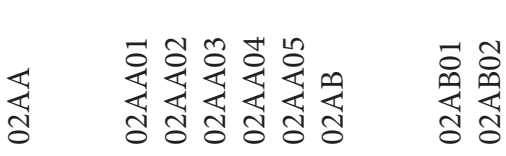

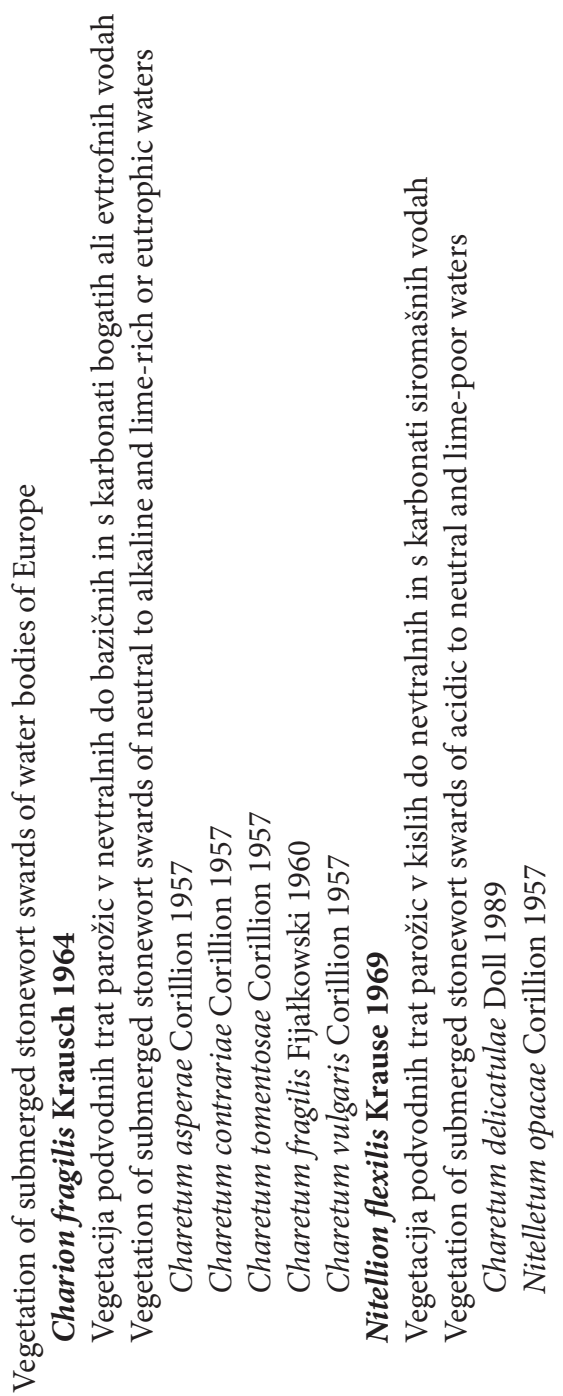

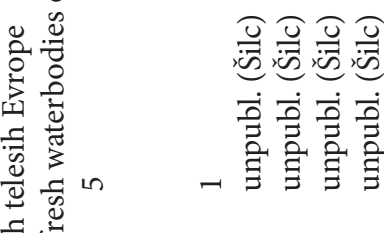

蜜总

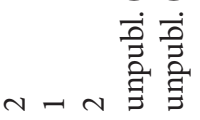

氙 
สิ

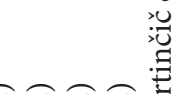

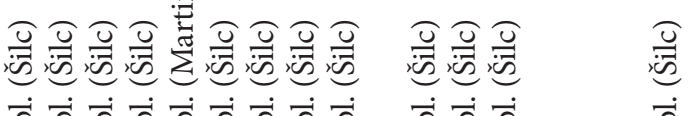

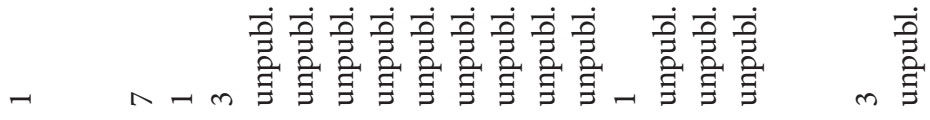

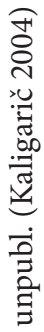

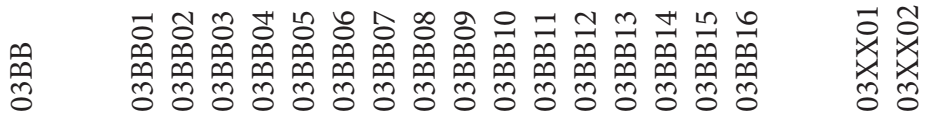

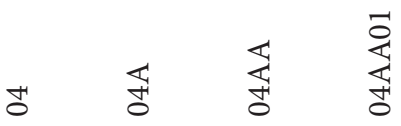

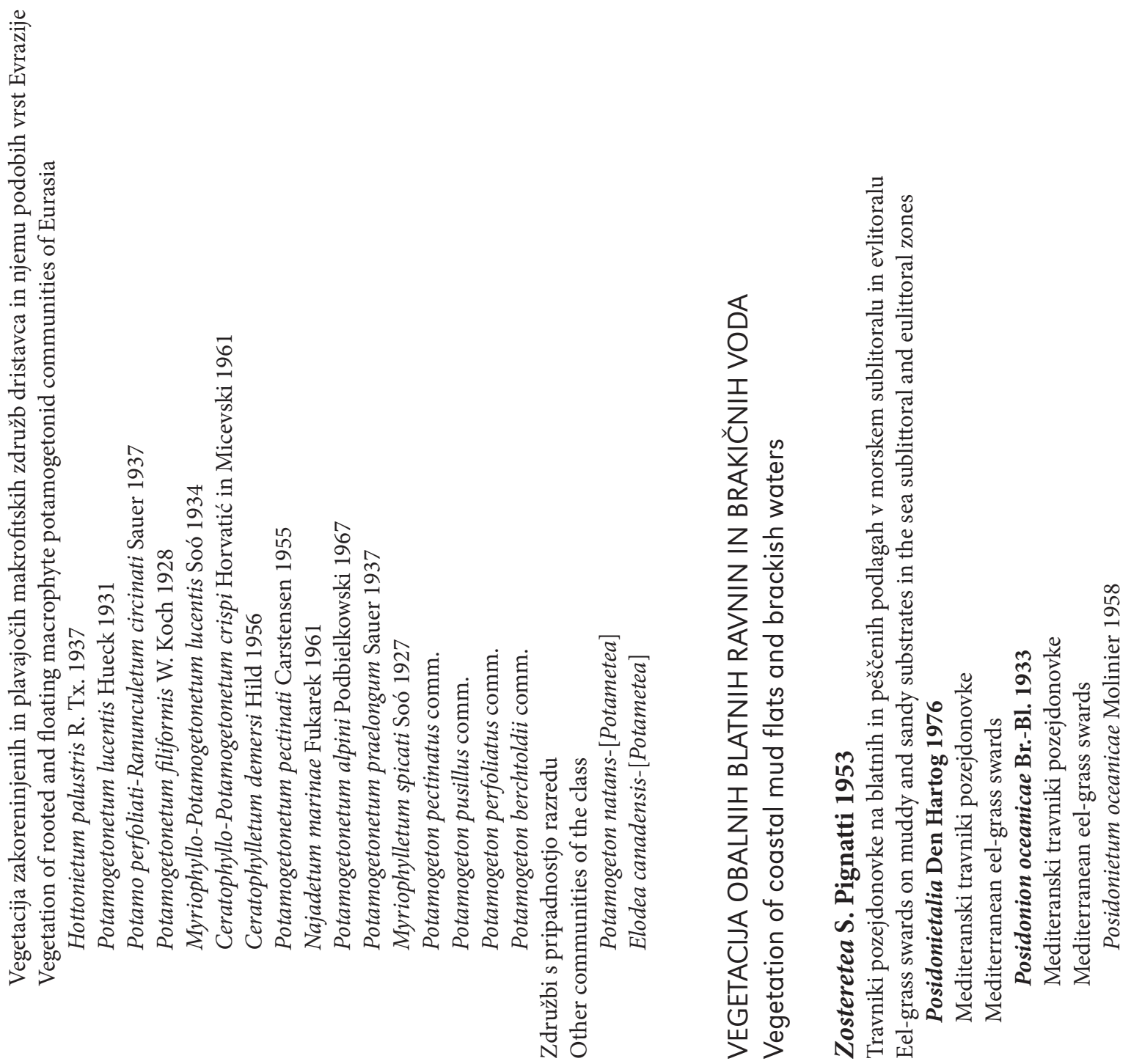




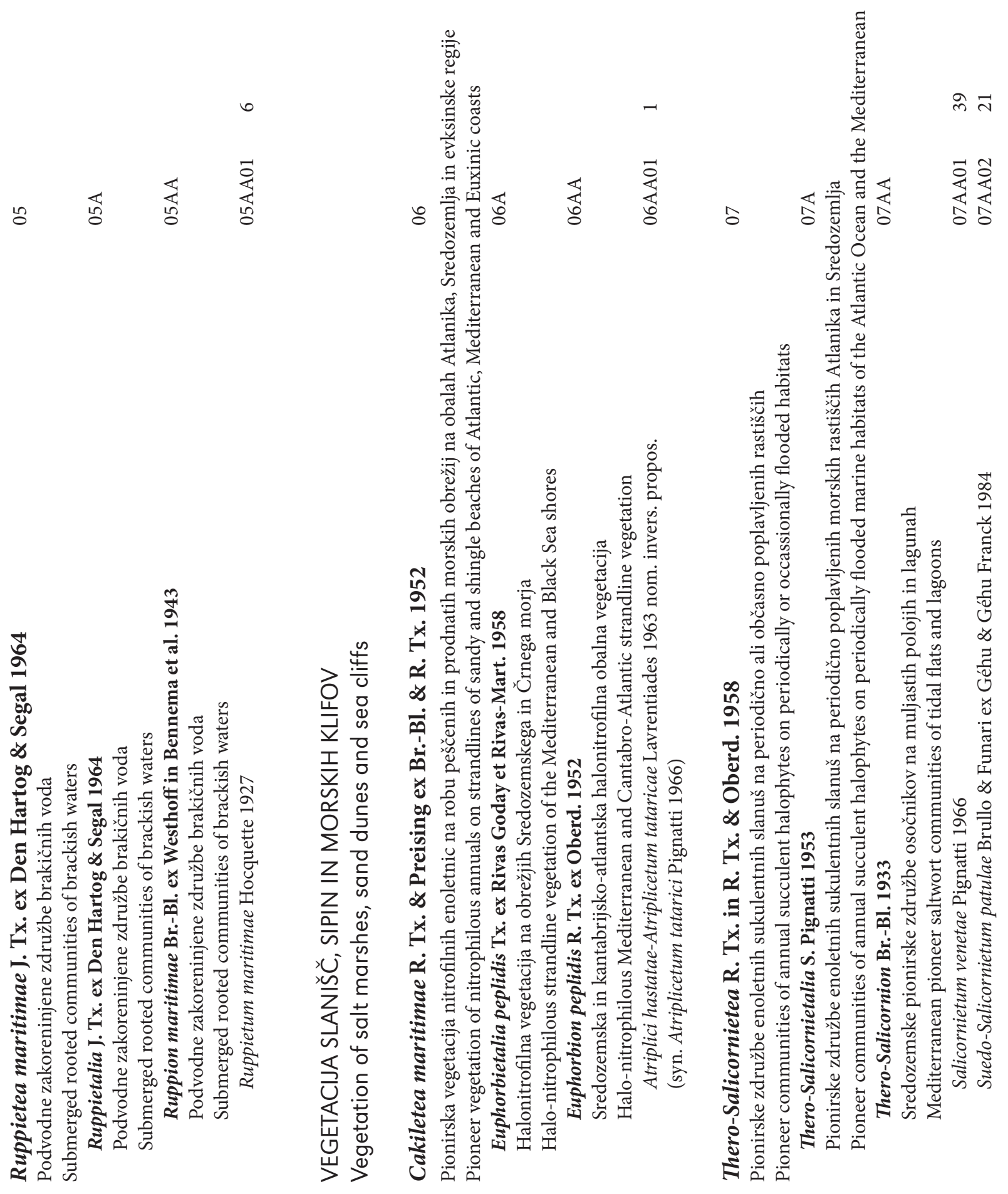




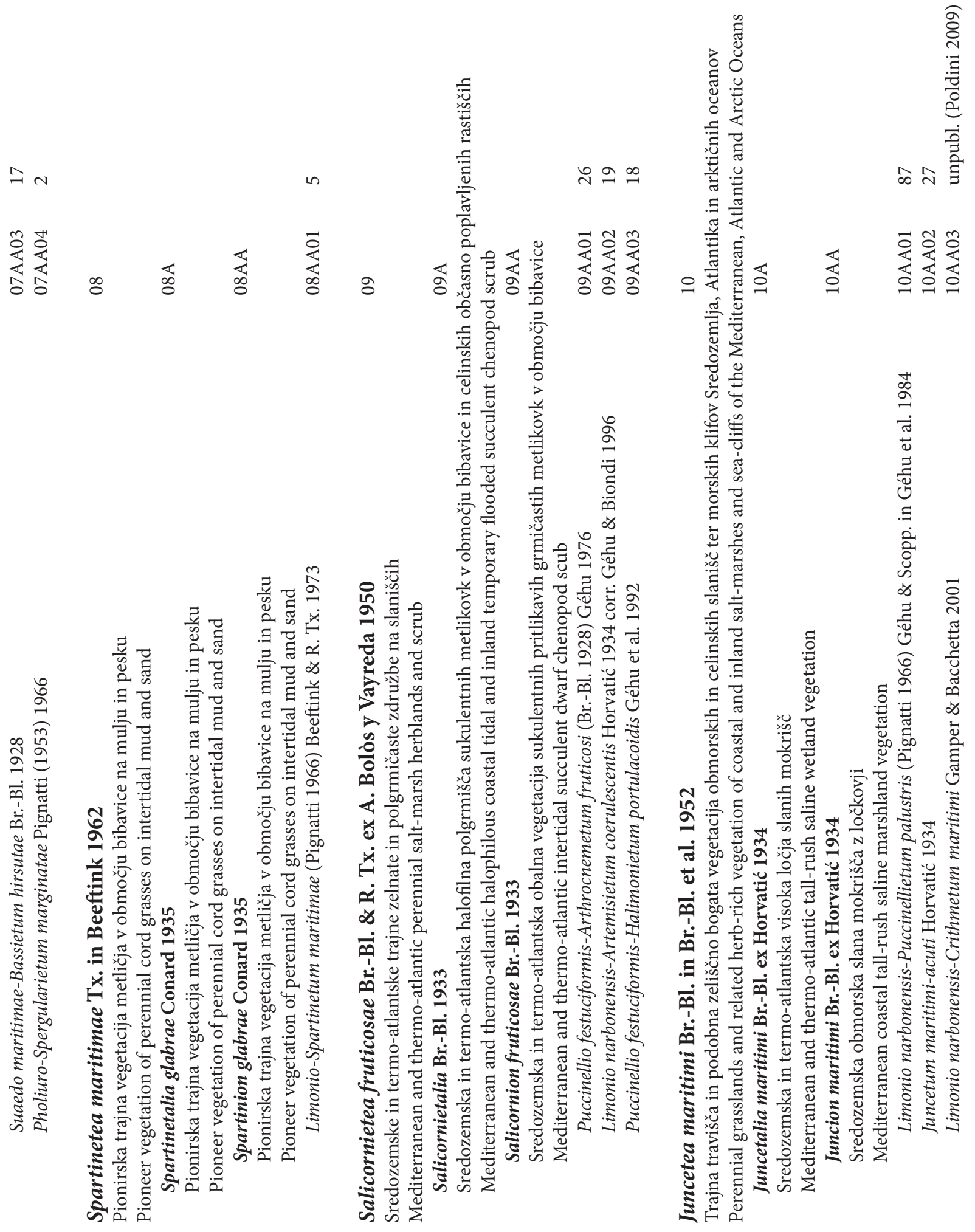




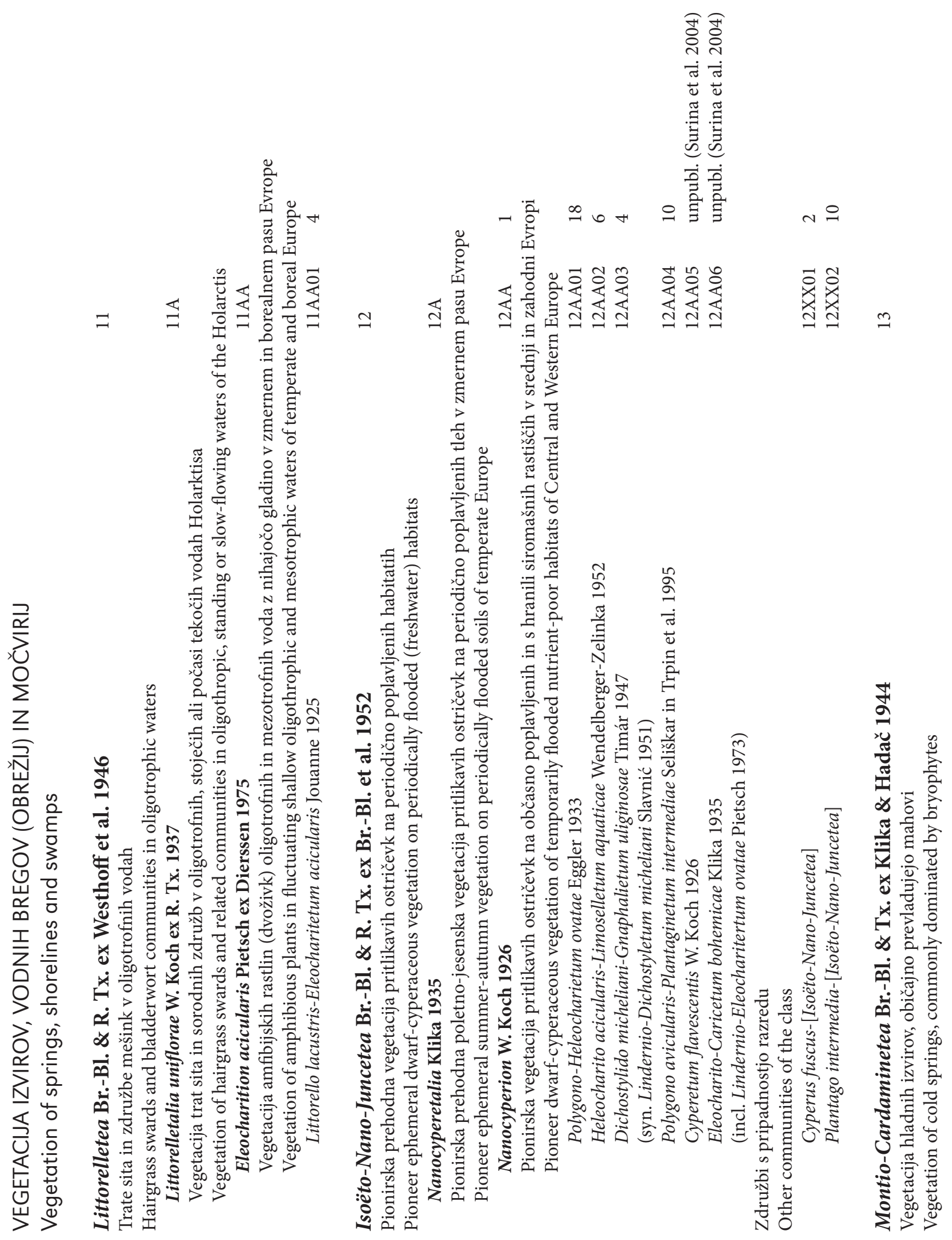



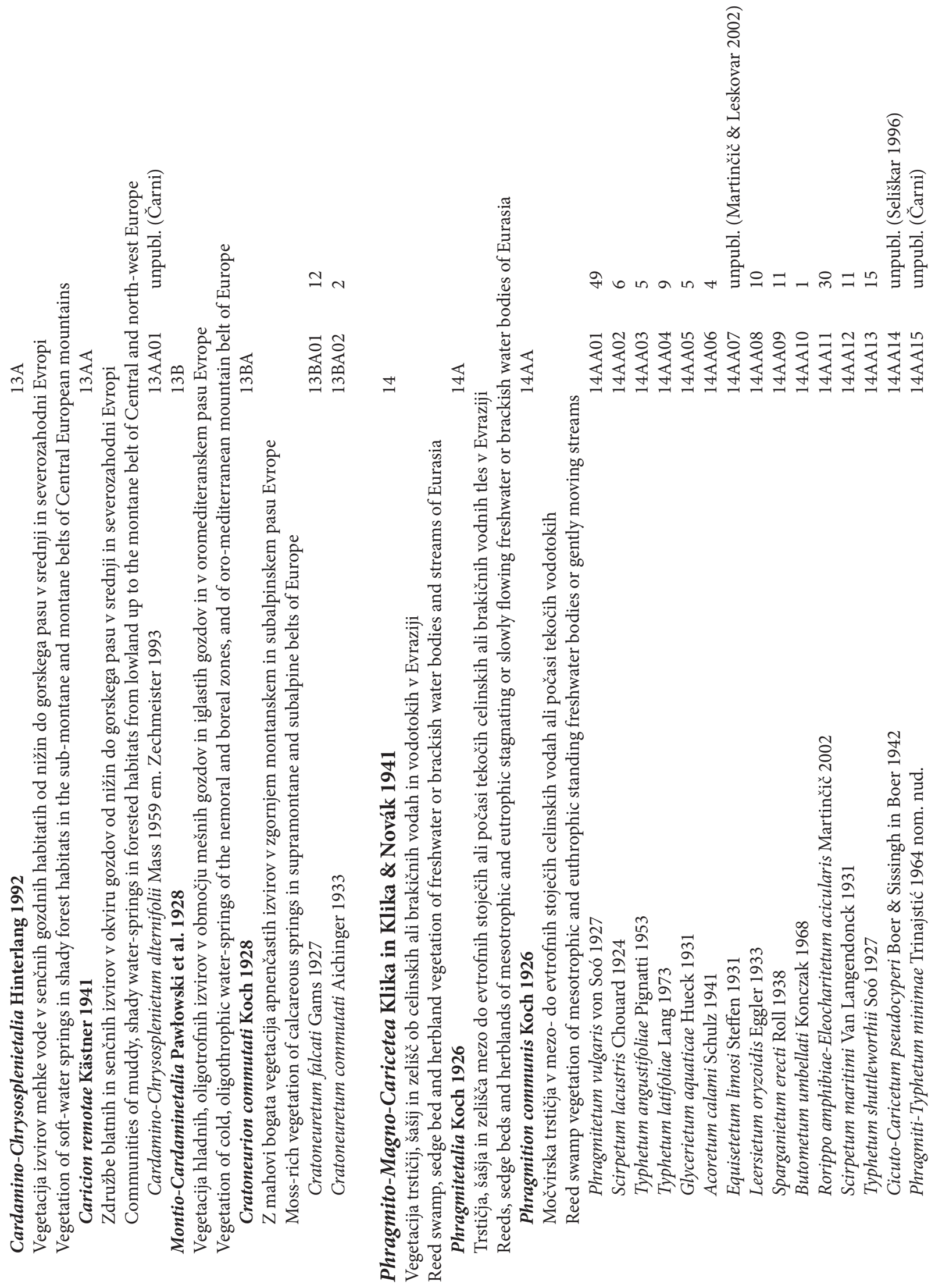


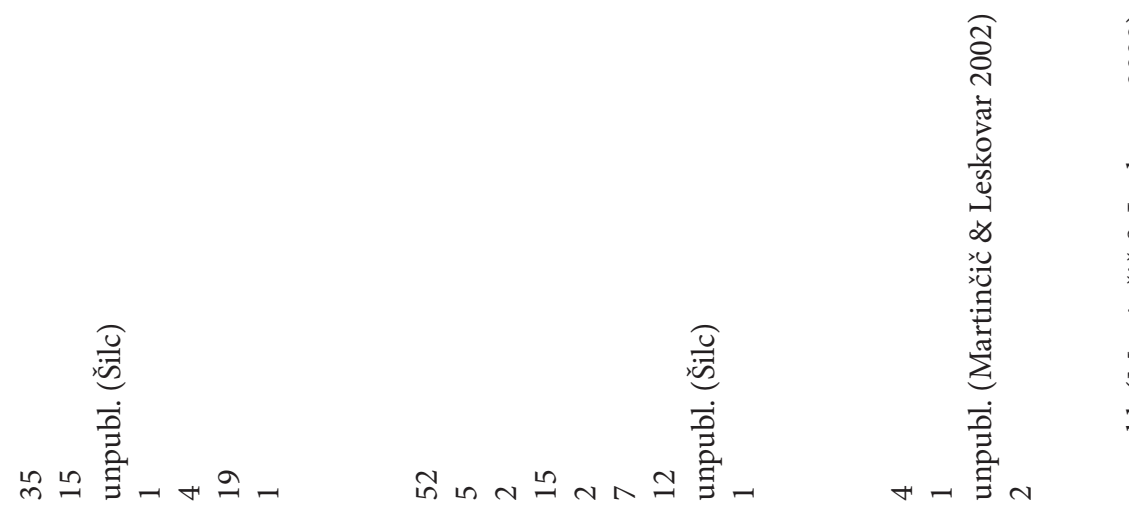

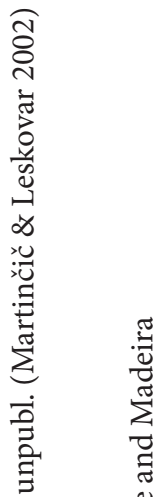

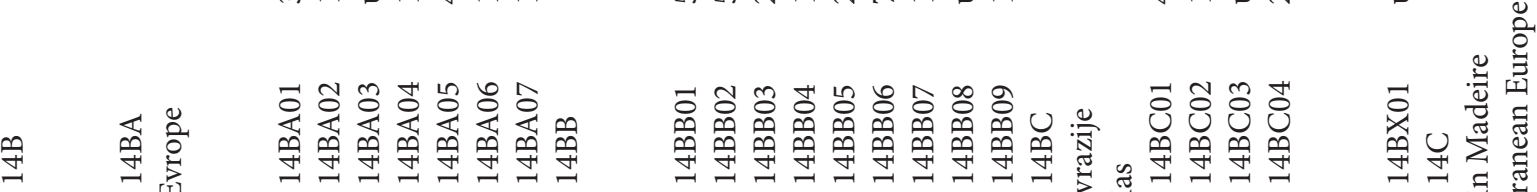

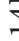
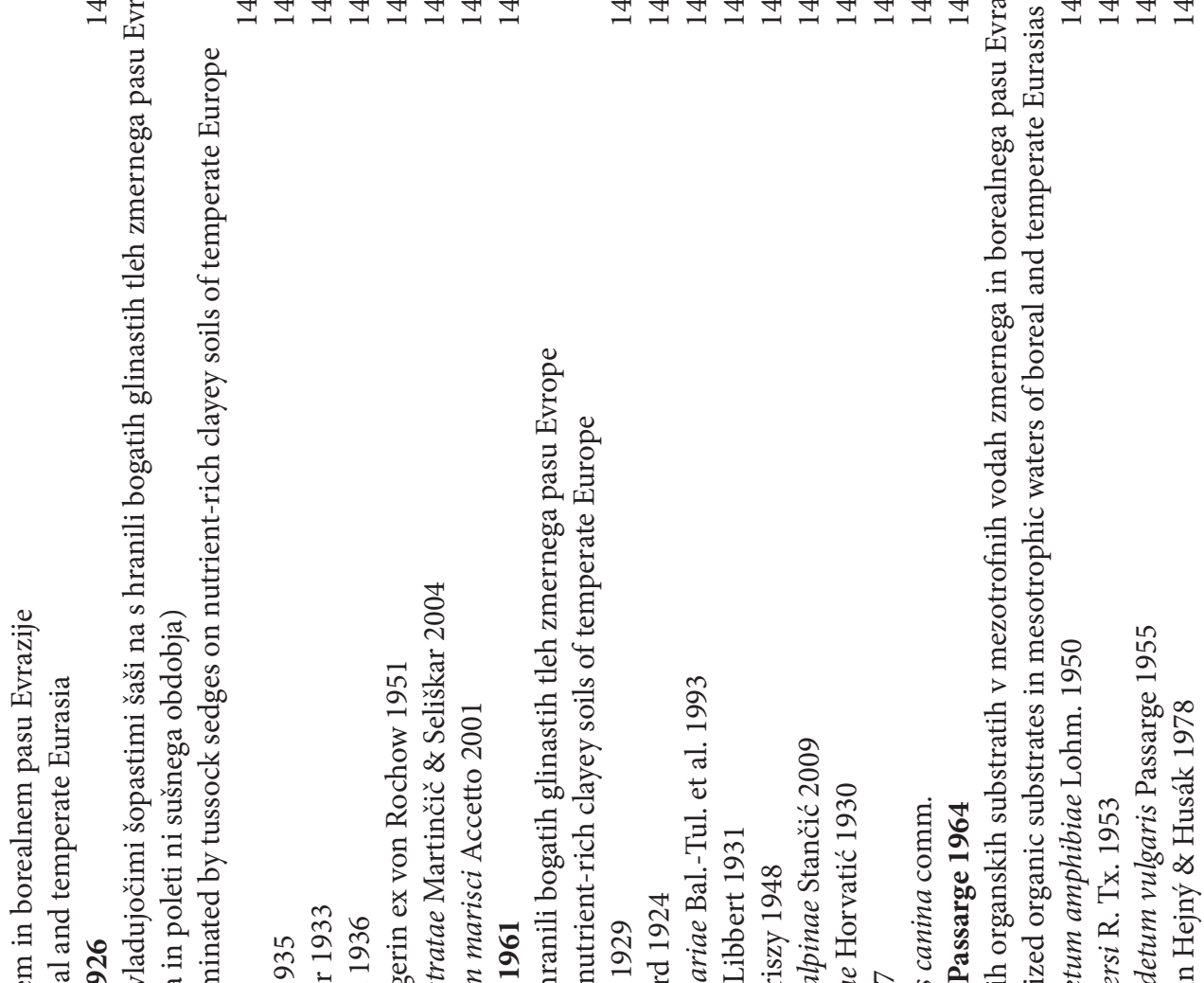

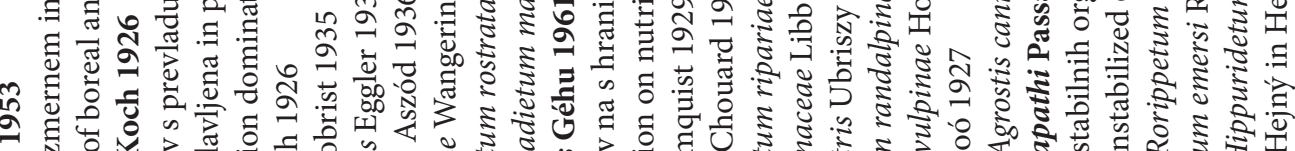

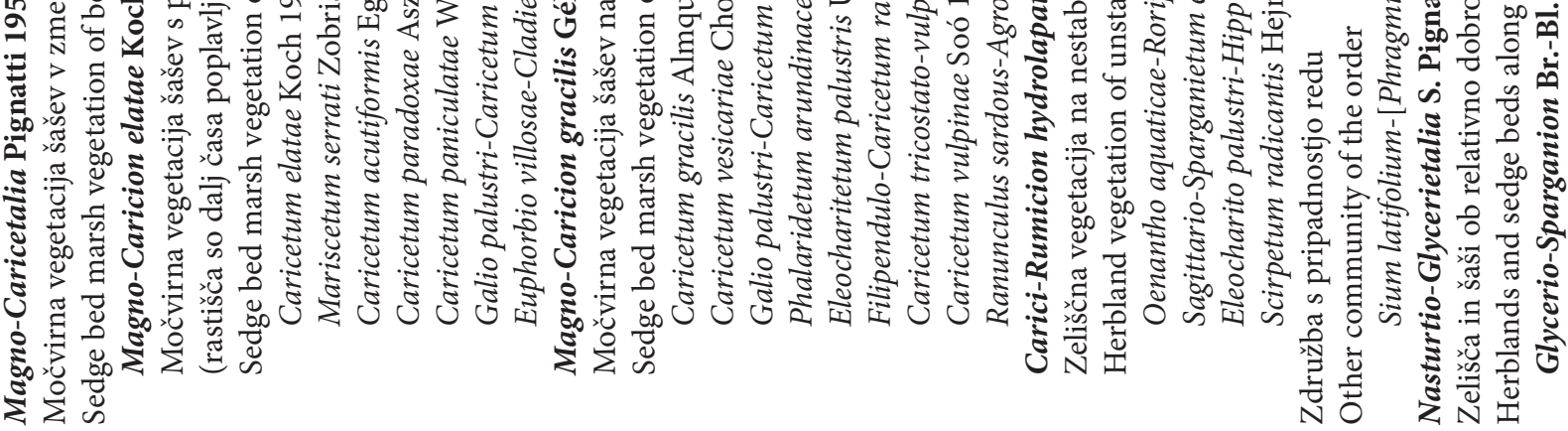




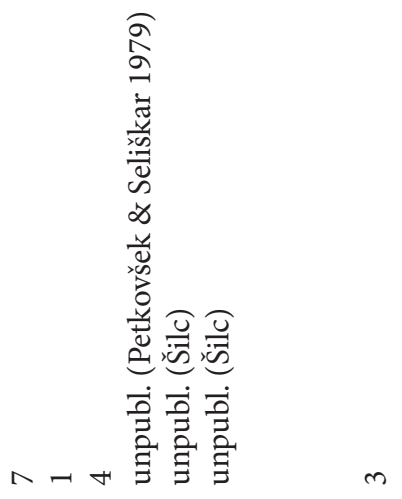

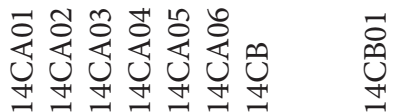

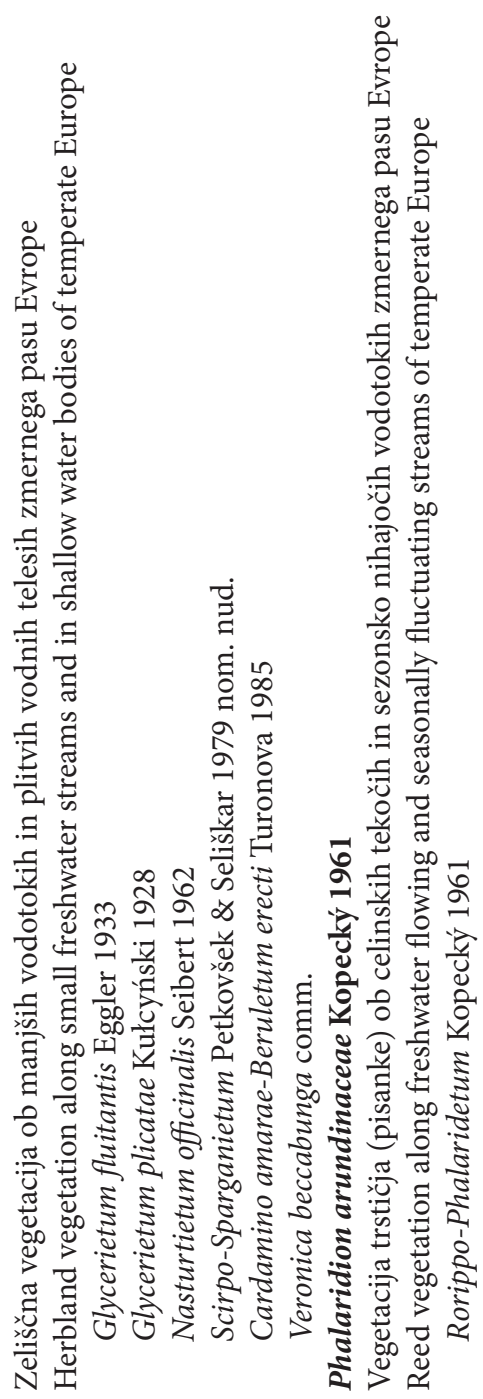

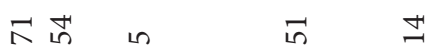

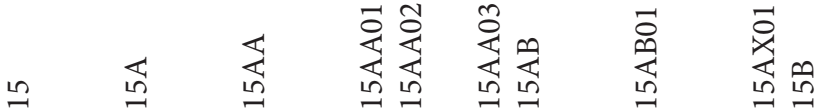

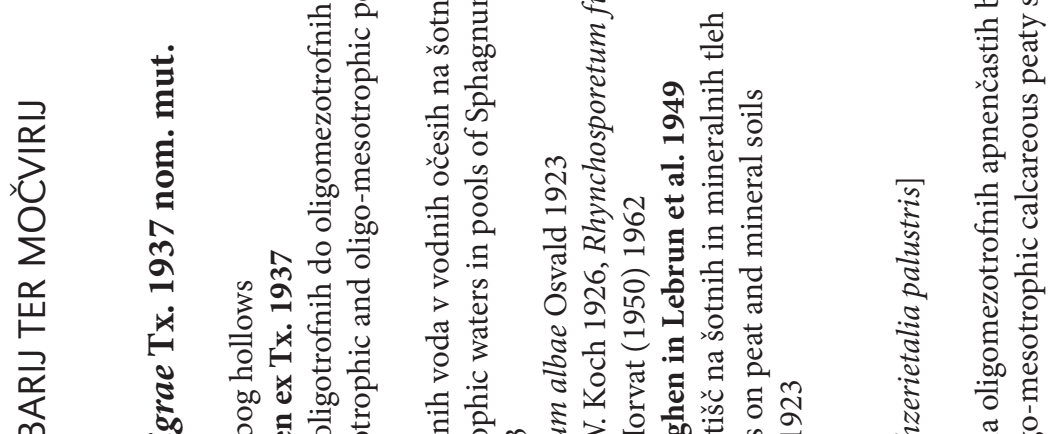
๙

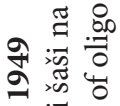

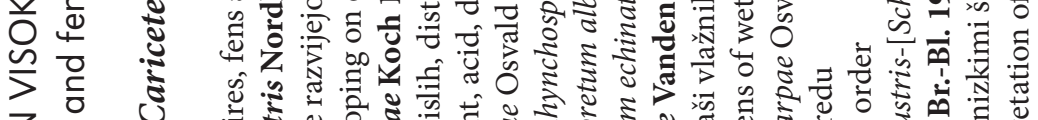

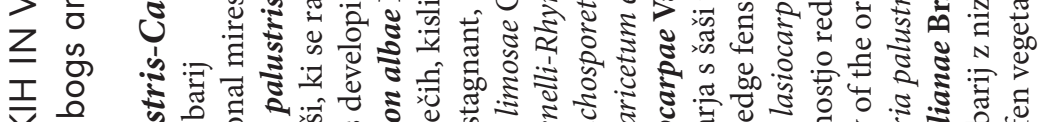

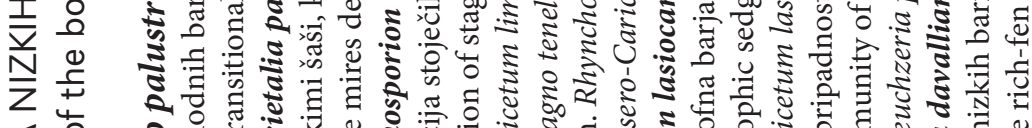

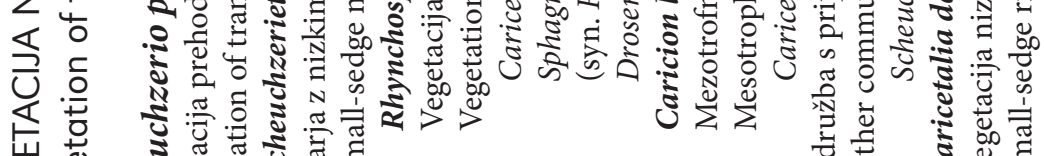

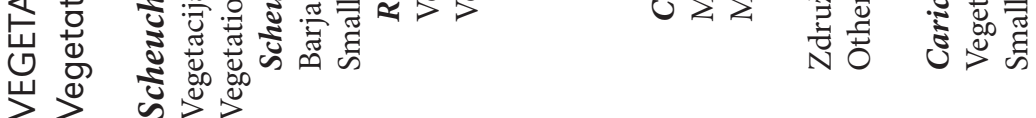
$\infty$ 


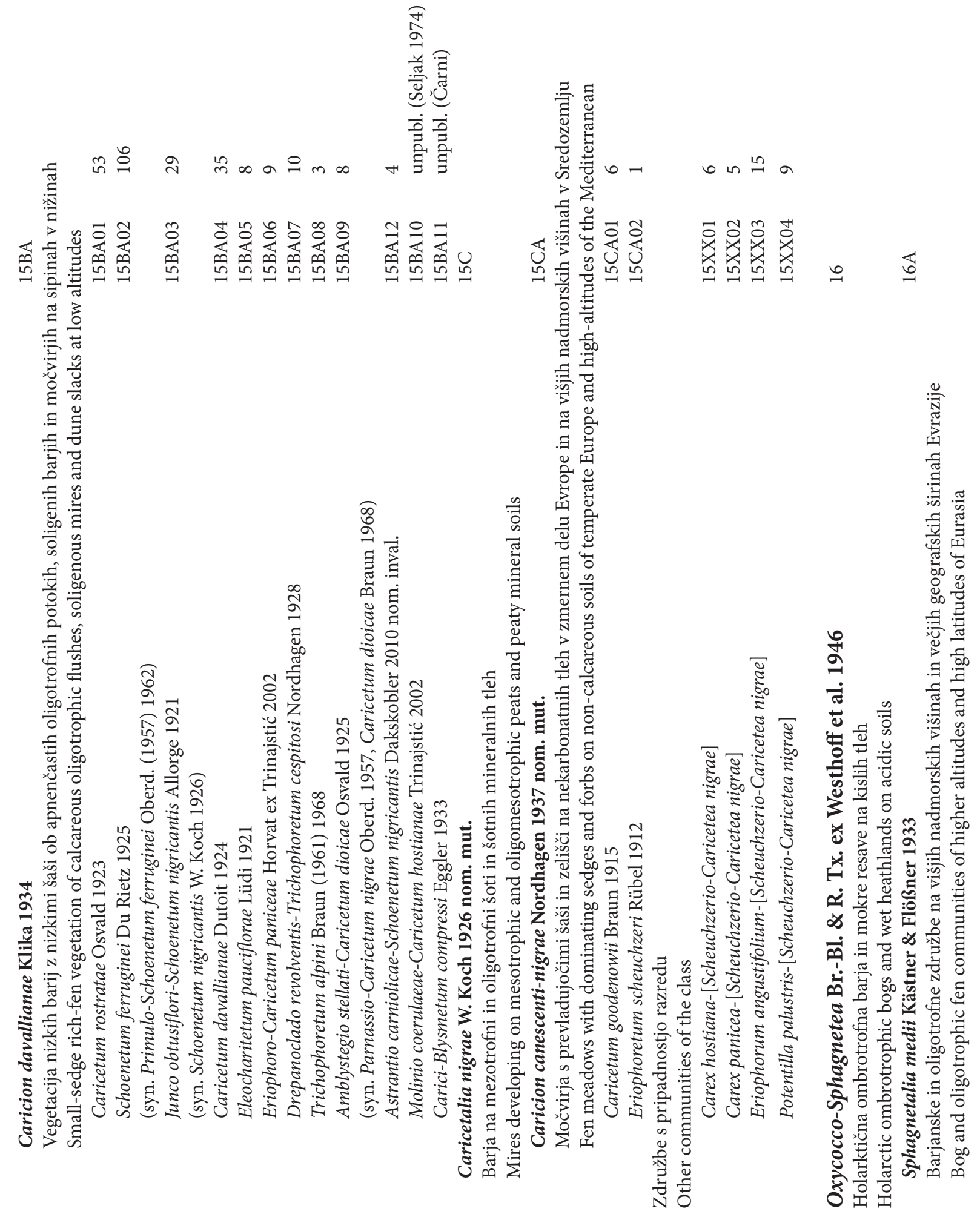




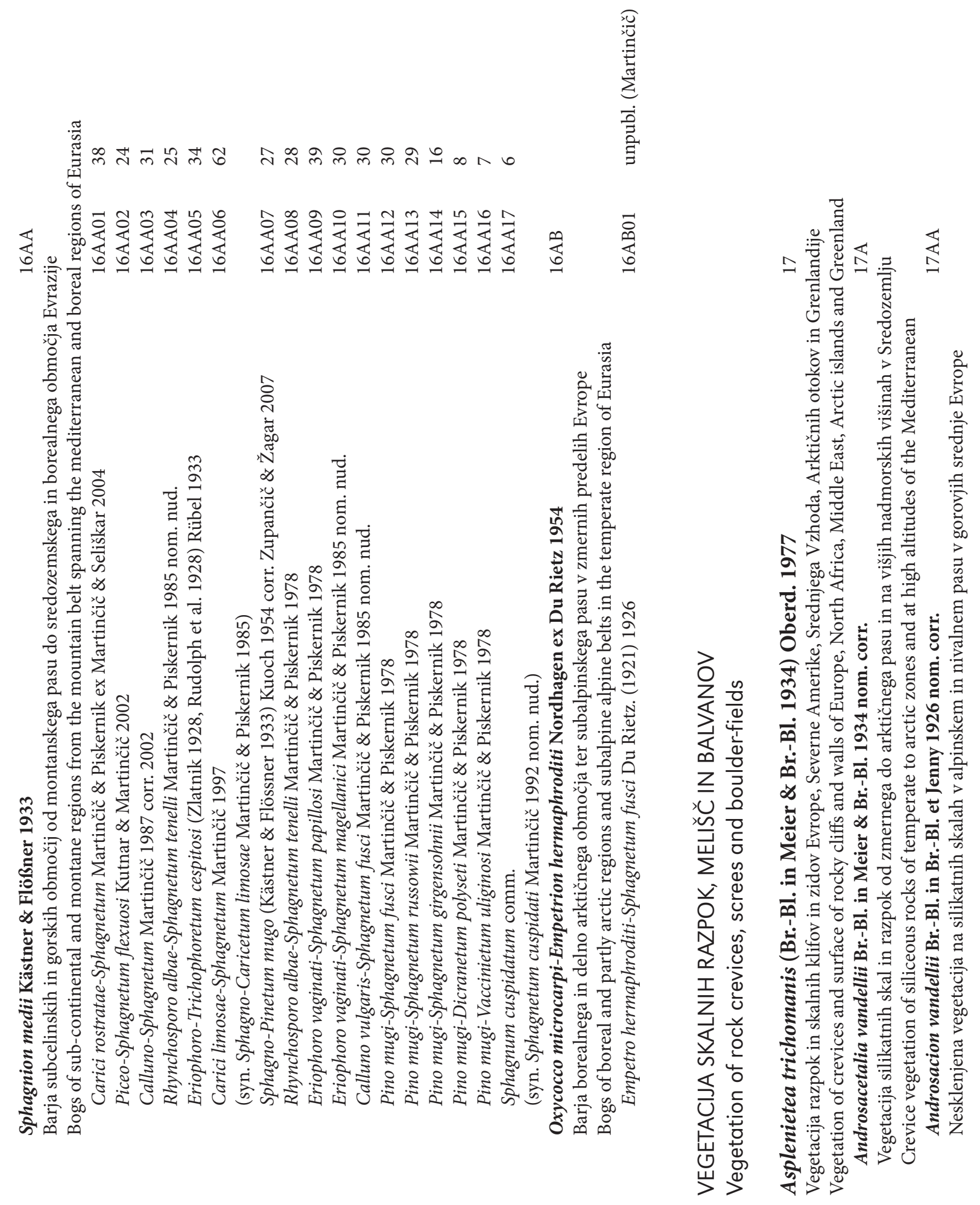




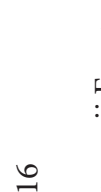

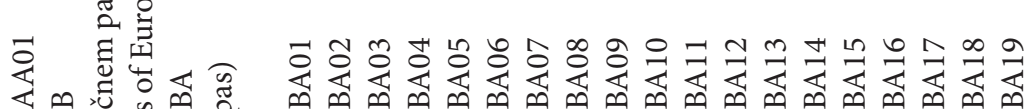

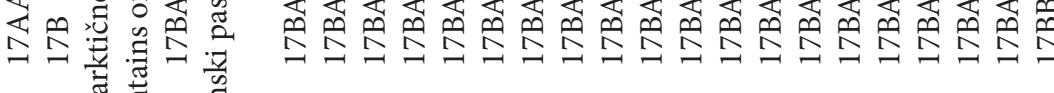

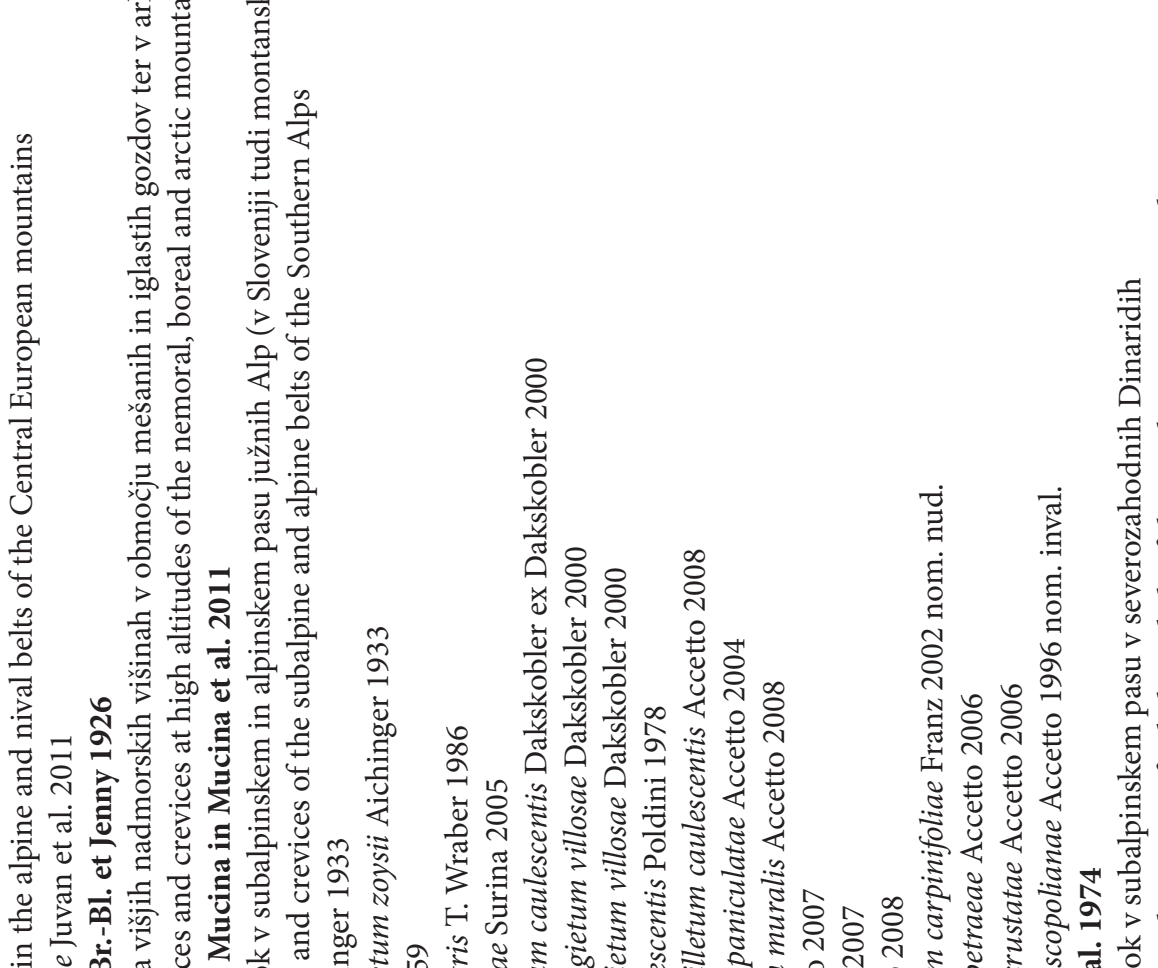

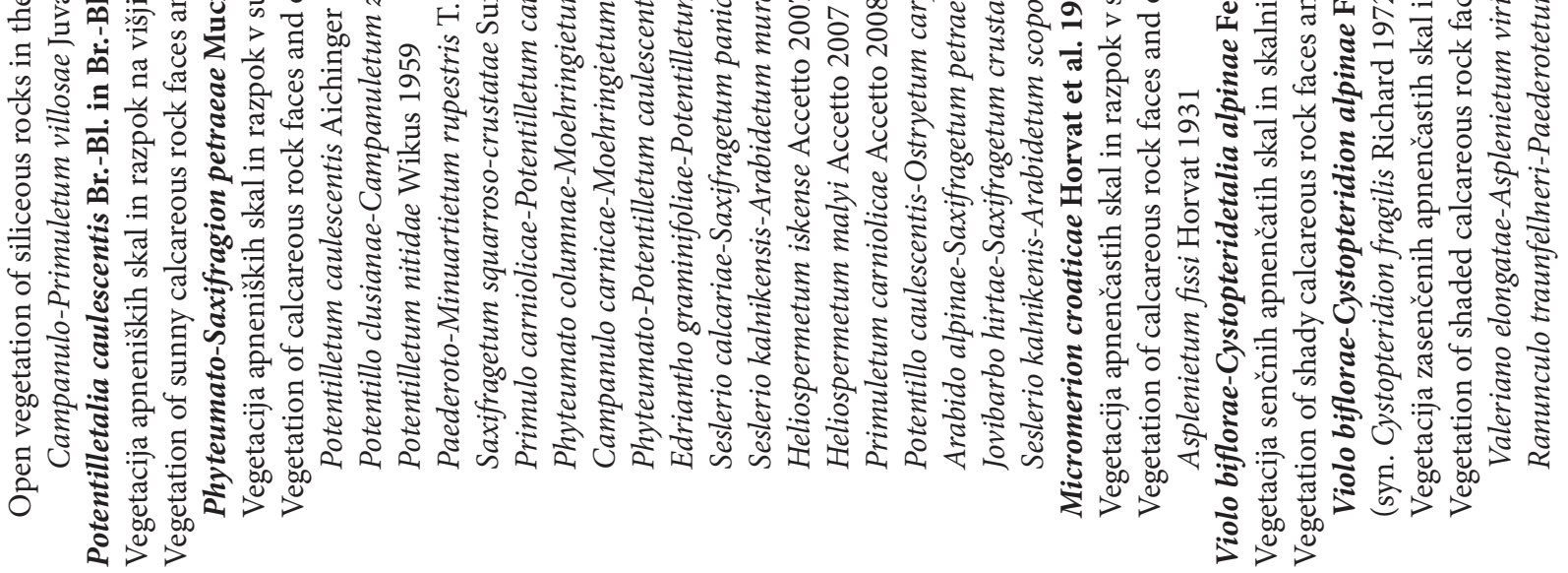




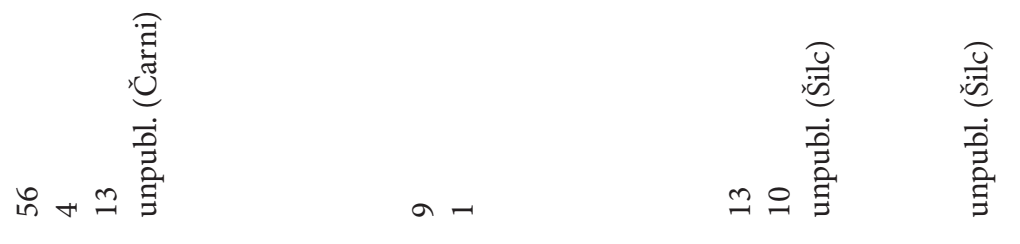

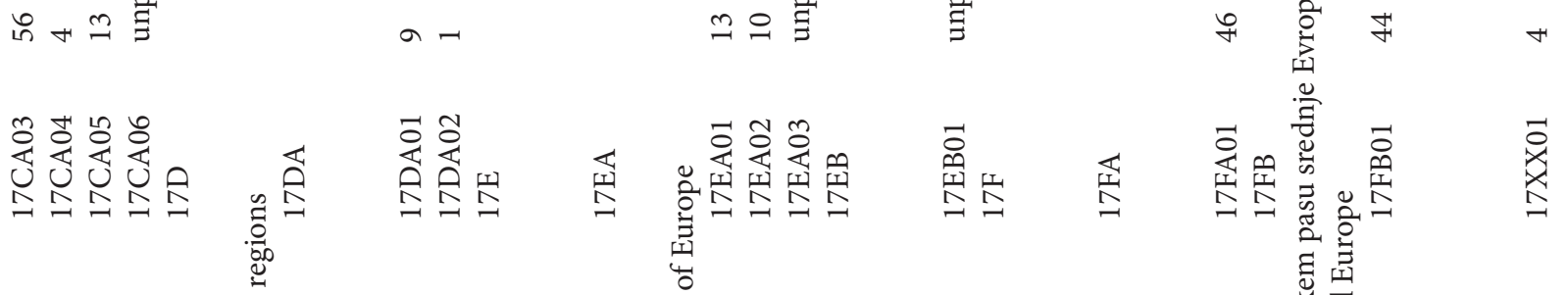

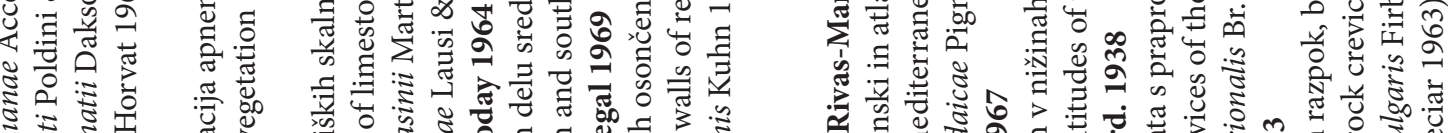

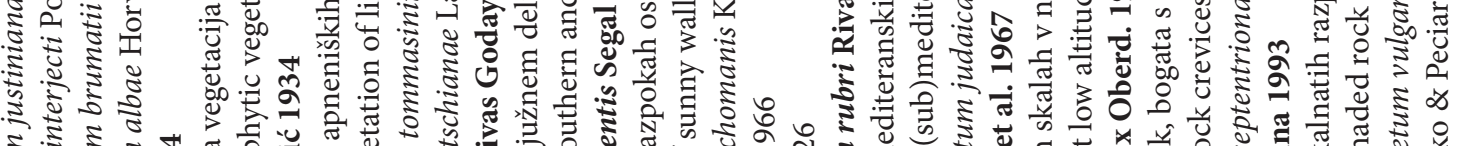

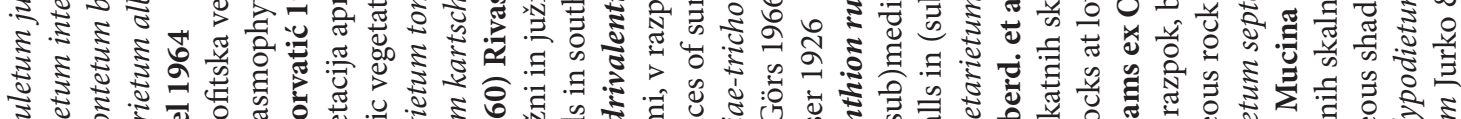

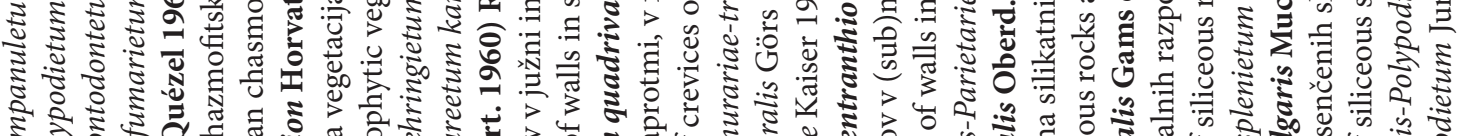

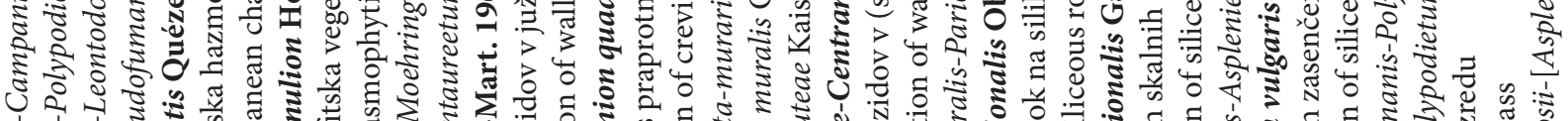

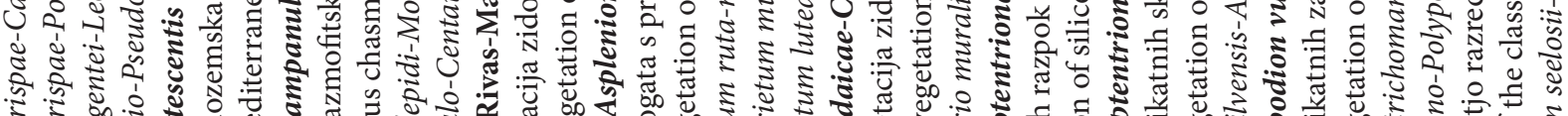

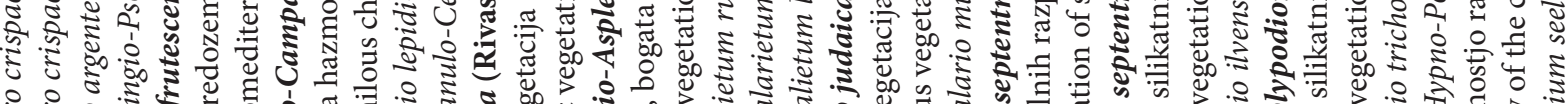

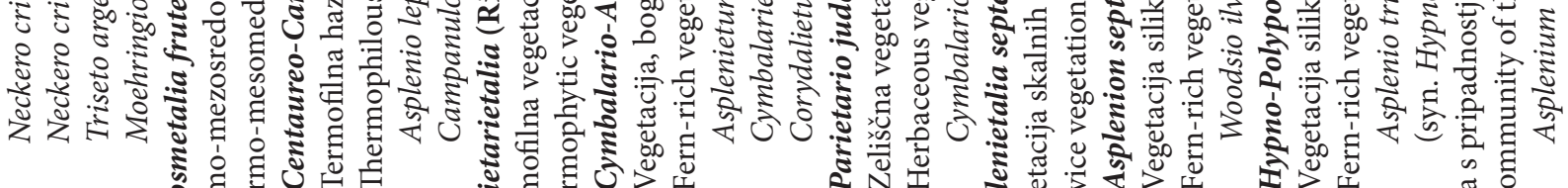

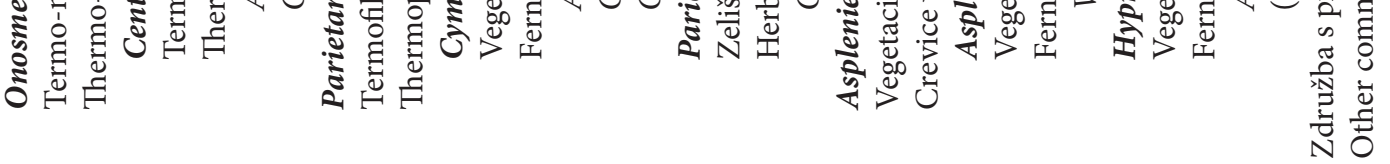




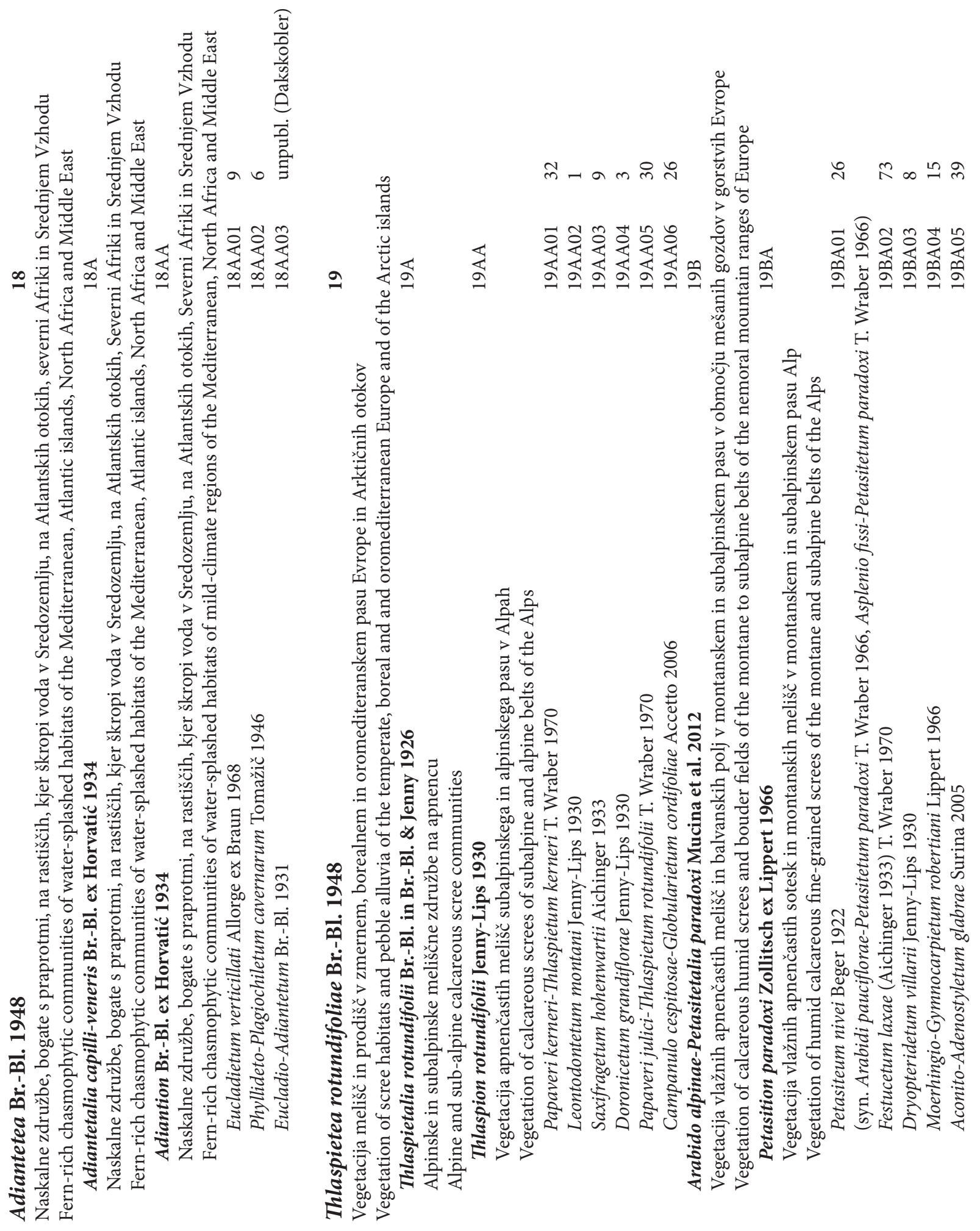




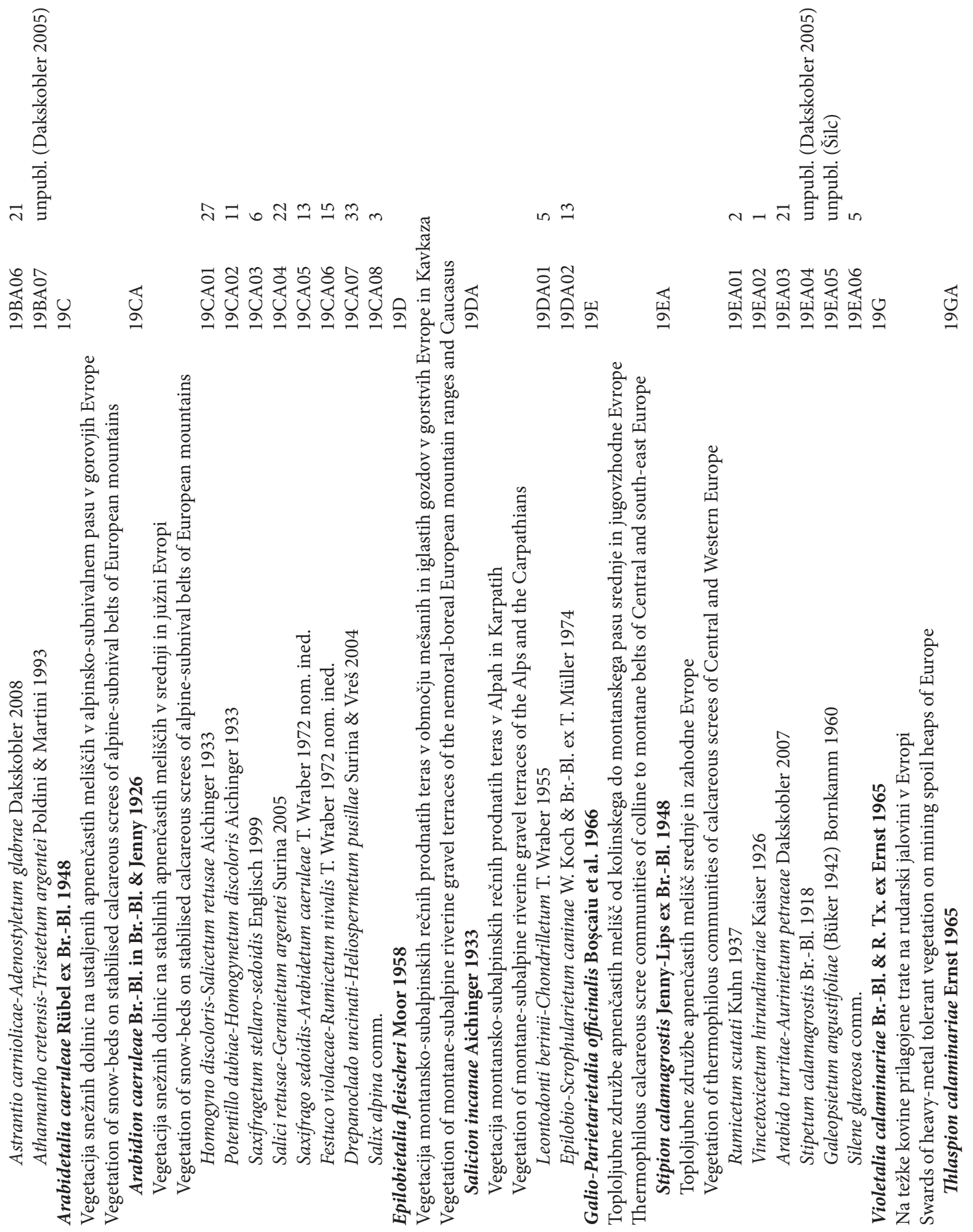




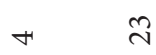

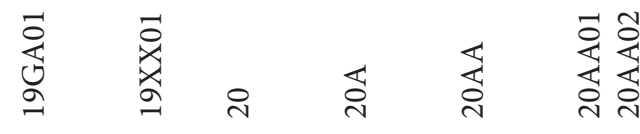

:

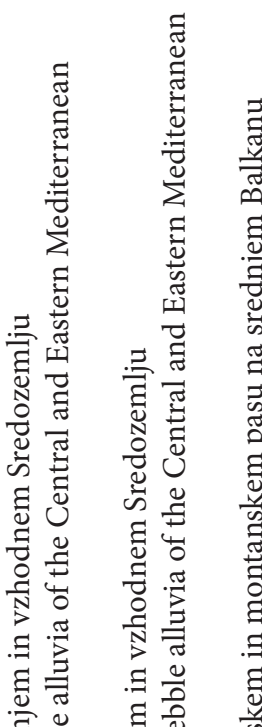

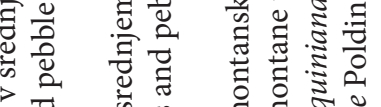

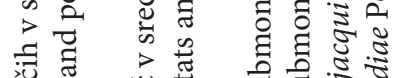

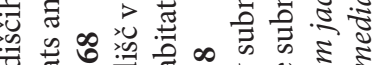

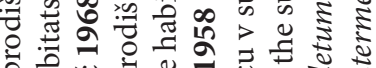

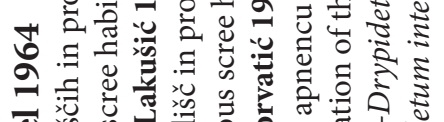

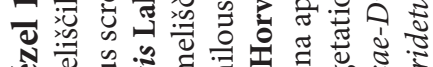

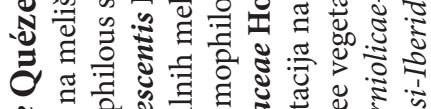

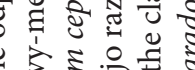

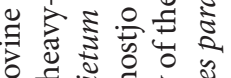

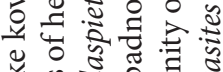

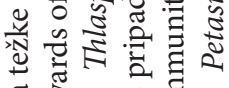

艺旁

\%

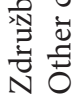

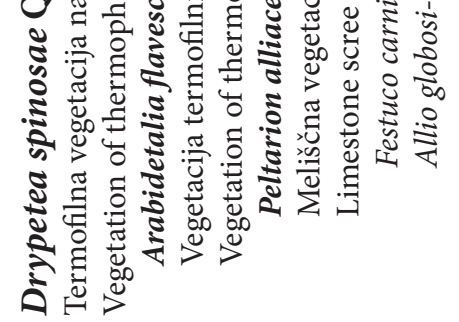

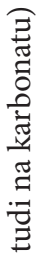

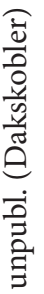

政

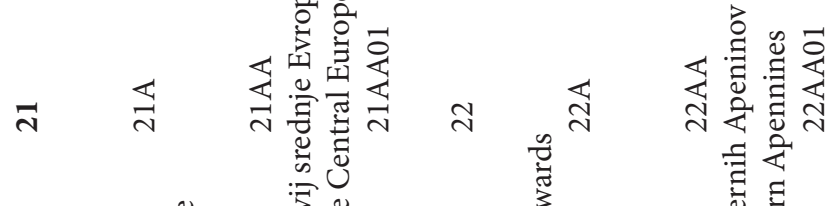
苛

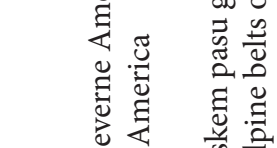

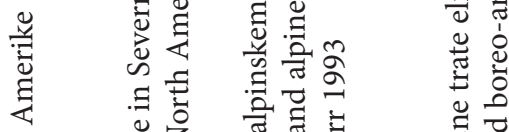

:

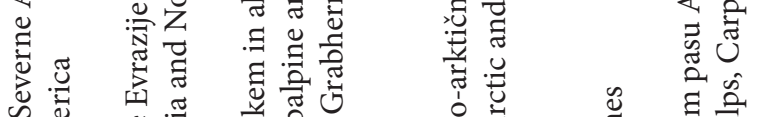

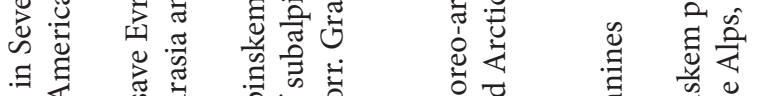

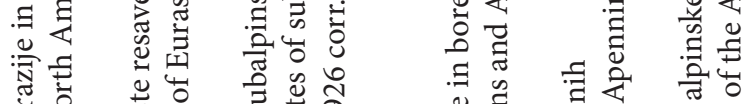

तु๊

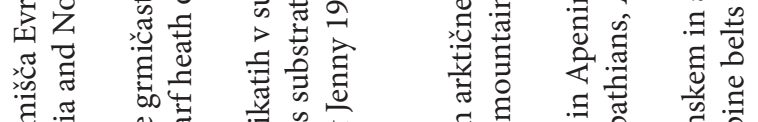

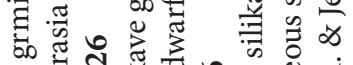

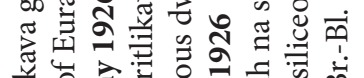

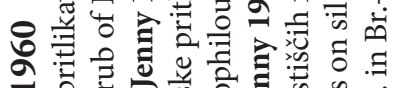

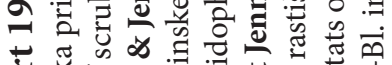

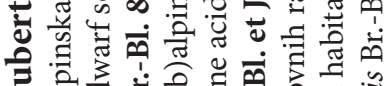

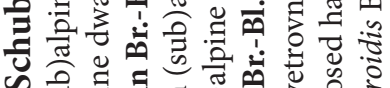

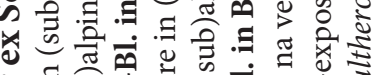

य $\Xi \begin{gathered}0 \\ 0\end{gathered}$

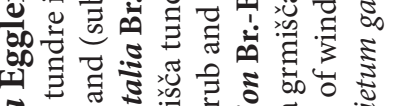

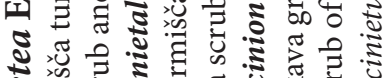

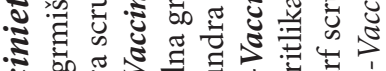

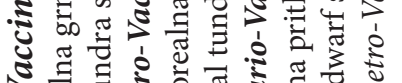

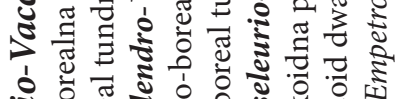

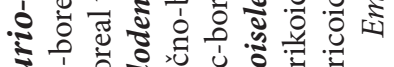

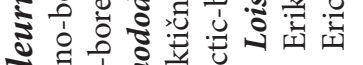

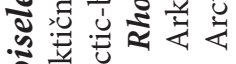

案安
5ू

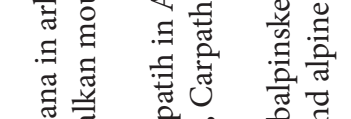

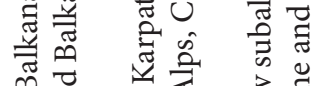

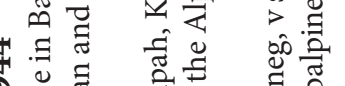

बै:

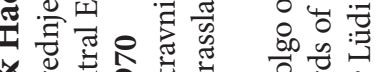

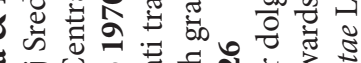
:

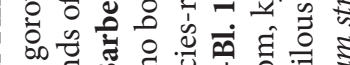

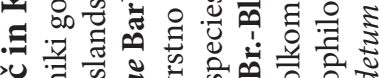
क्षे 5 की की के

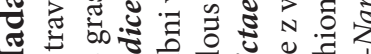
च ₹ 0 을 की

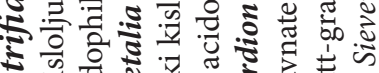

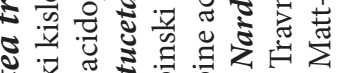

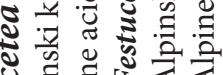

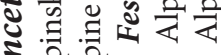

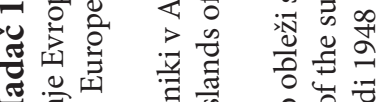




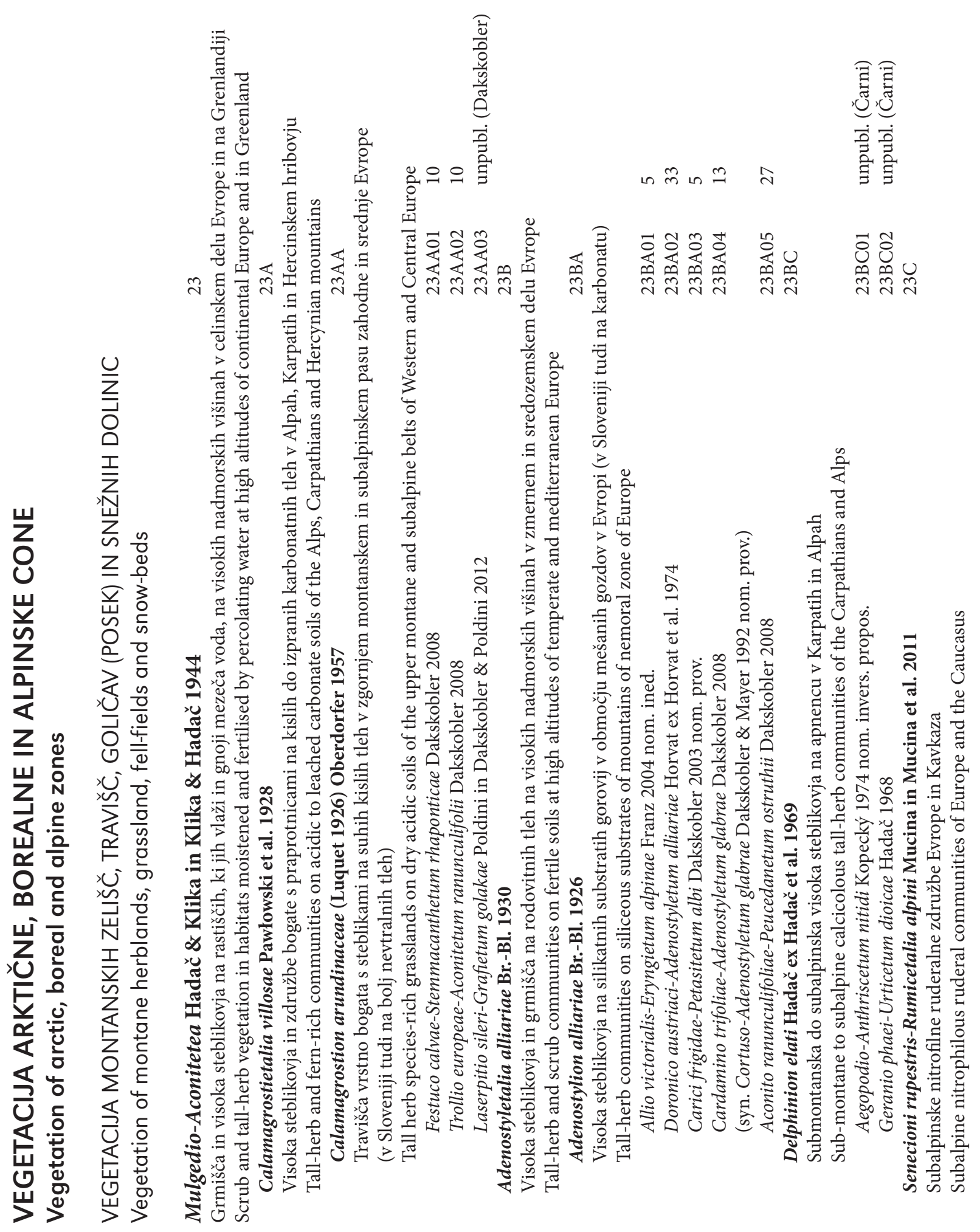




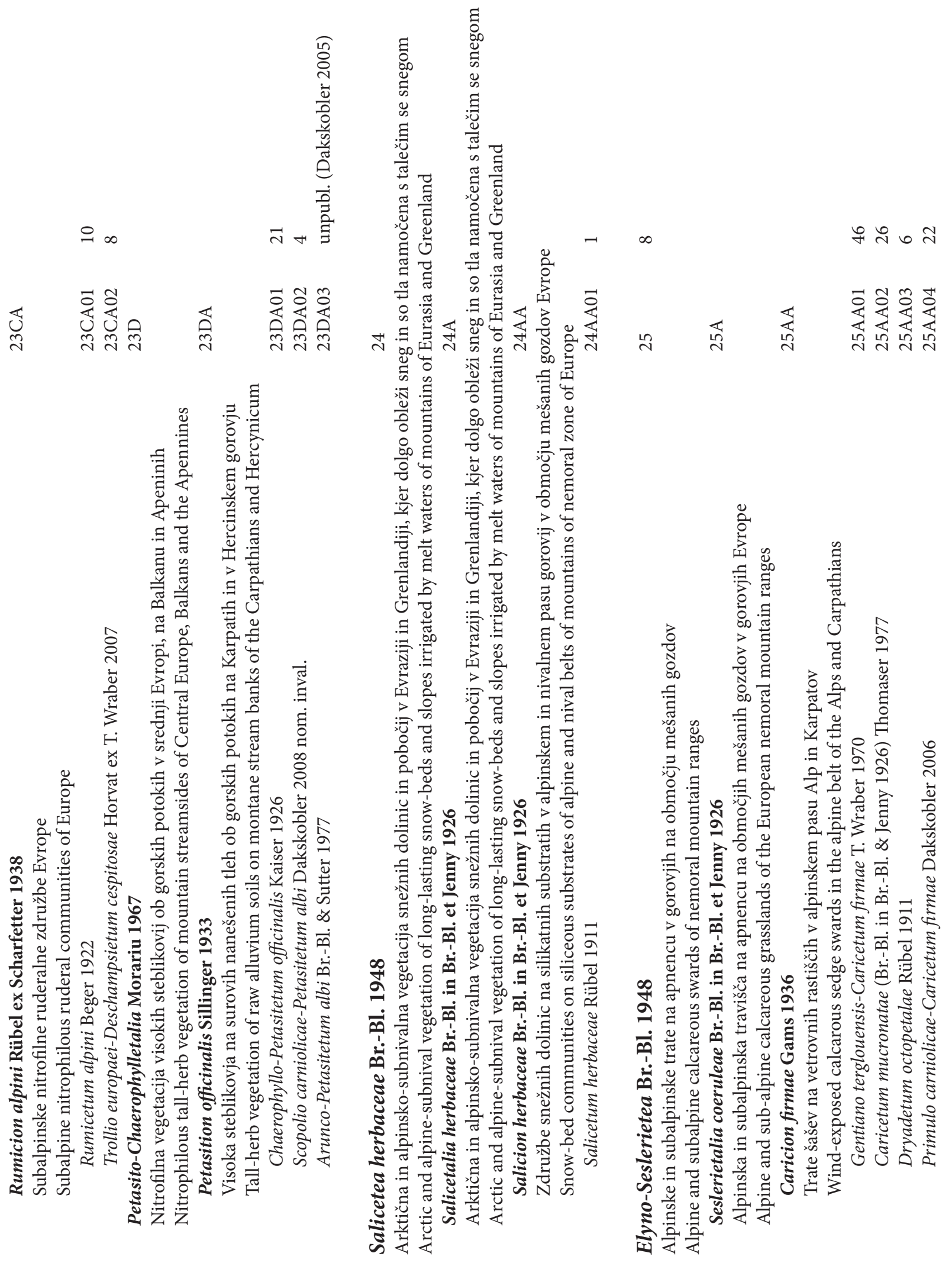




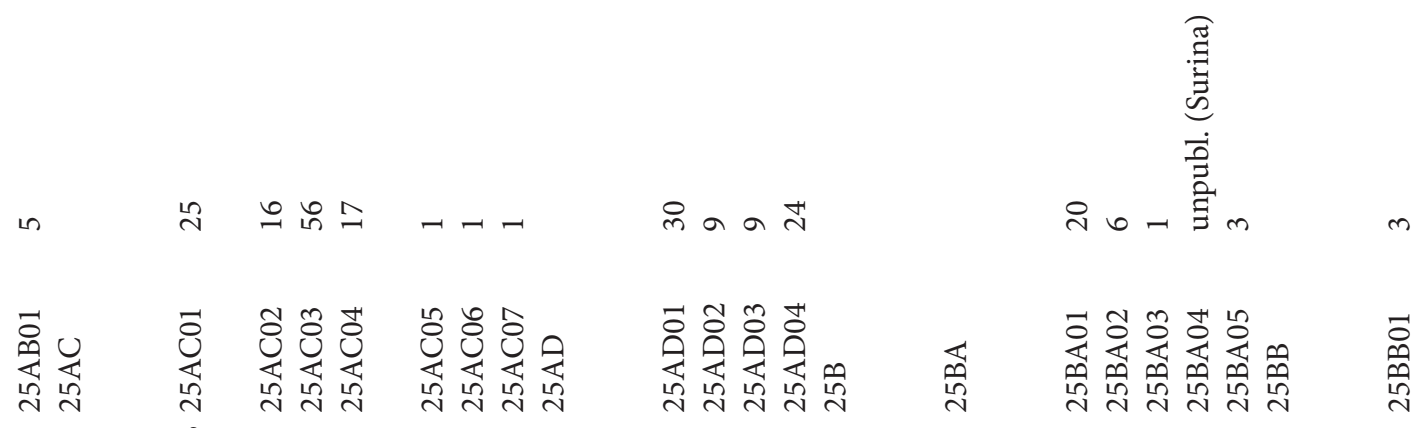

है ڤે

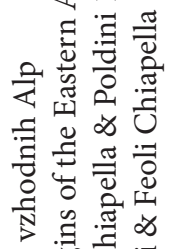

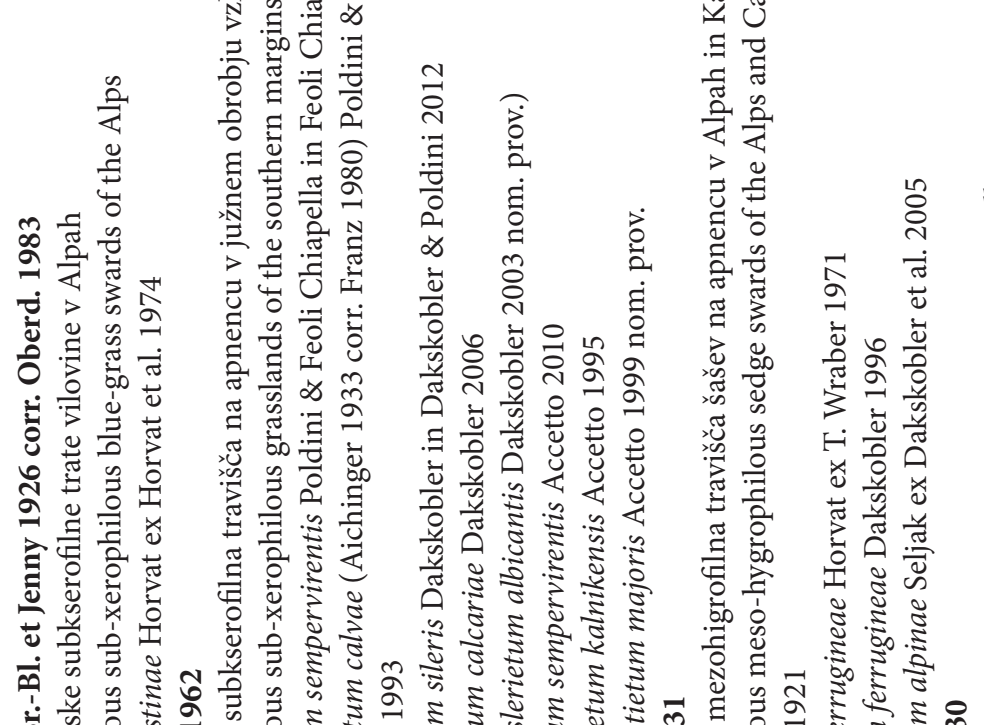

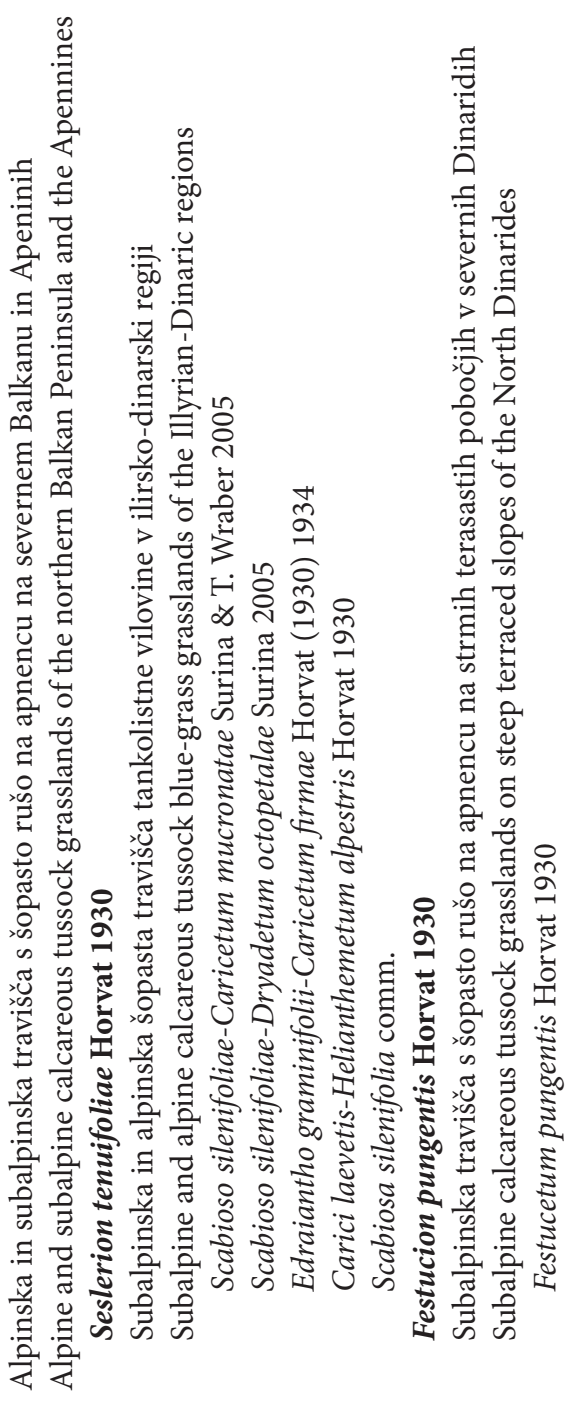




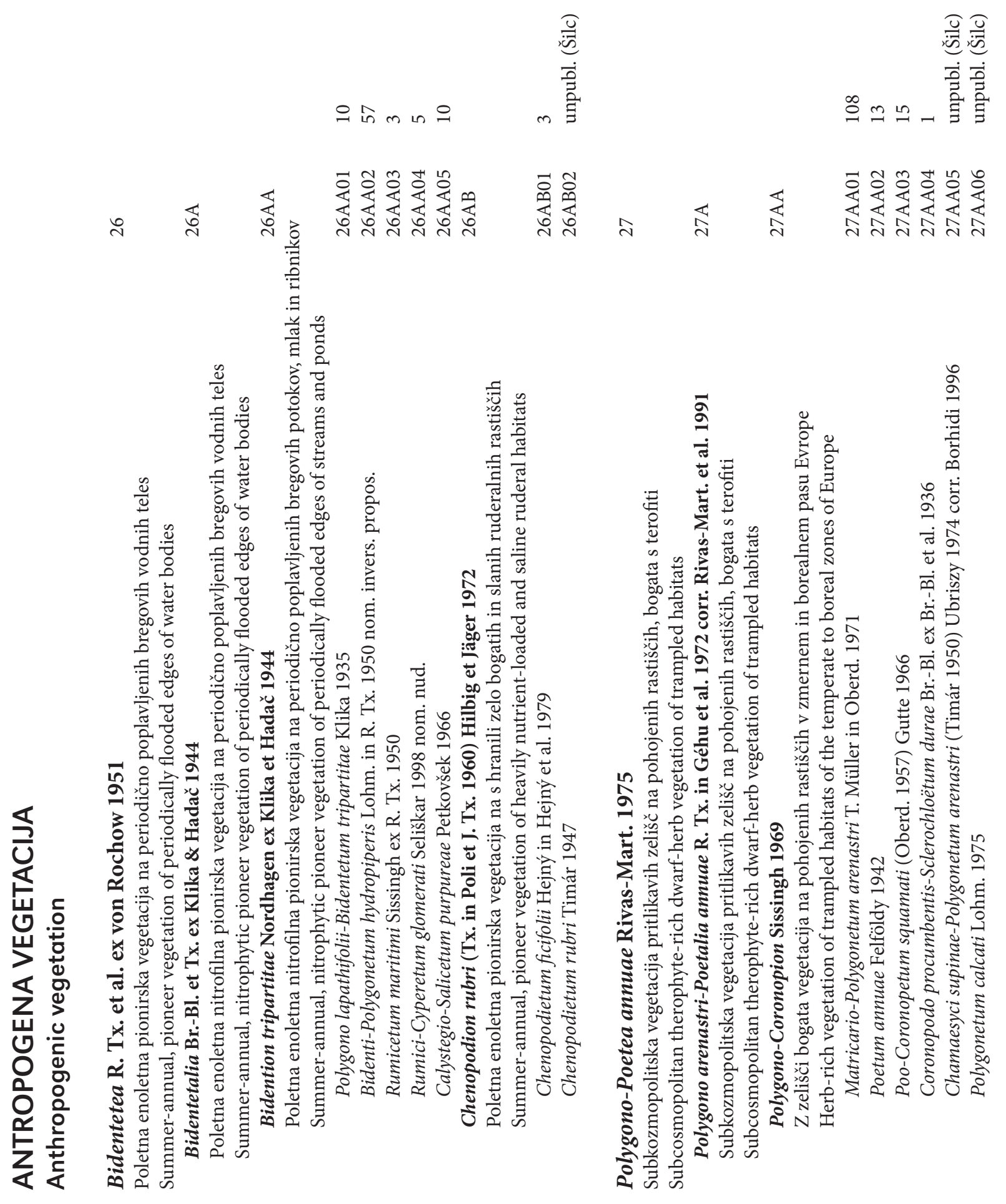




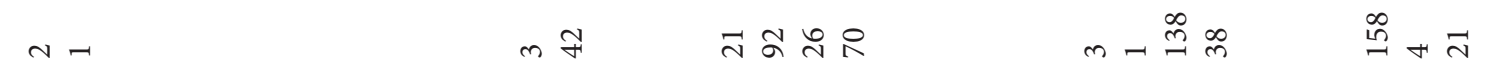

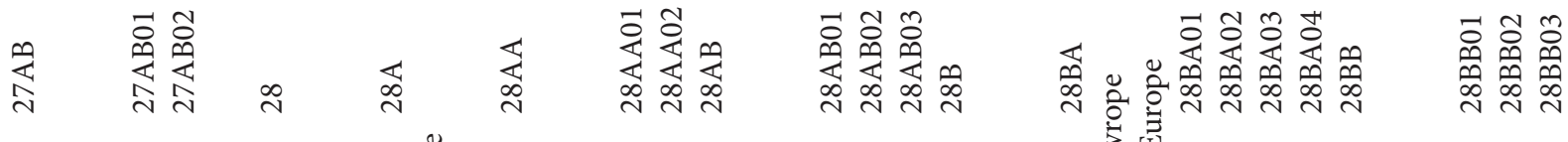

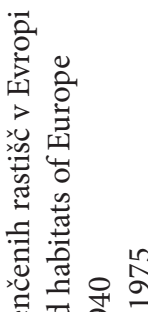

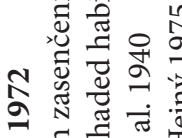

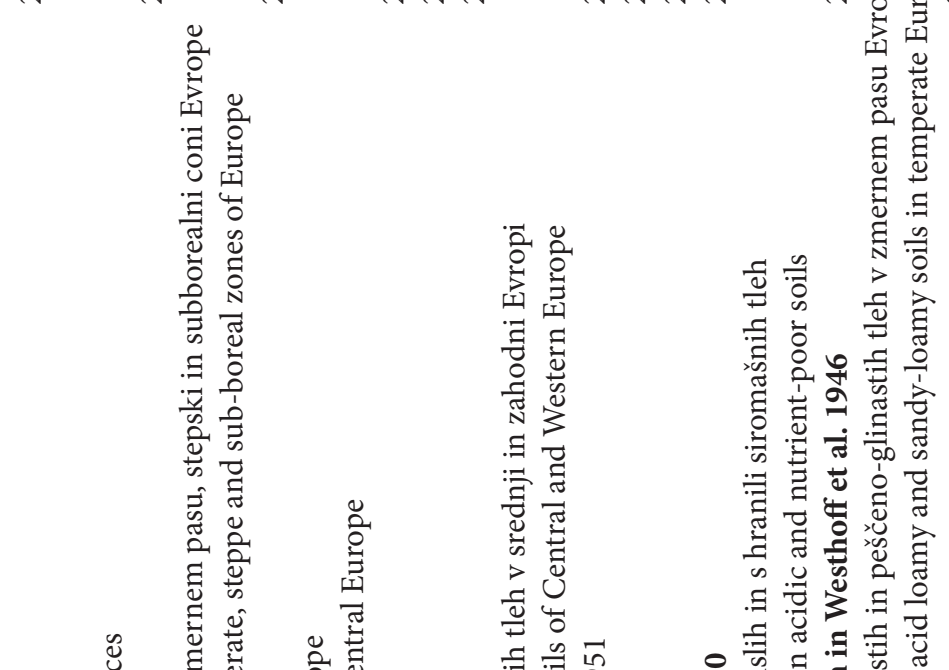

营

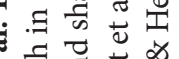

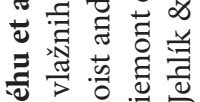

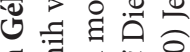

$\exists$ 司芯芯

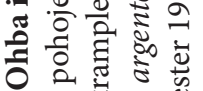

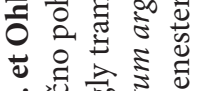

म

व

: :

ธัँ

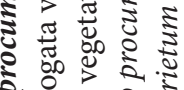

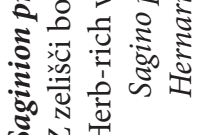

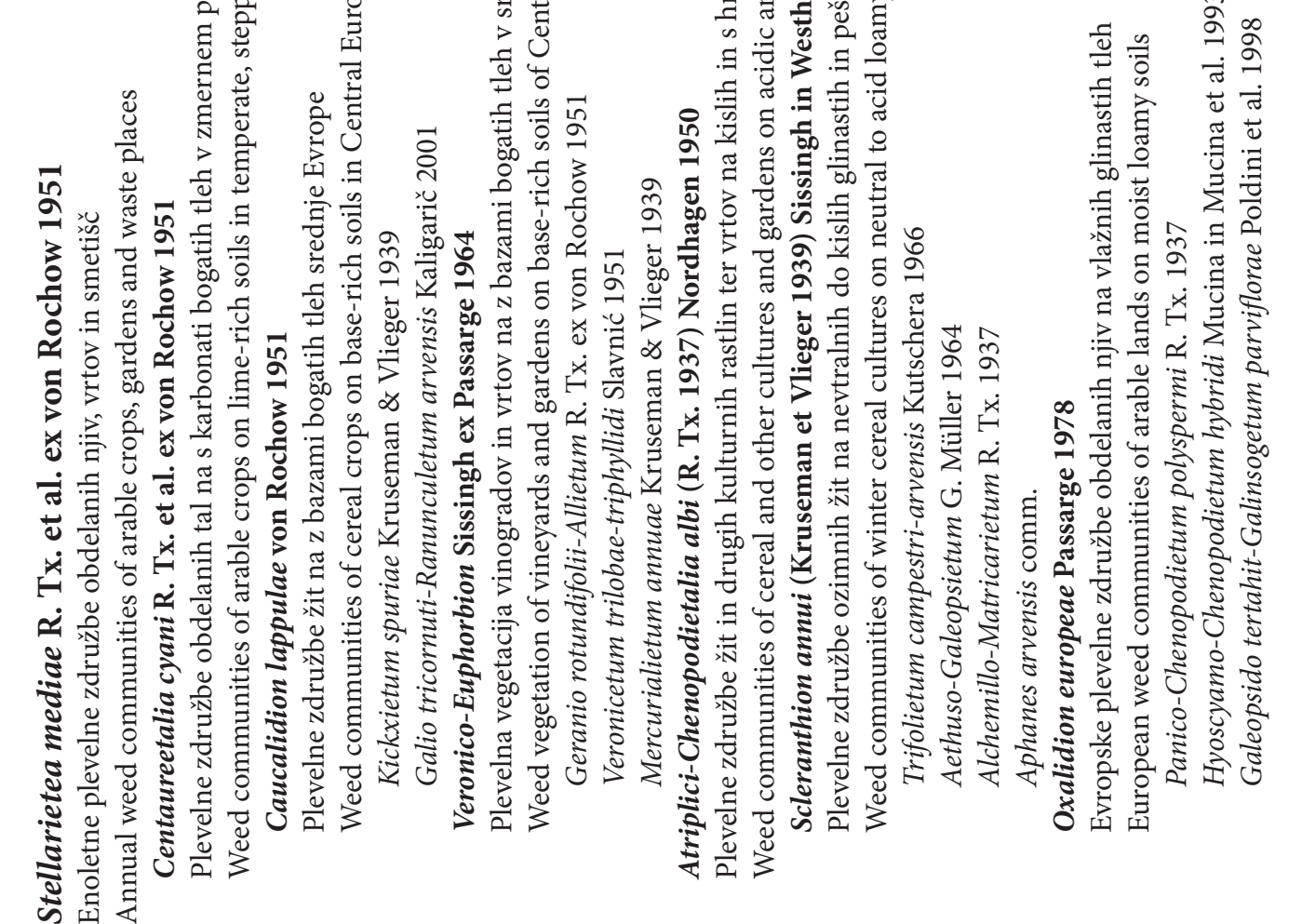




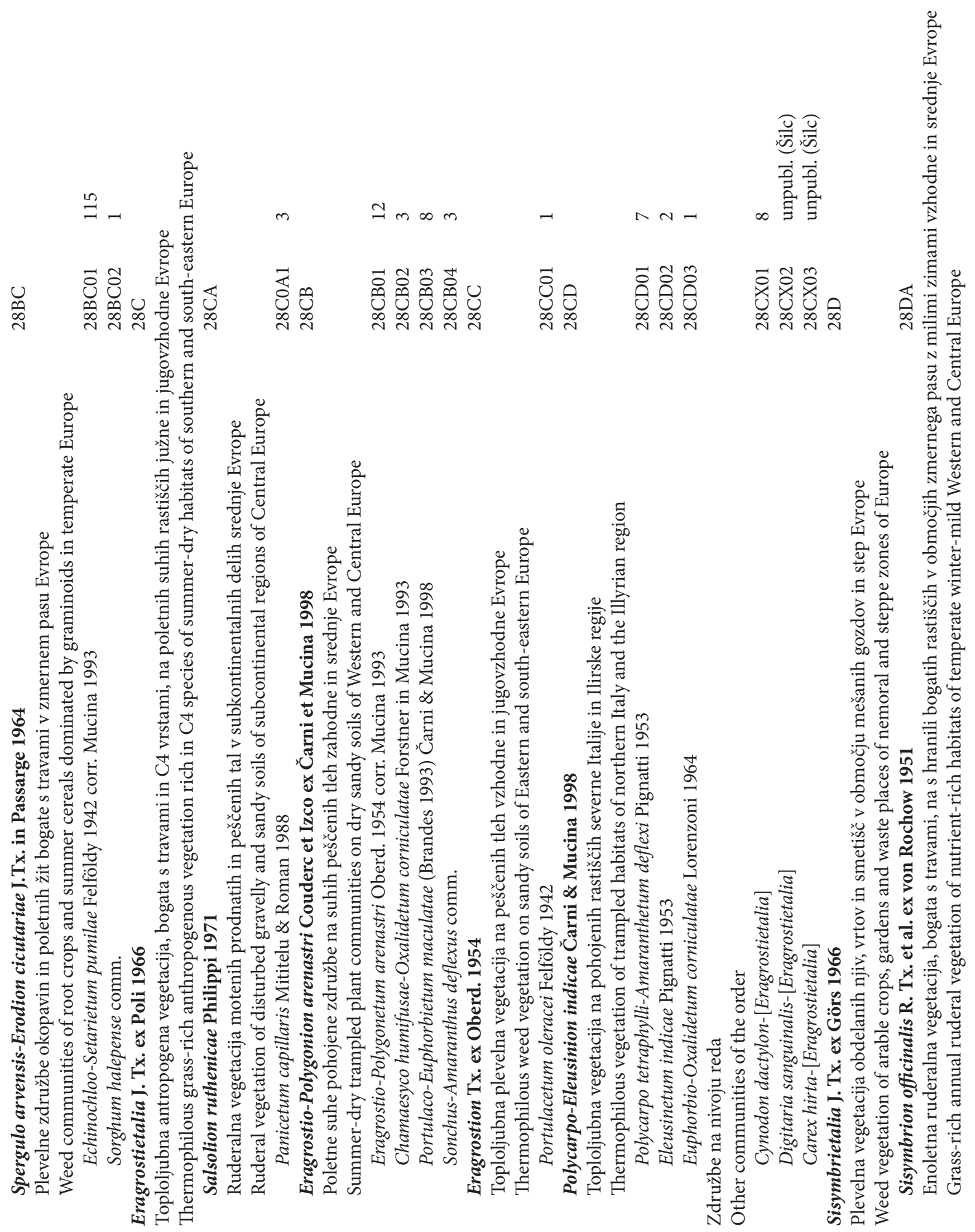




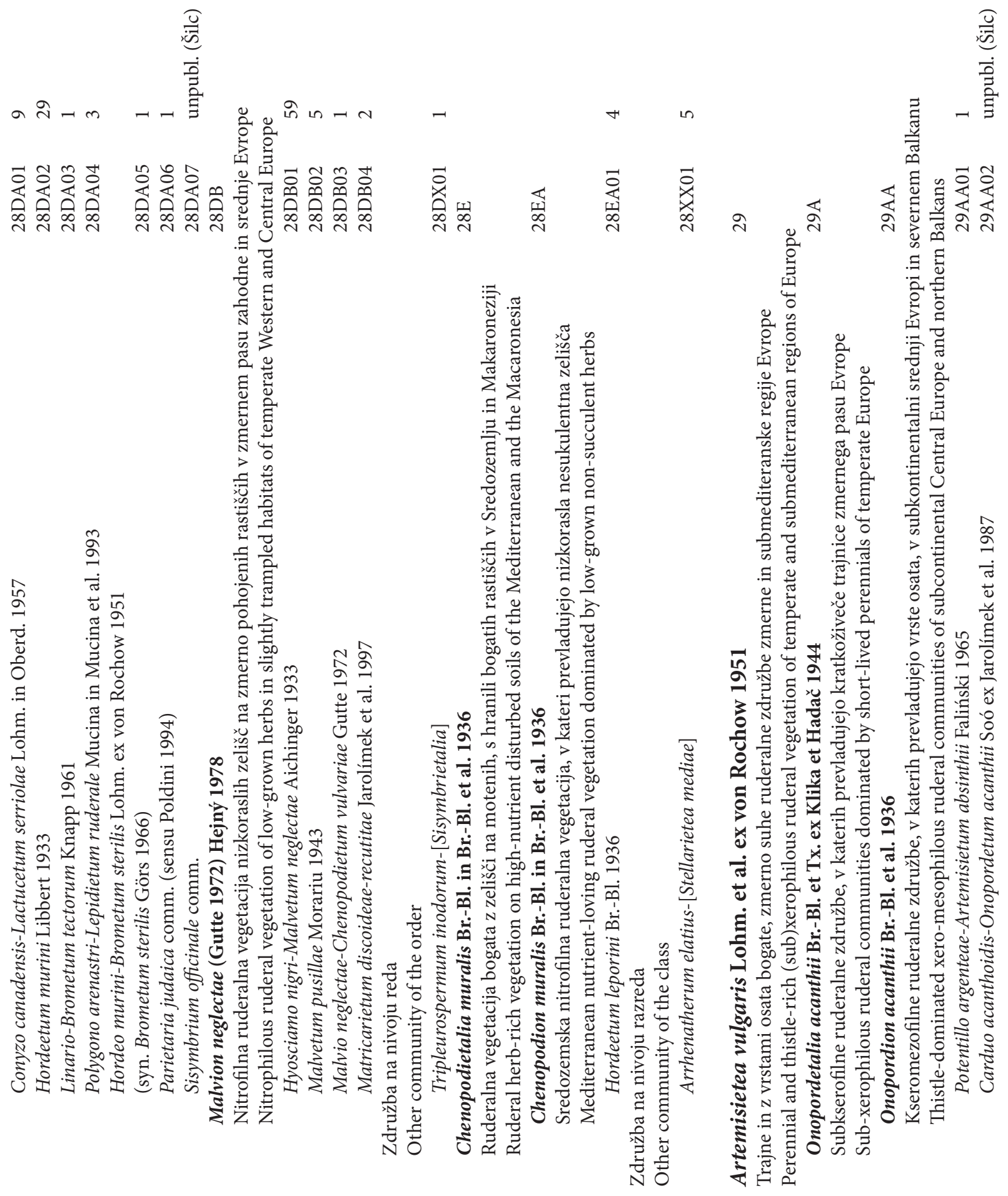



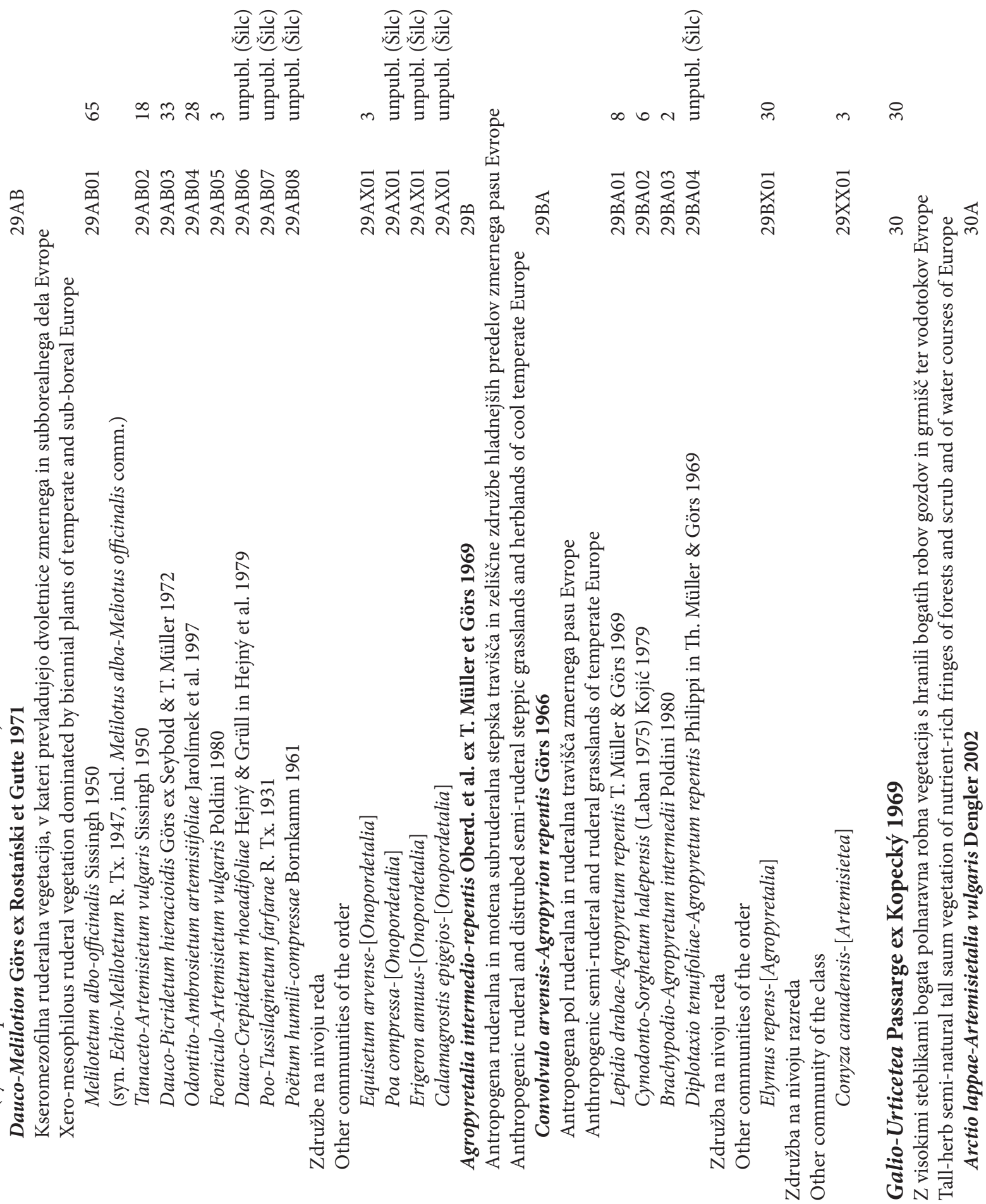


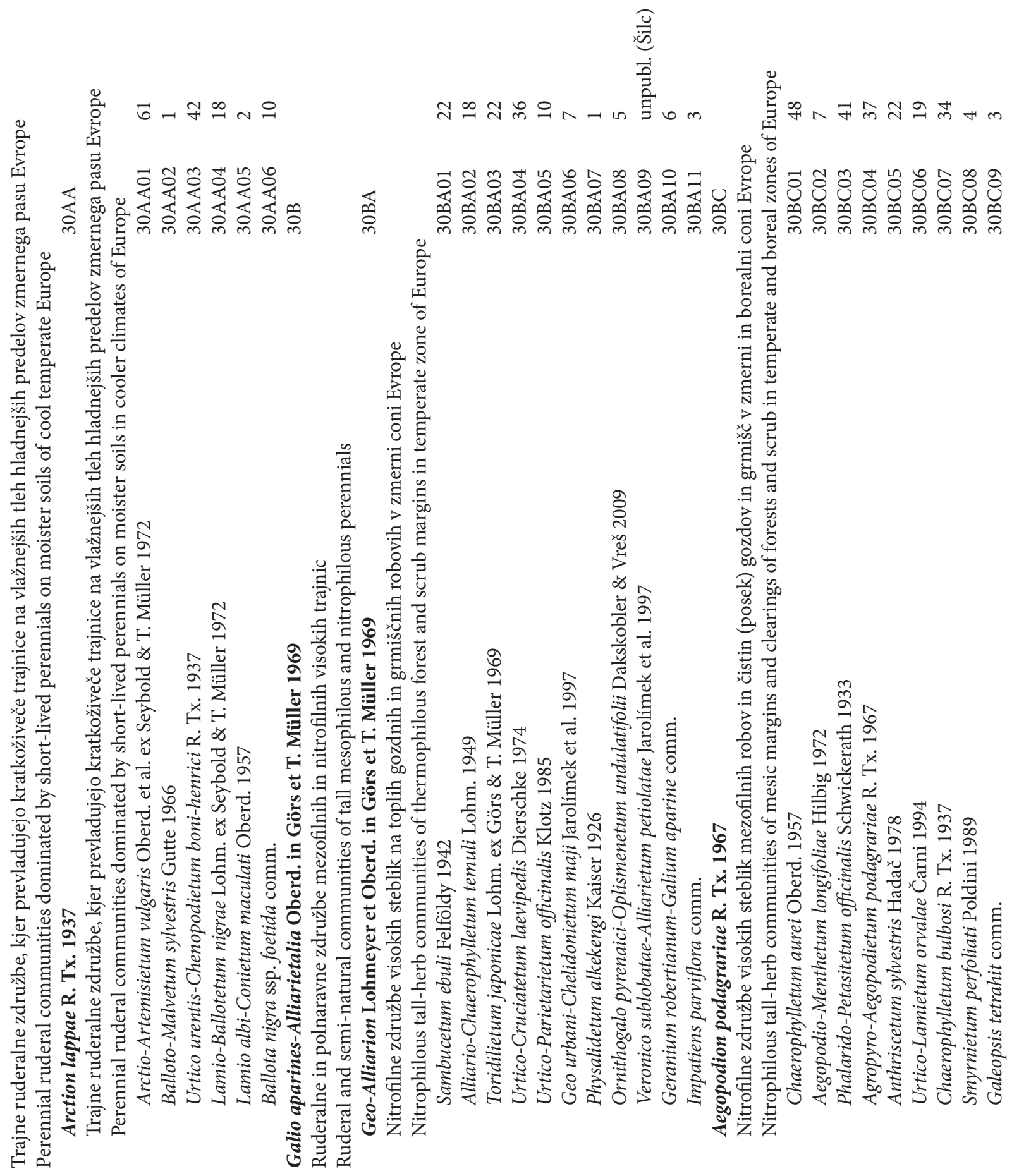




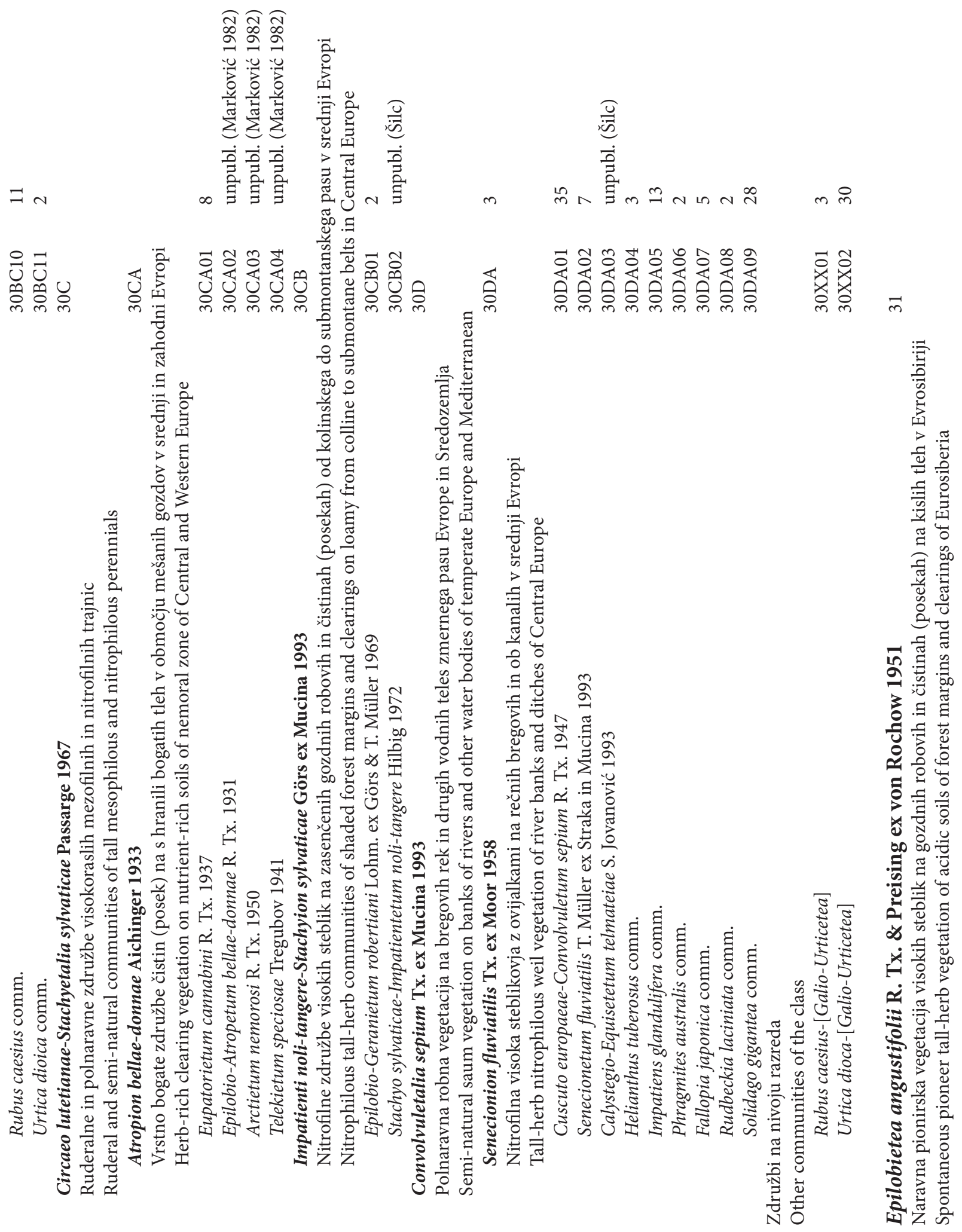




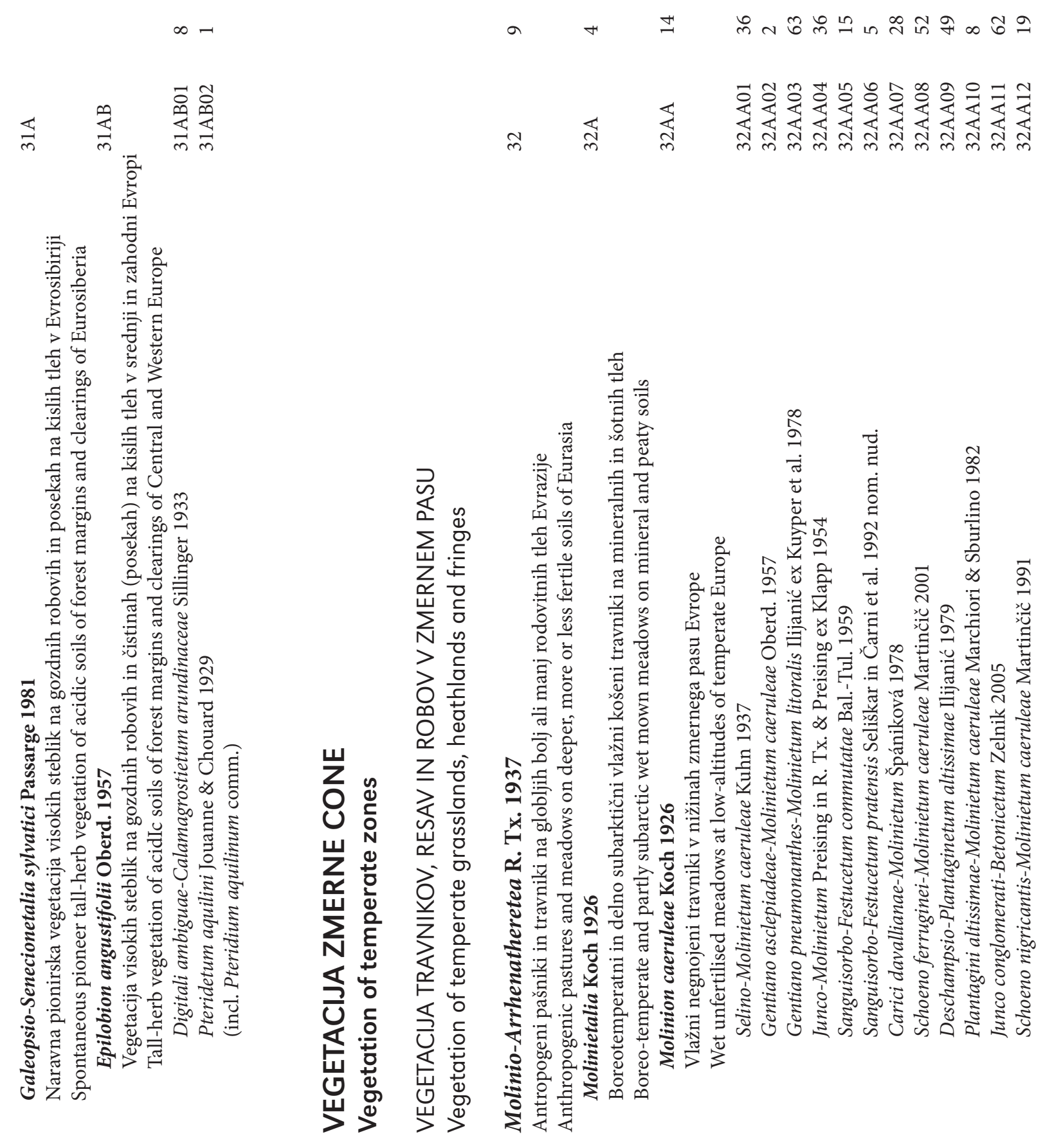



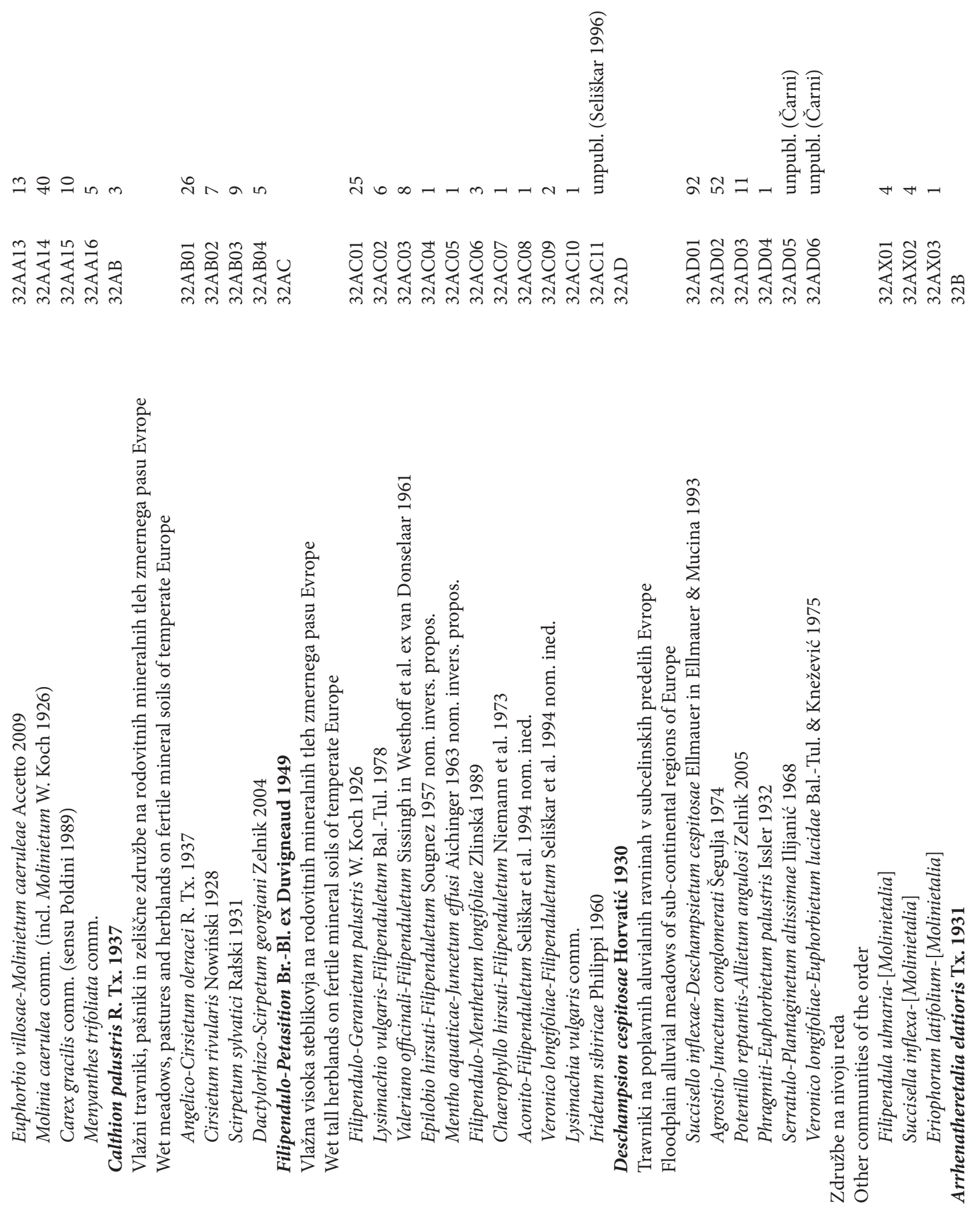

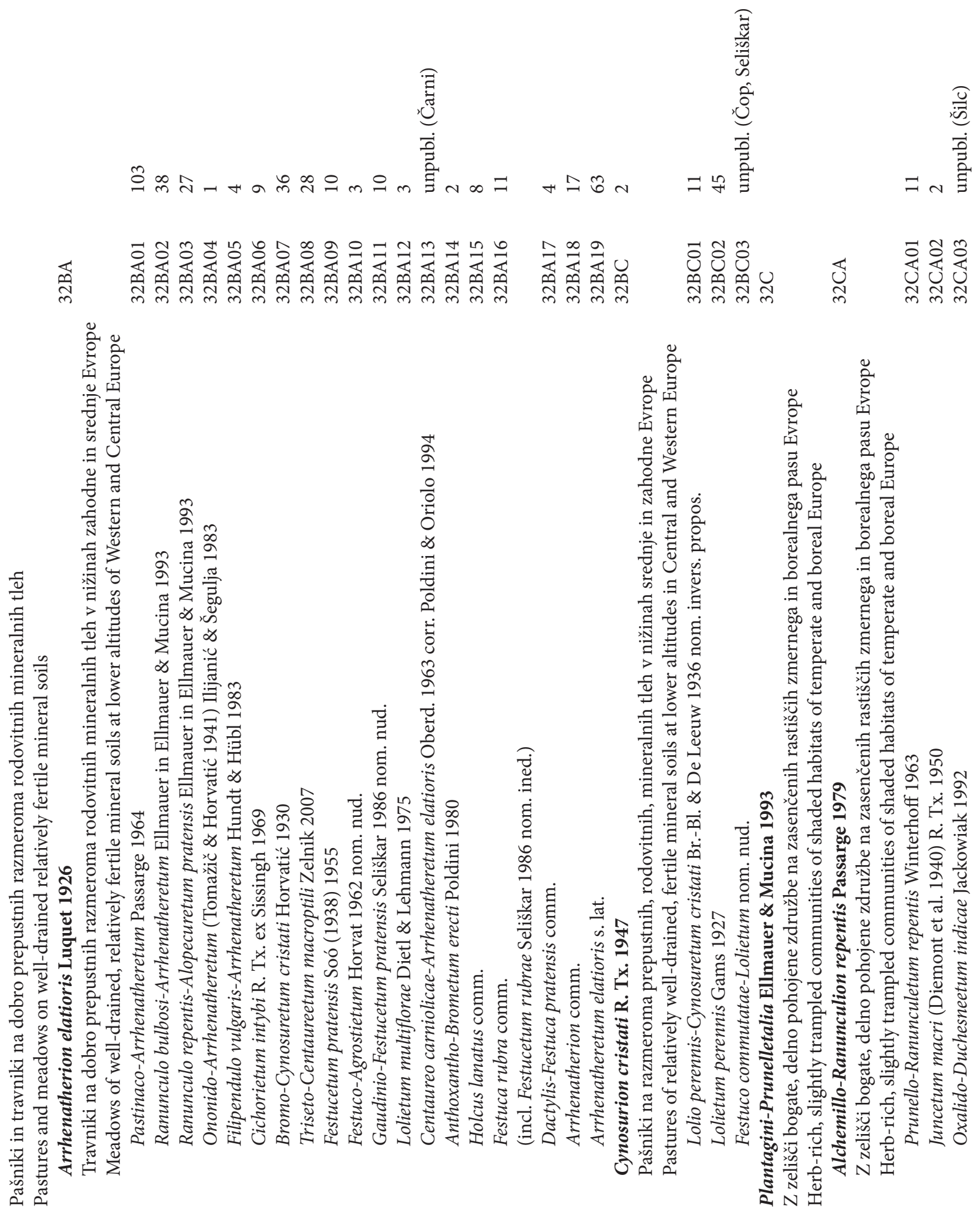

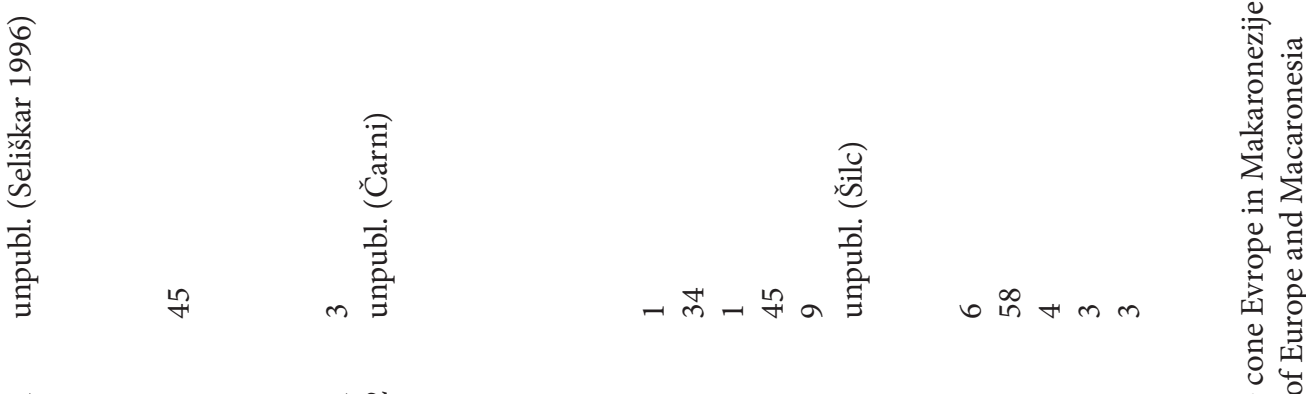

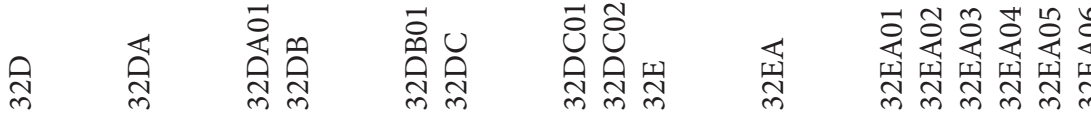

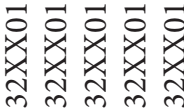

藏 $m$

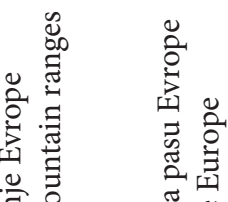

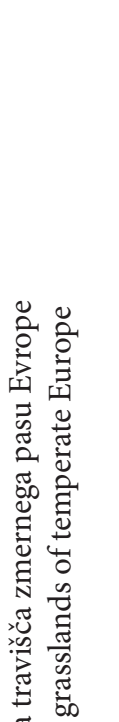

苛

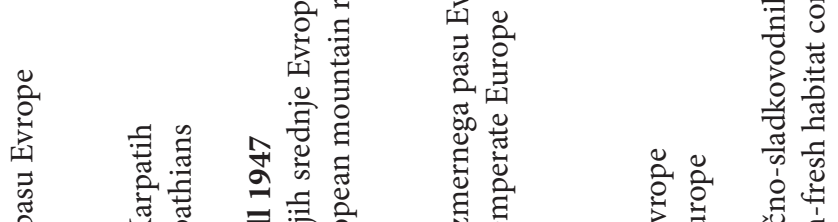

$\frac{\widehat{0}}{v^{2}}$

ー मேー भ

$0 \stackrel{\infty}{n}+m m$

, তี

을

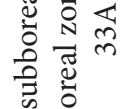

율

藏

च

:

है

के

'

㱐

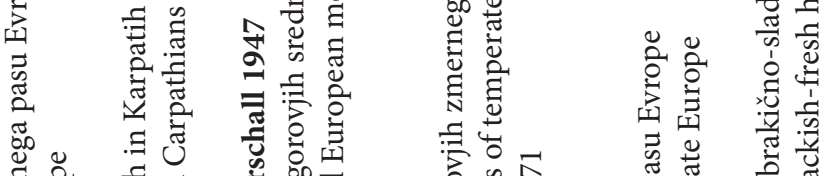

焉

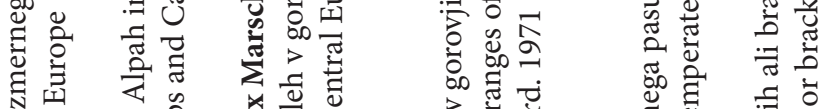

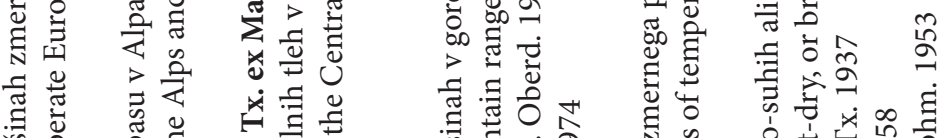

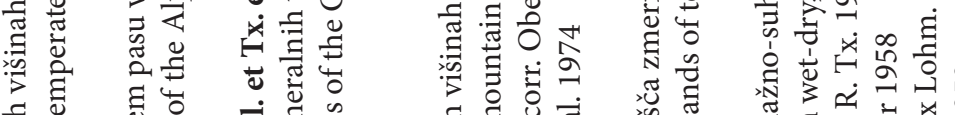

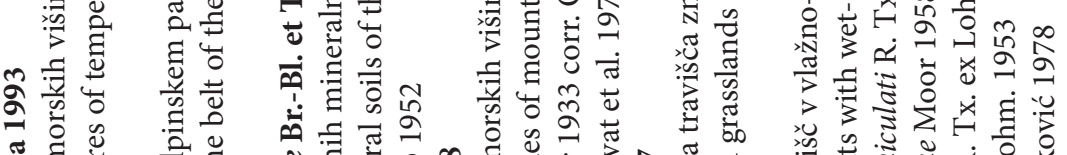

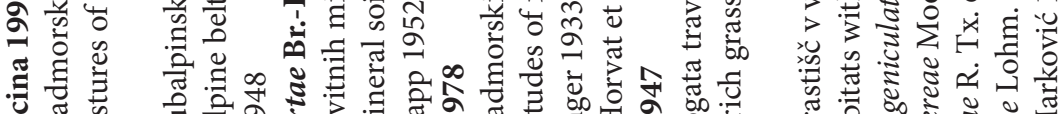

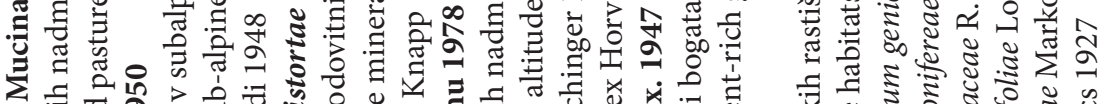

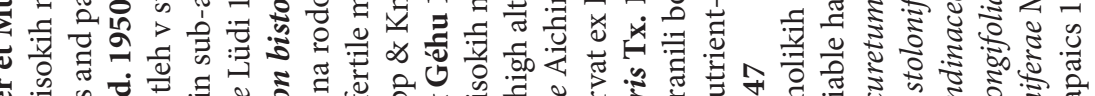

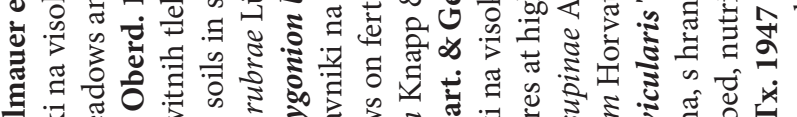

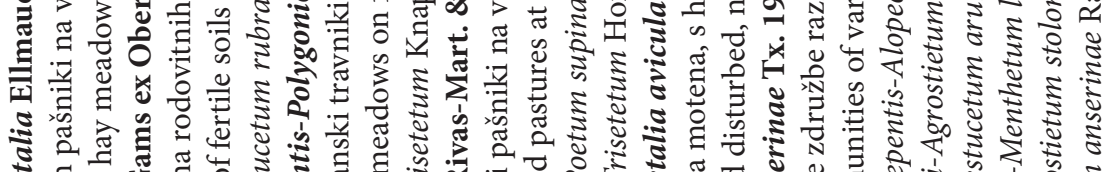

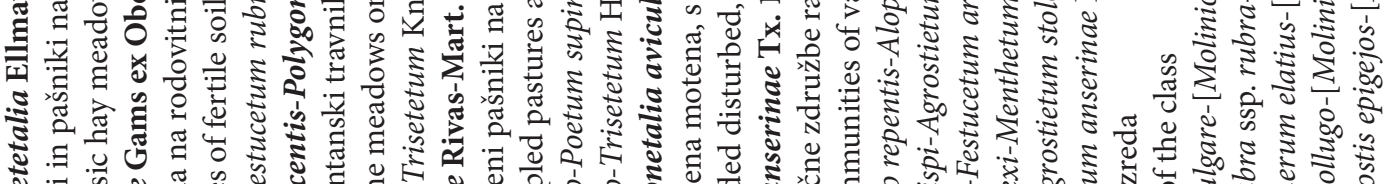

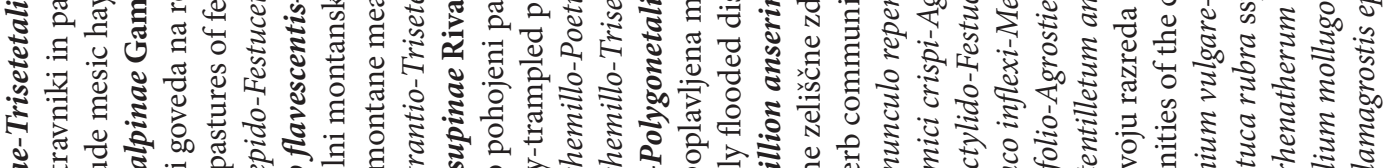

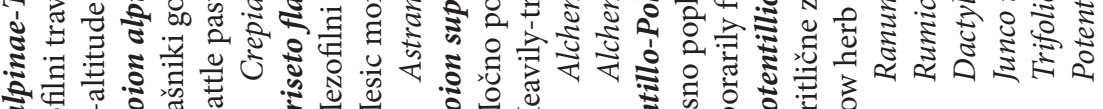

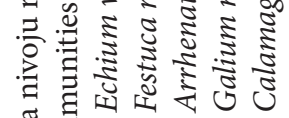

ह

$\therefore \sum^{\infty}$ 


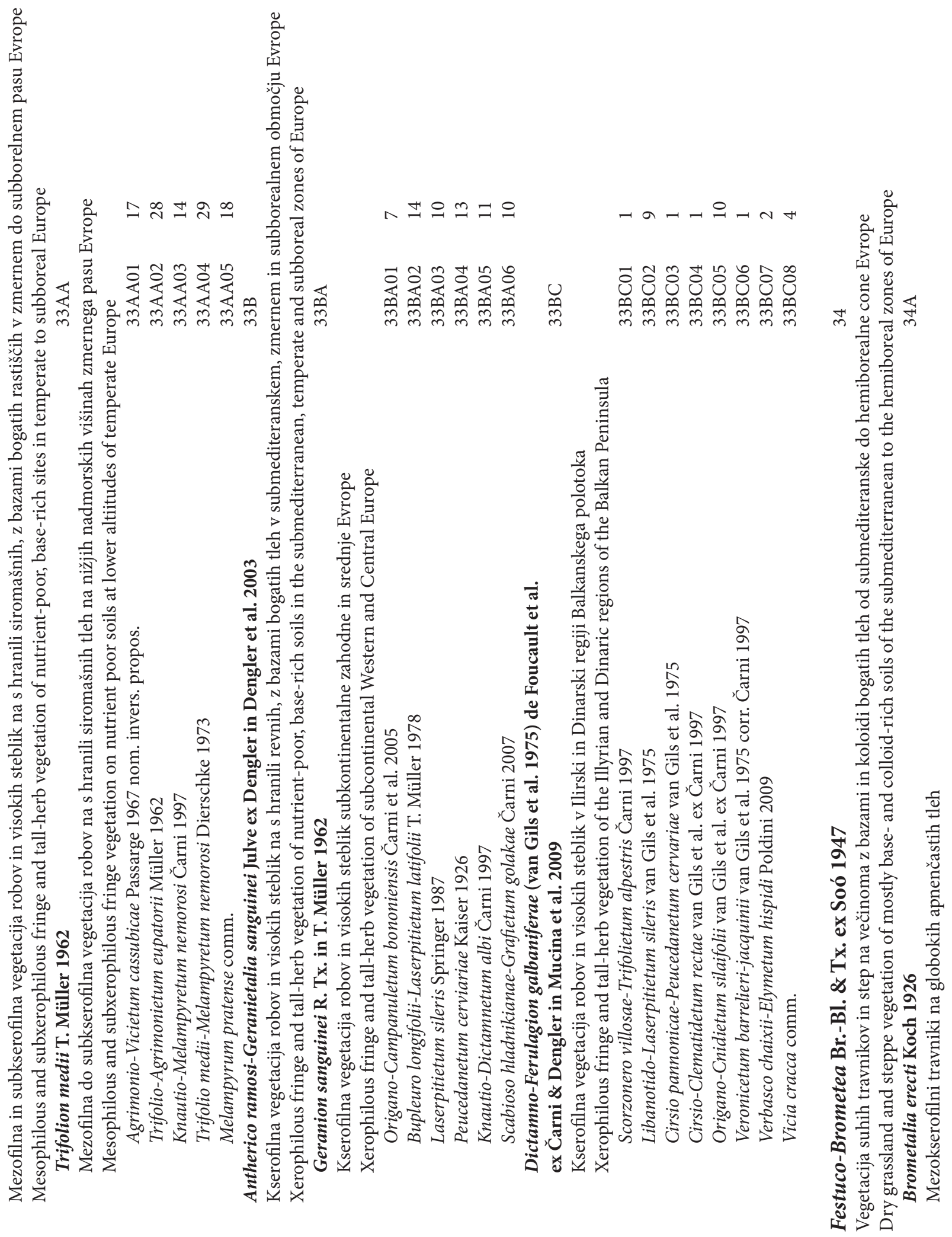




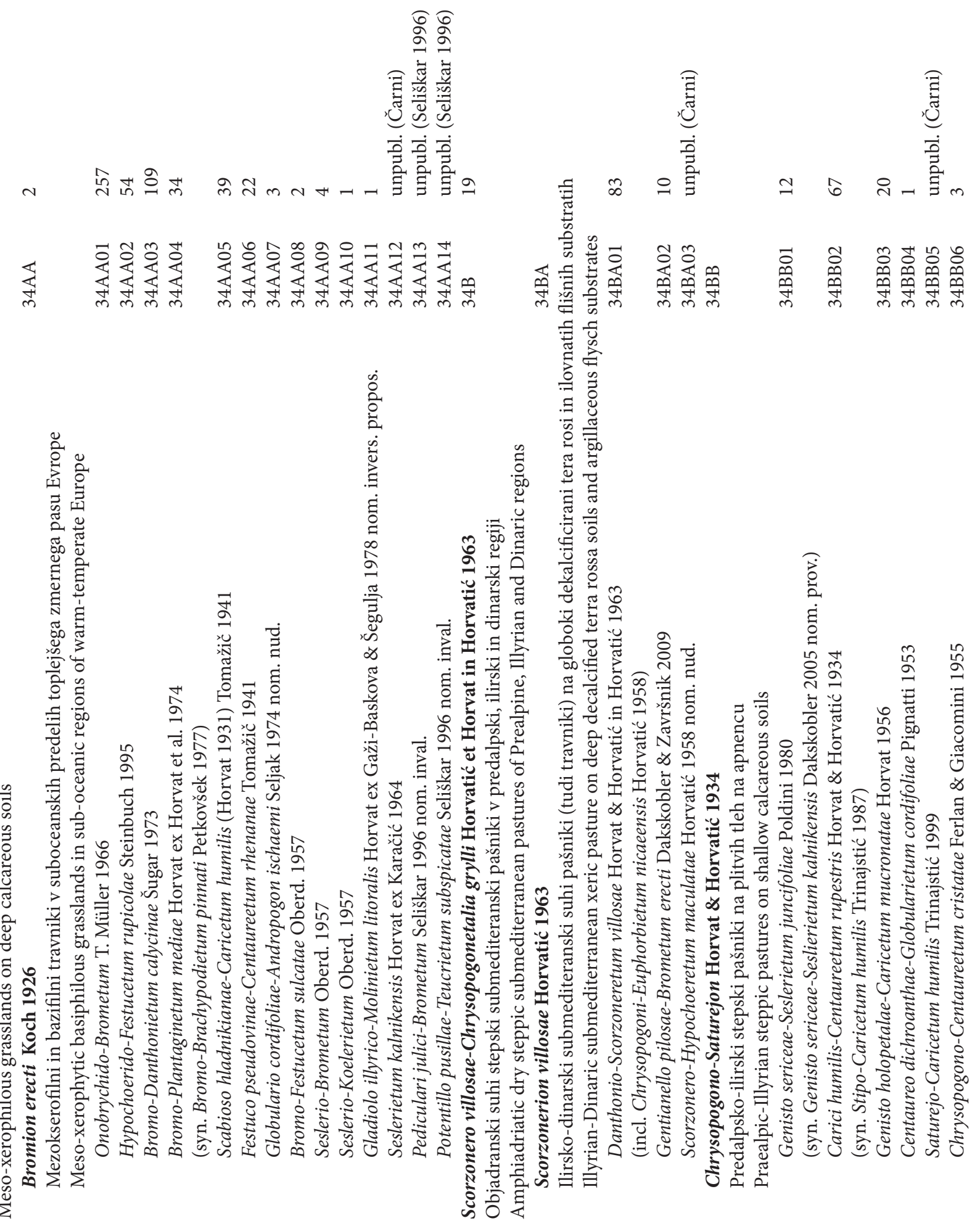




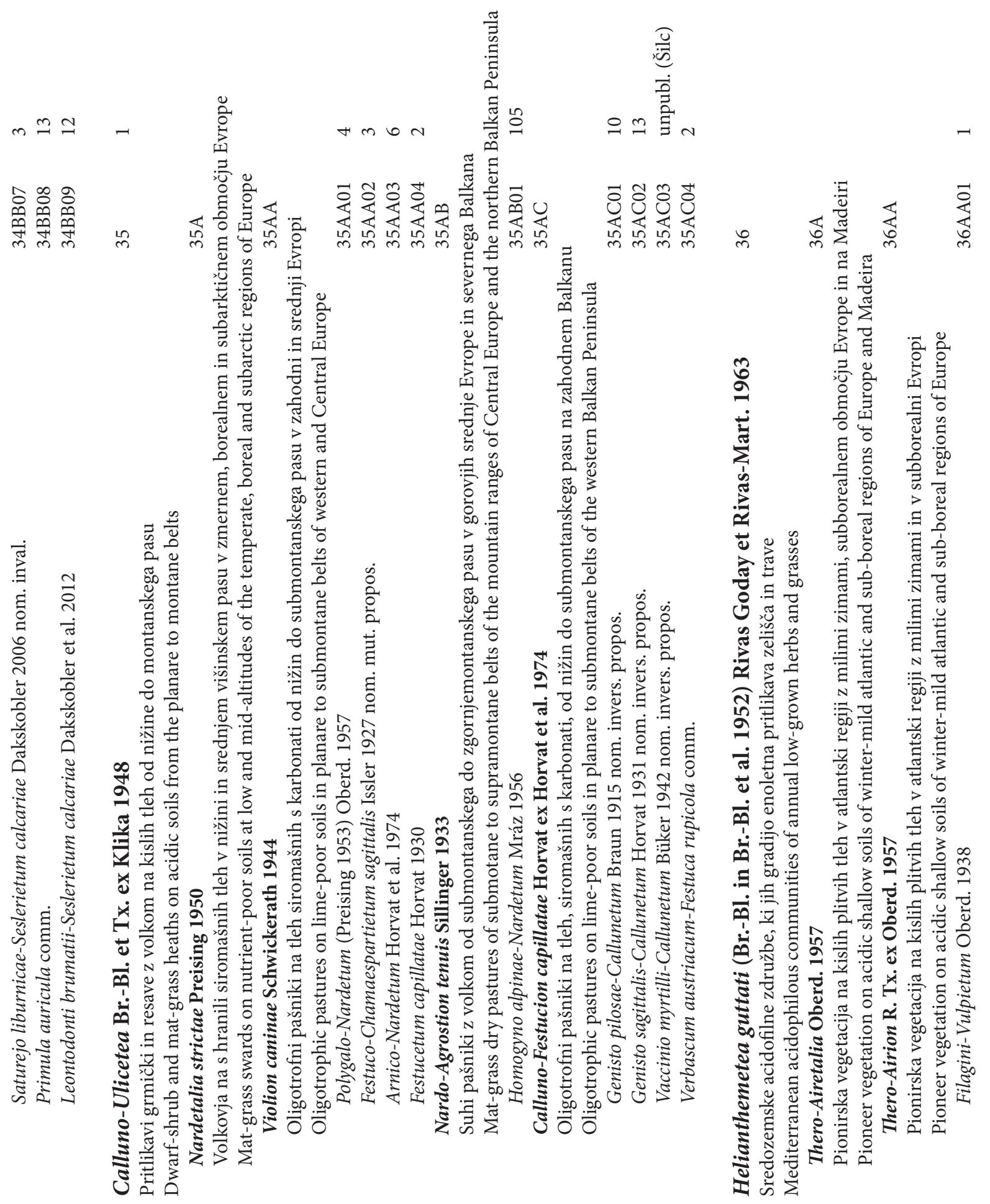




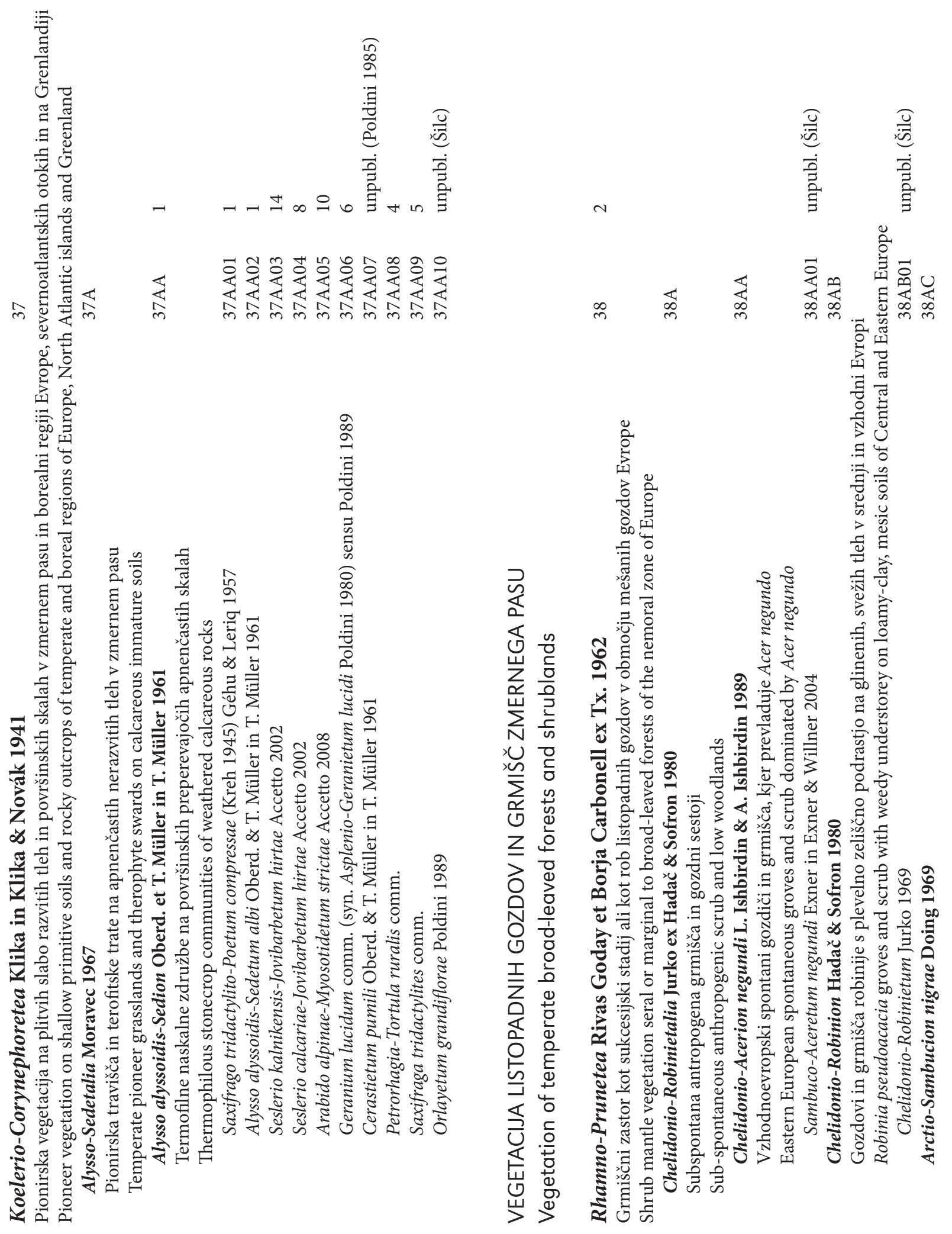




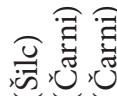

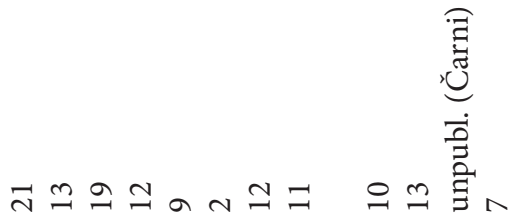

$\stackrel{\circ}{\sim}$

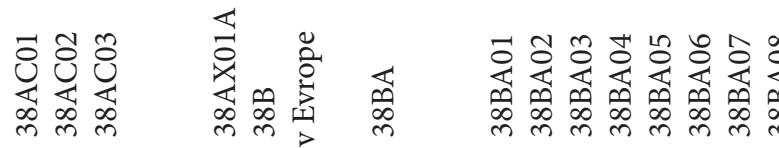

$\stackrel{0}{0}: \exists \approx$

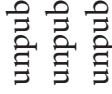

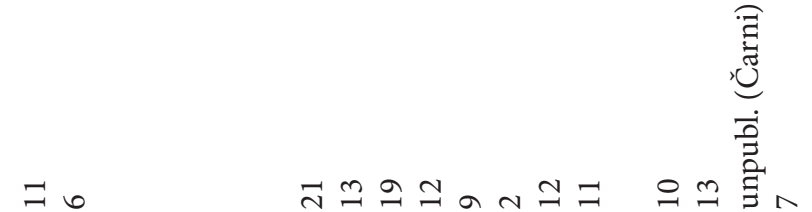

总

ڤั.

离

蒙

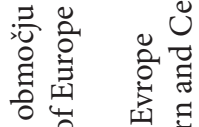

苍语

귱

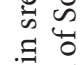

峲覃

น้

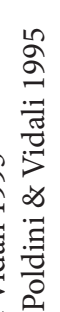

苛

촗 윯

$\exists$

吾

䨌

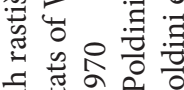

这

สี

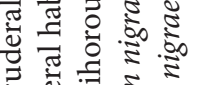

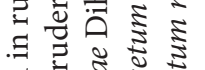

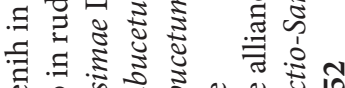

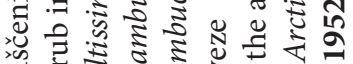

总

究岁这

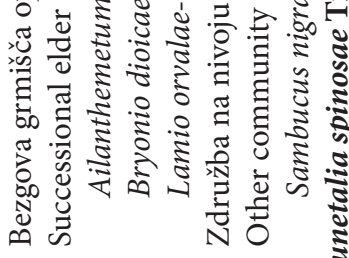

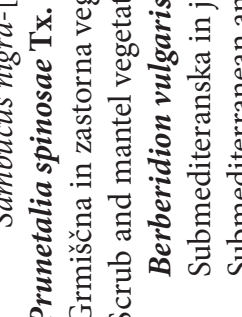

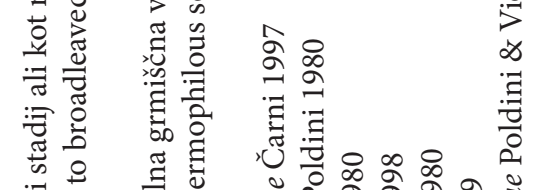

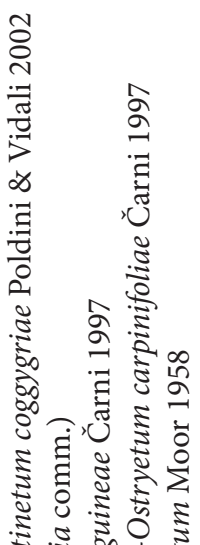

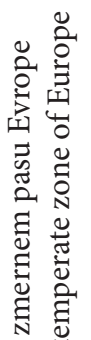

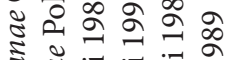

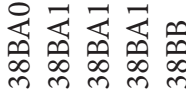

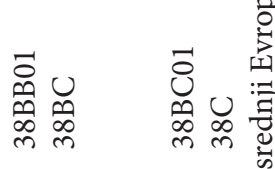

空

응

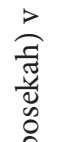

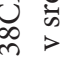

悉

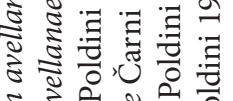

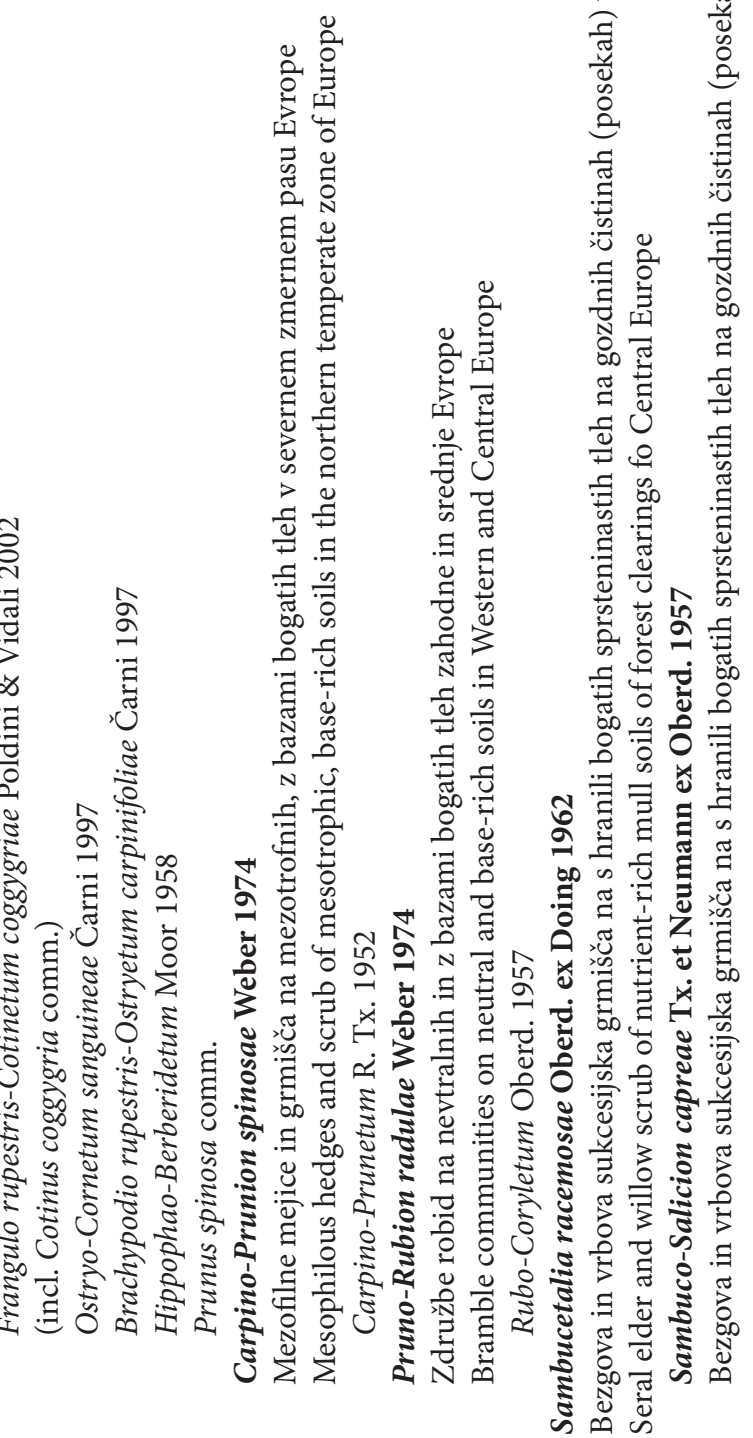




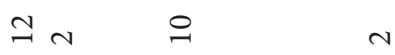

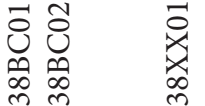
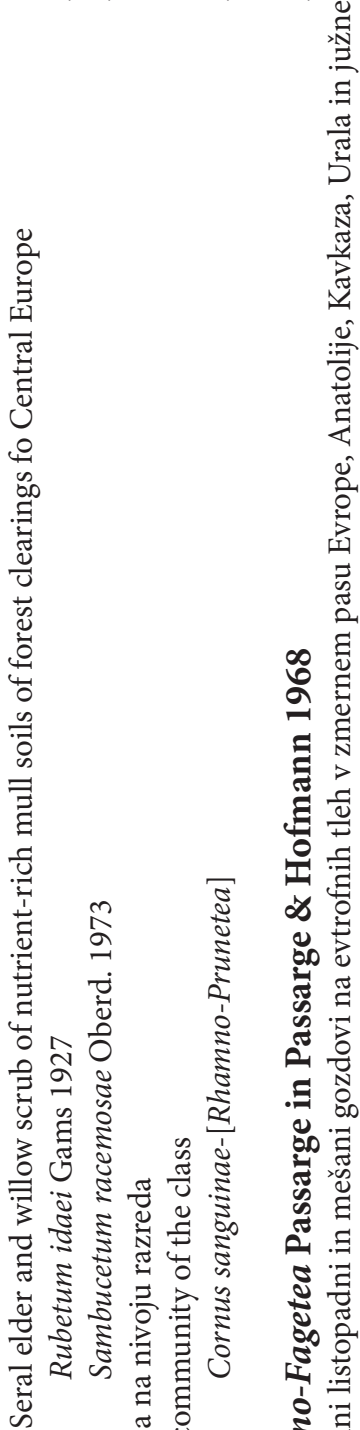

है

臣

군

芩5

$\cong$

龸

苚苛

空

泀

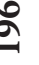

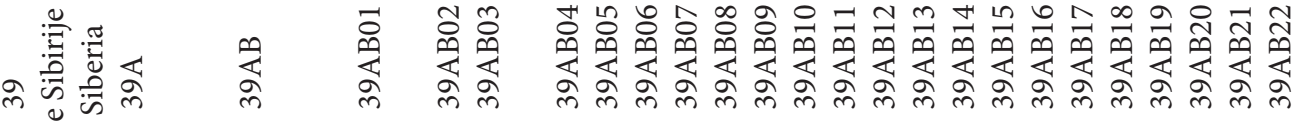

氙旅

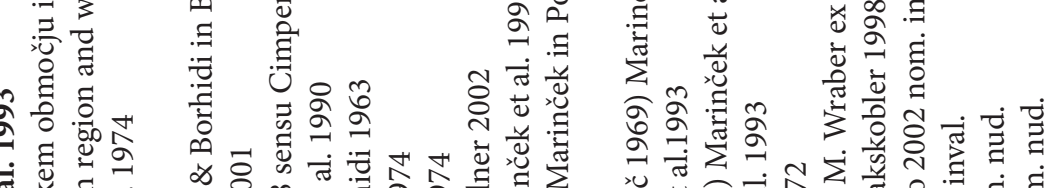

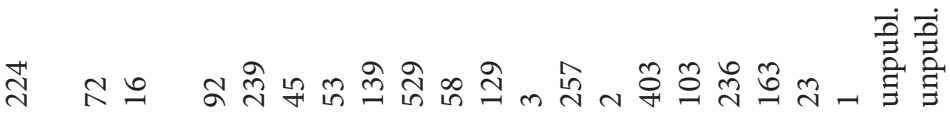

仓ิ

清: 毒

N 屯ै.

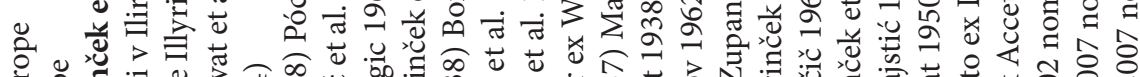

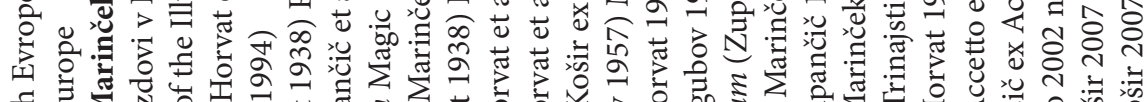

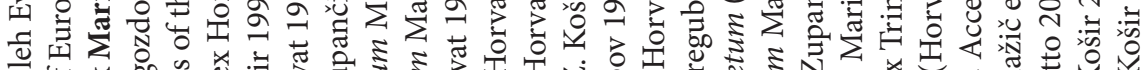
出

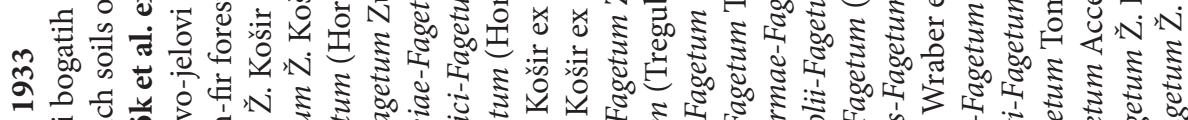

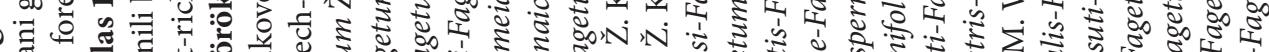

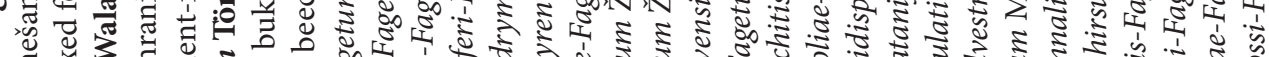

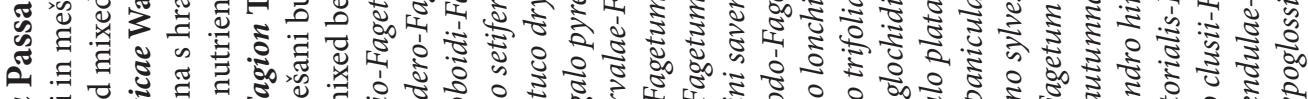

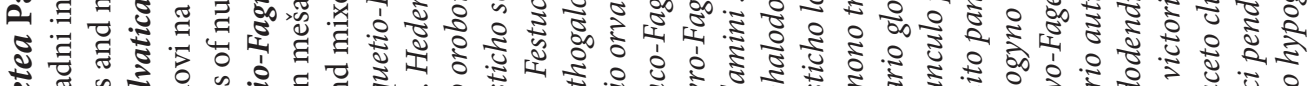

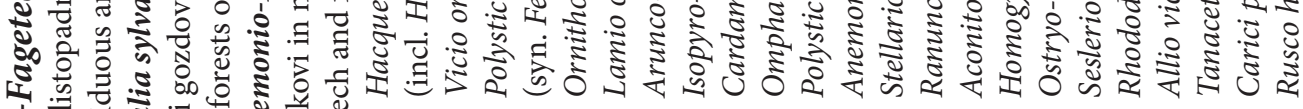

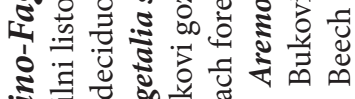




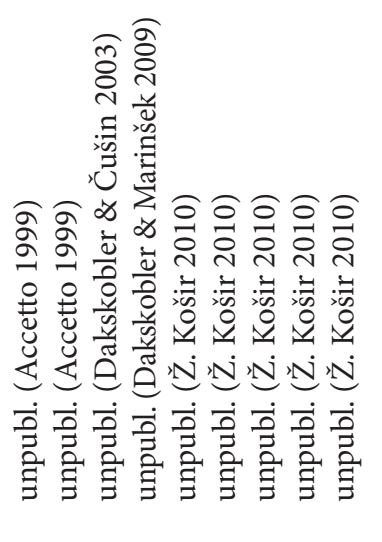

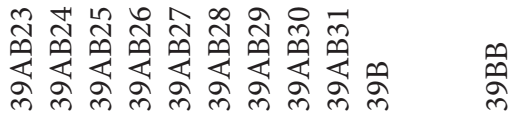

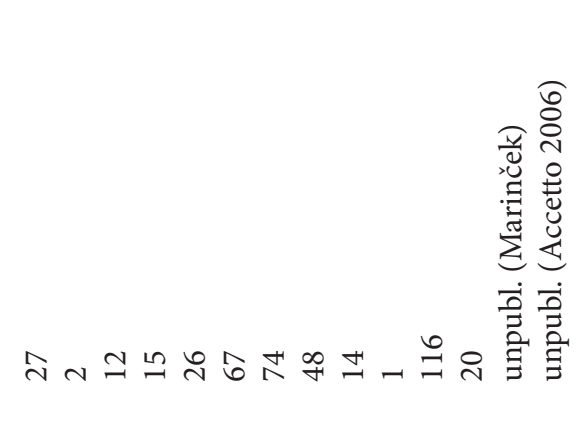

$\overrightarrow{0}$ 论

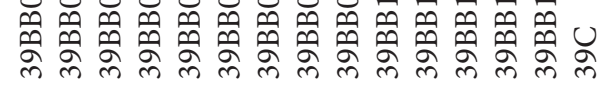
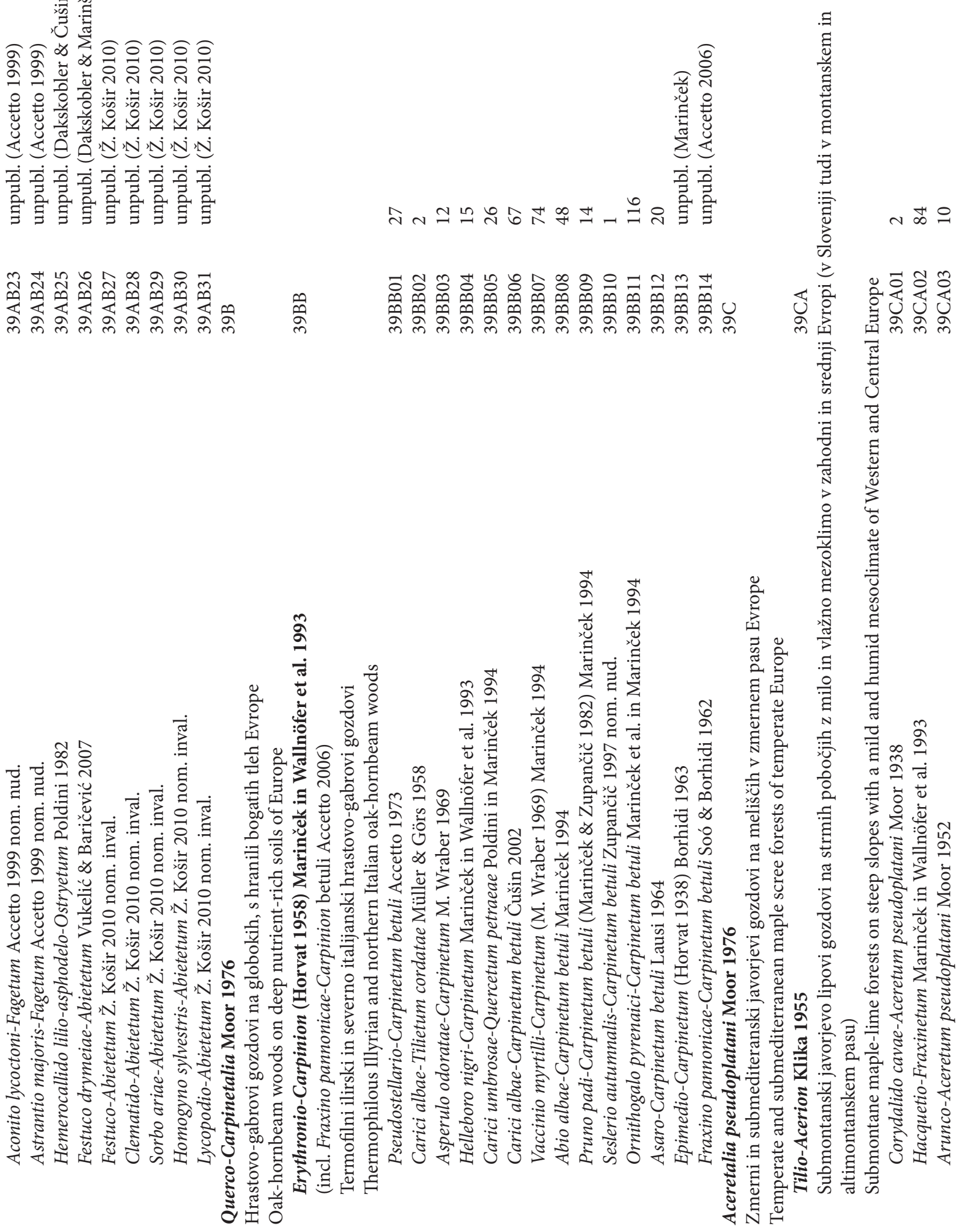


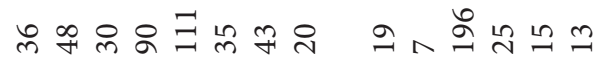

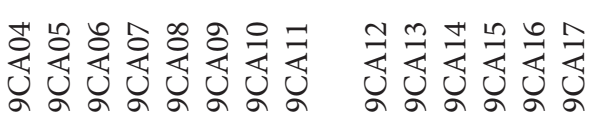

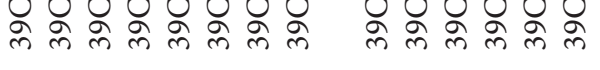

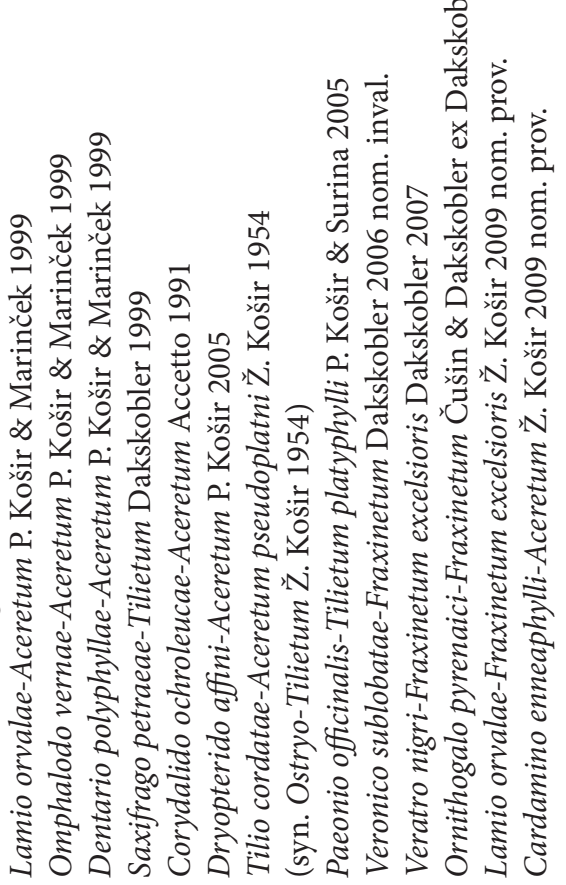

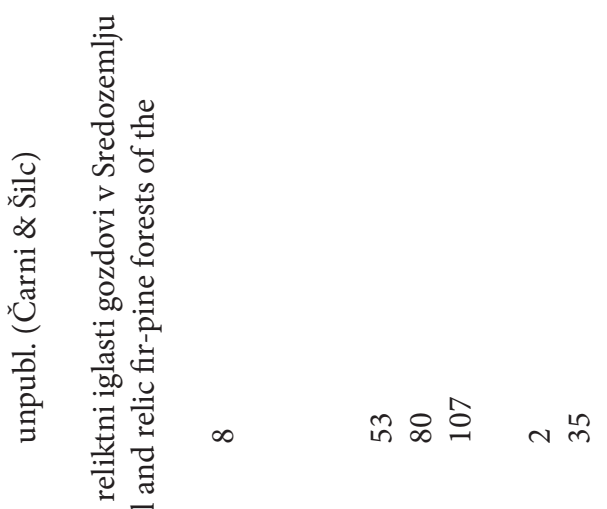

:

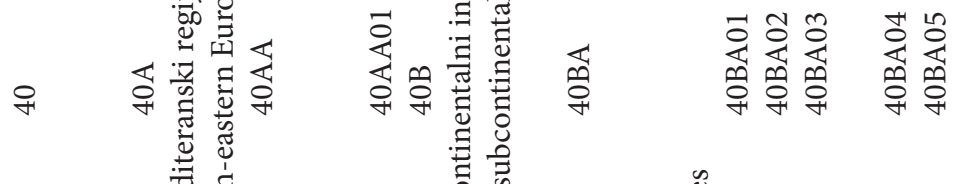

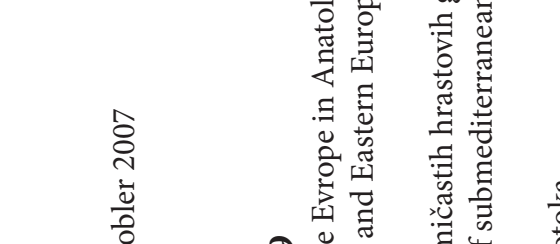

(1)

मूे

药 娄

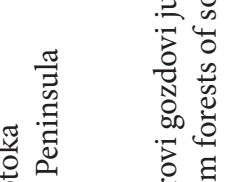

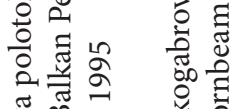
吅 要过

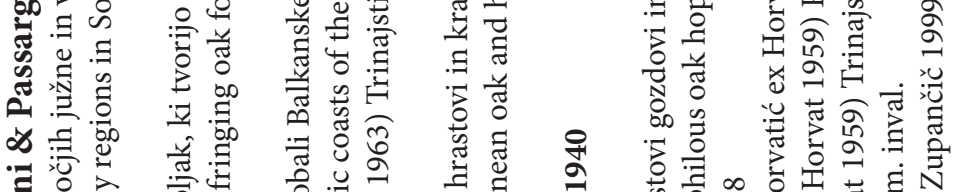

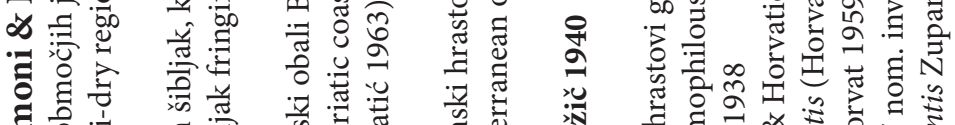

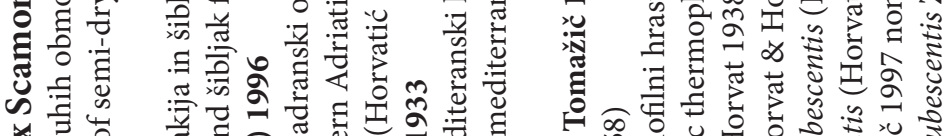

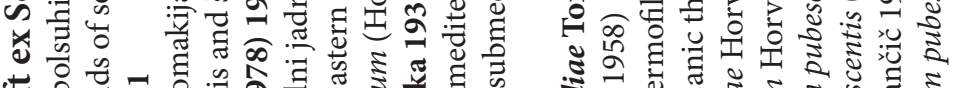

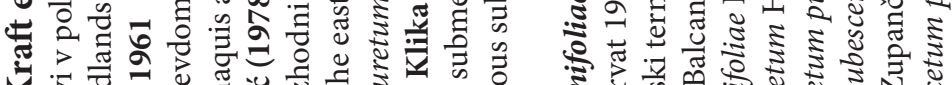

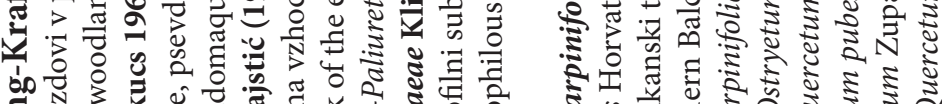

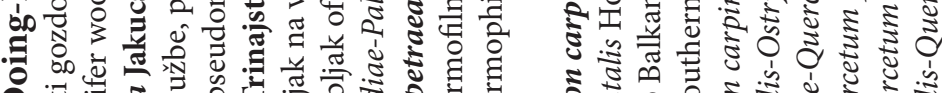

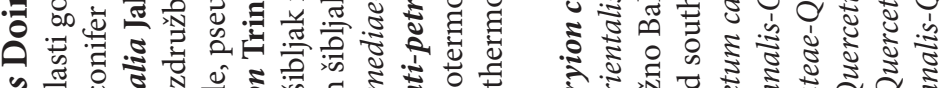

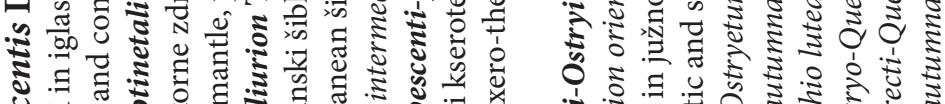

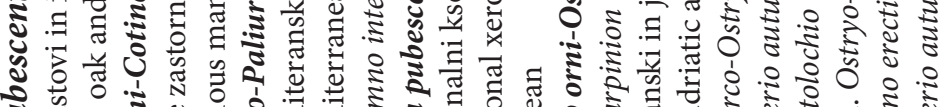

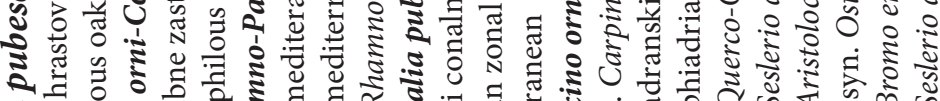

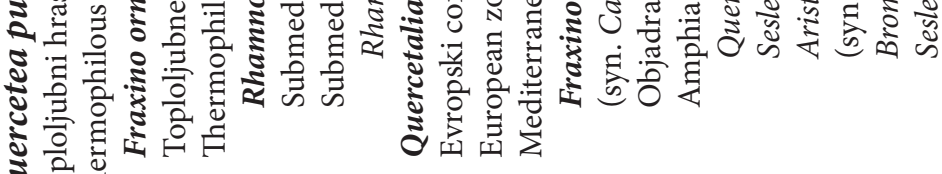

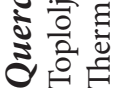




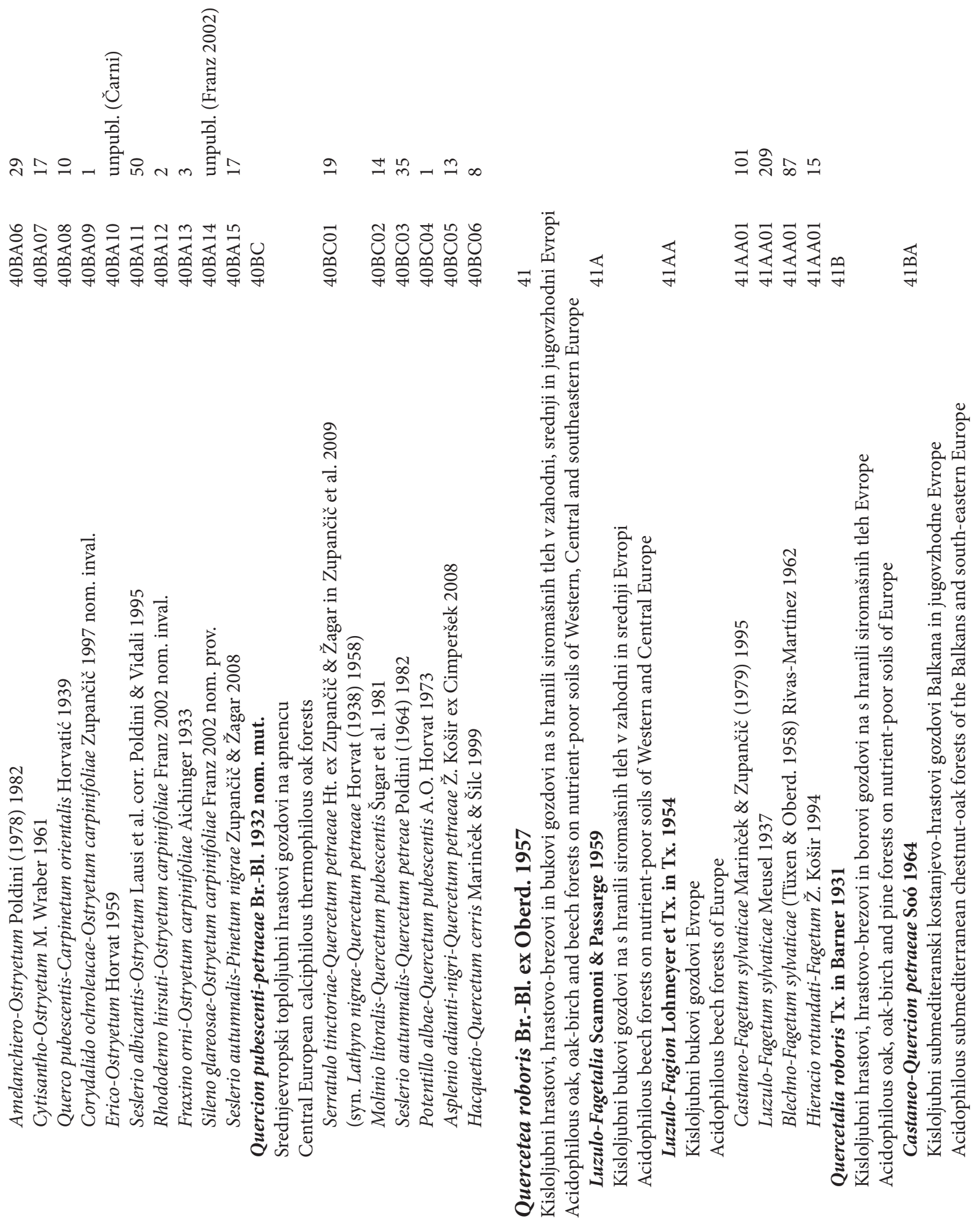




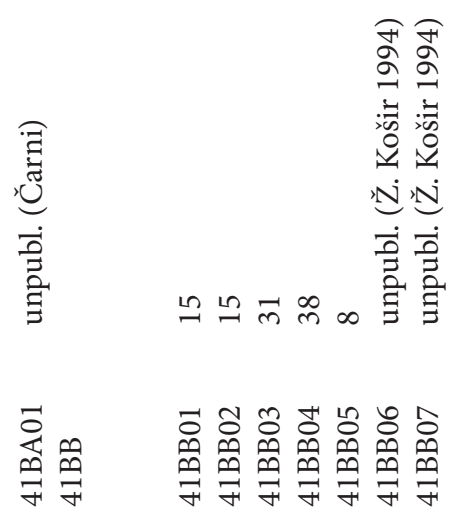

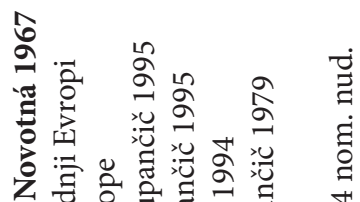

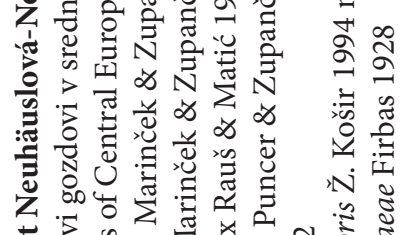

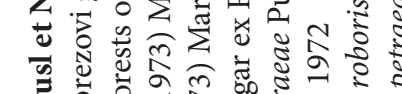

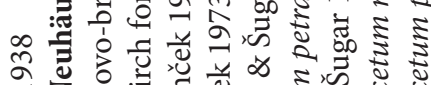

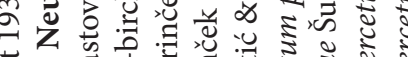

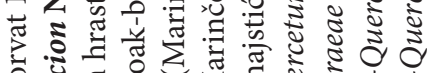

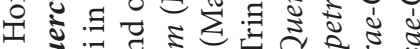

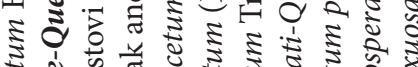

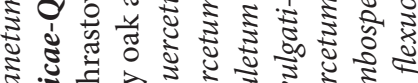

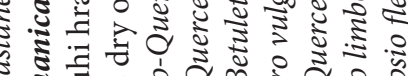
0
0
0 0.

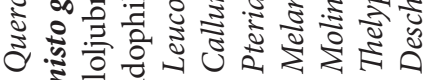

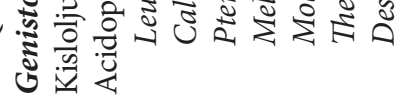

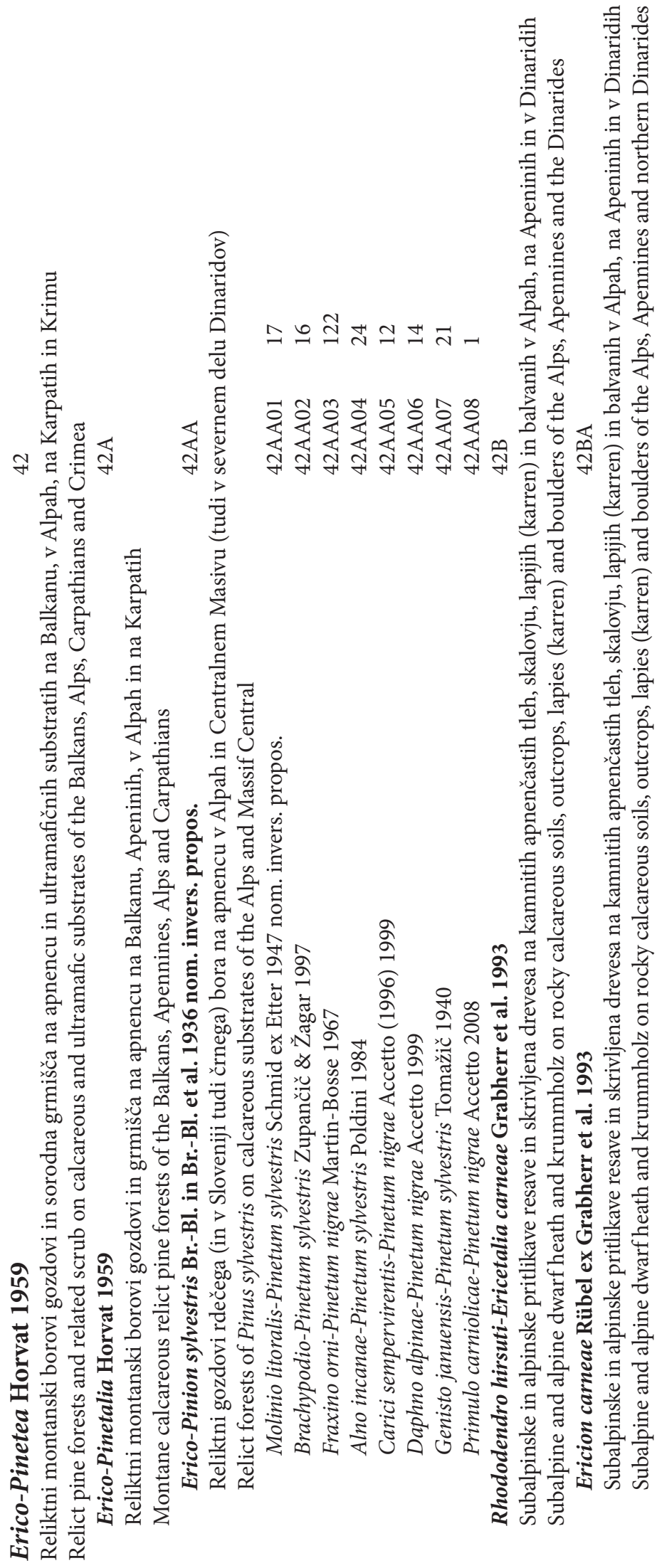




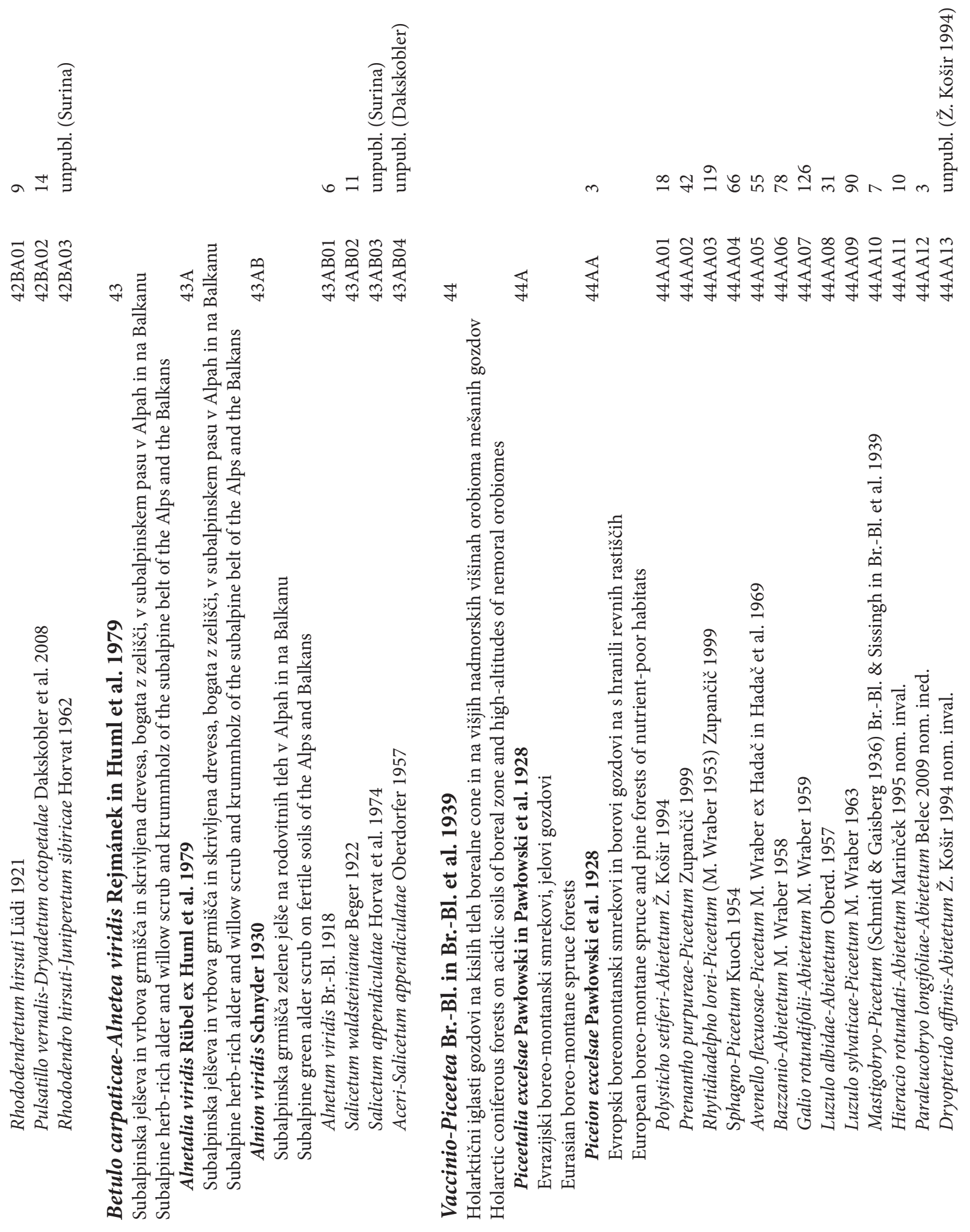




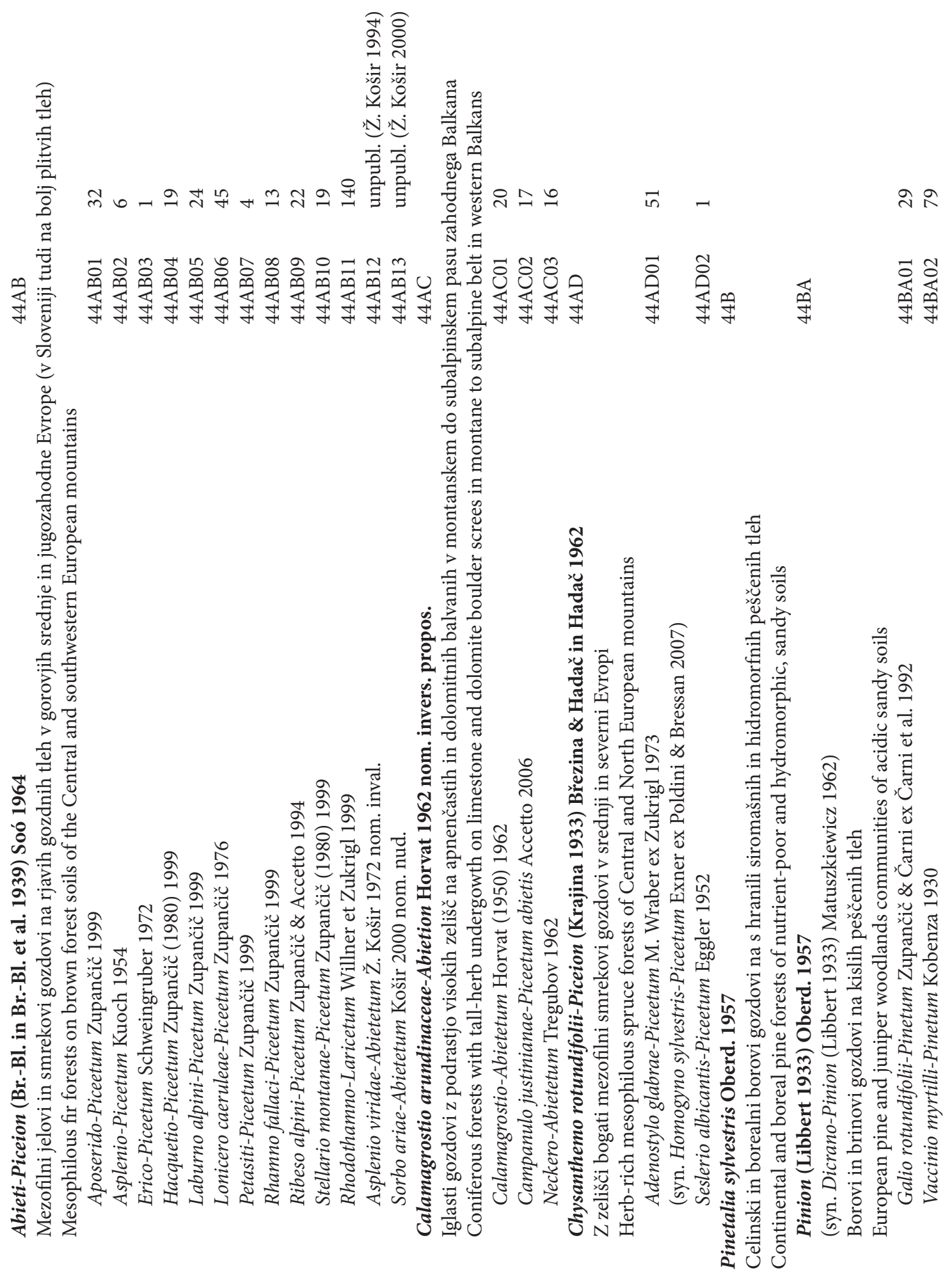




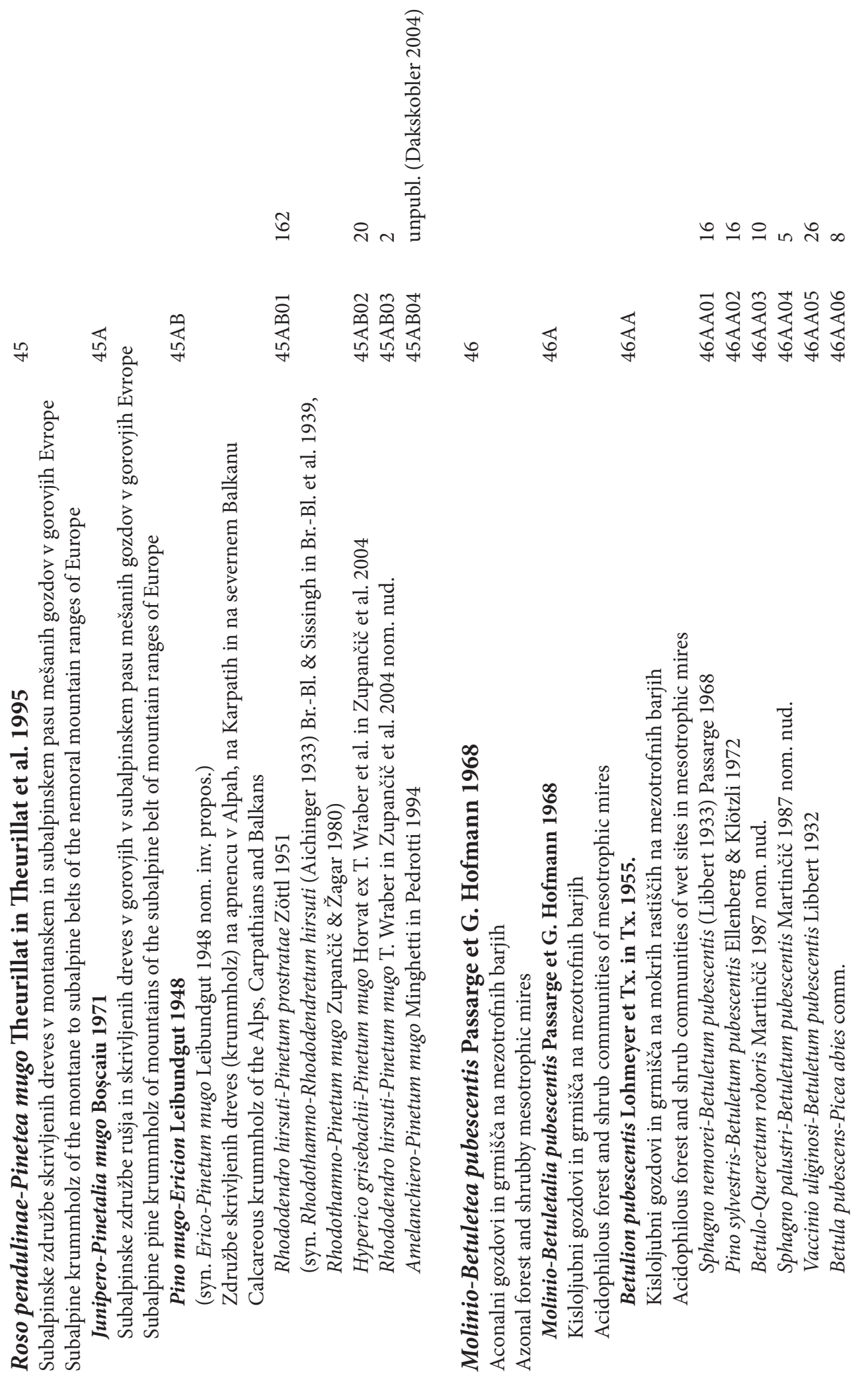




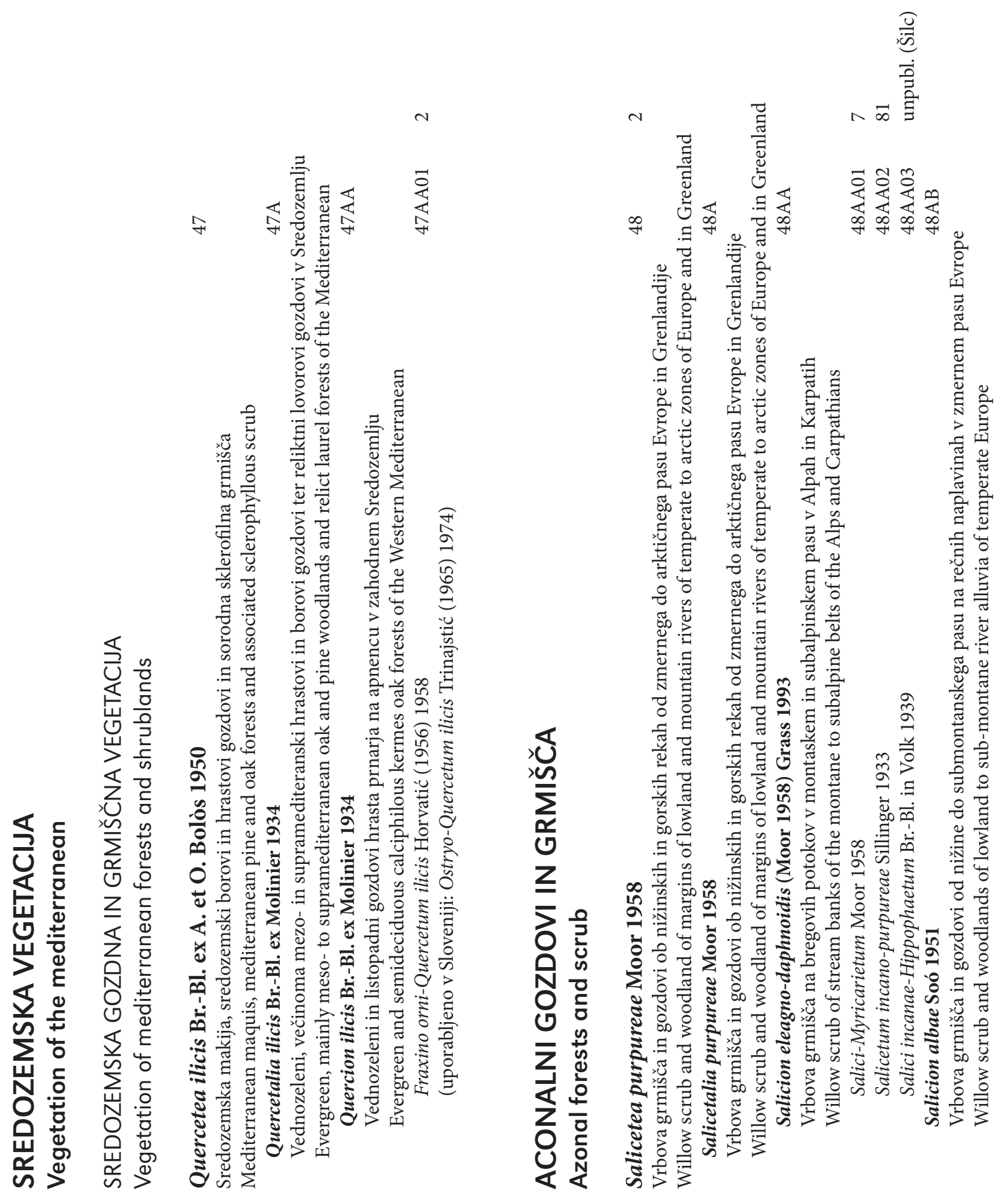




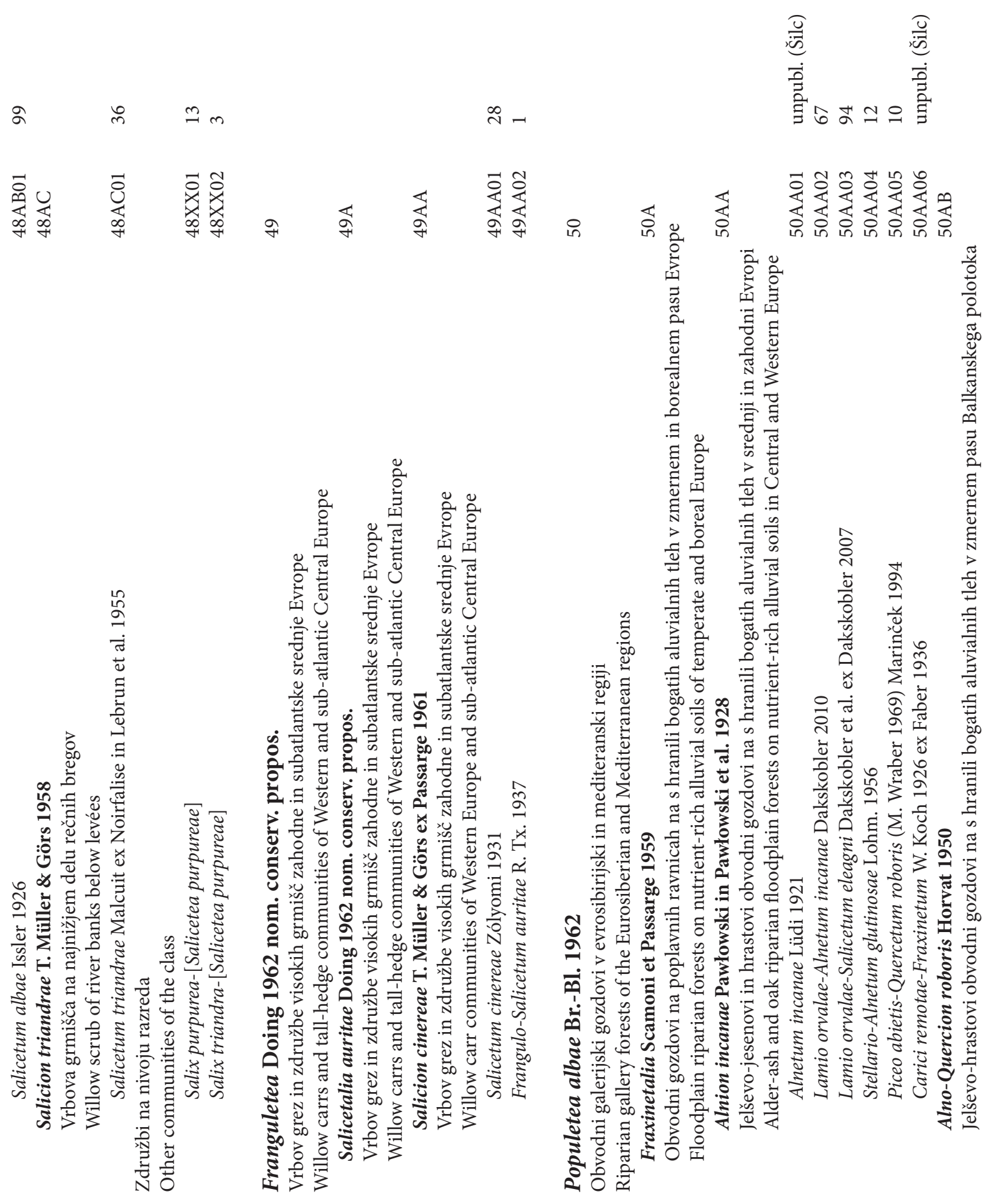



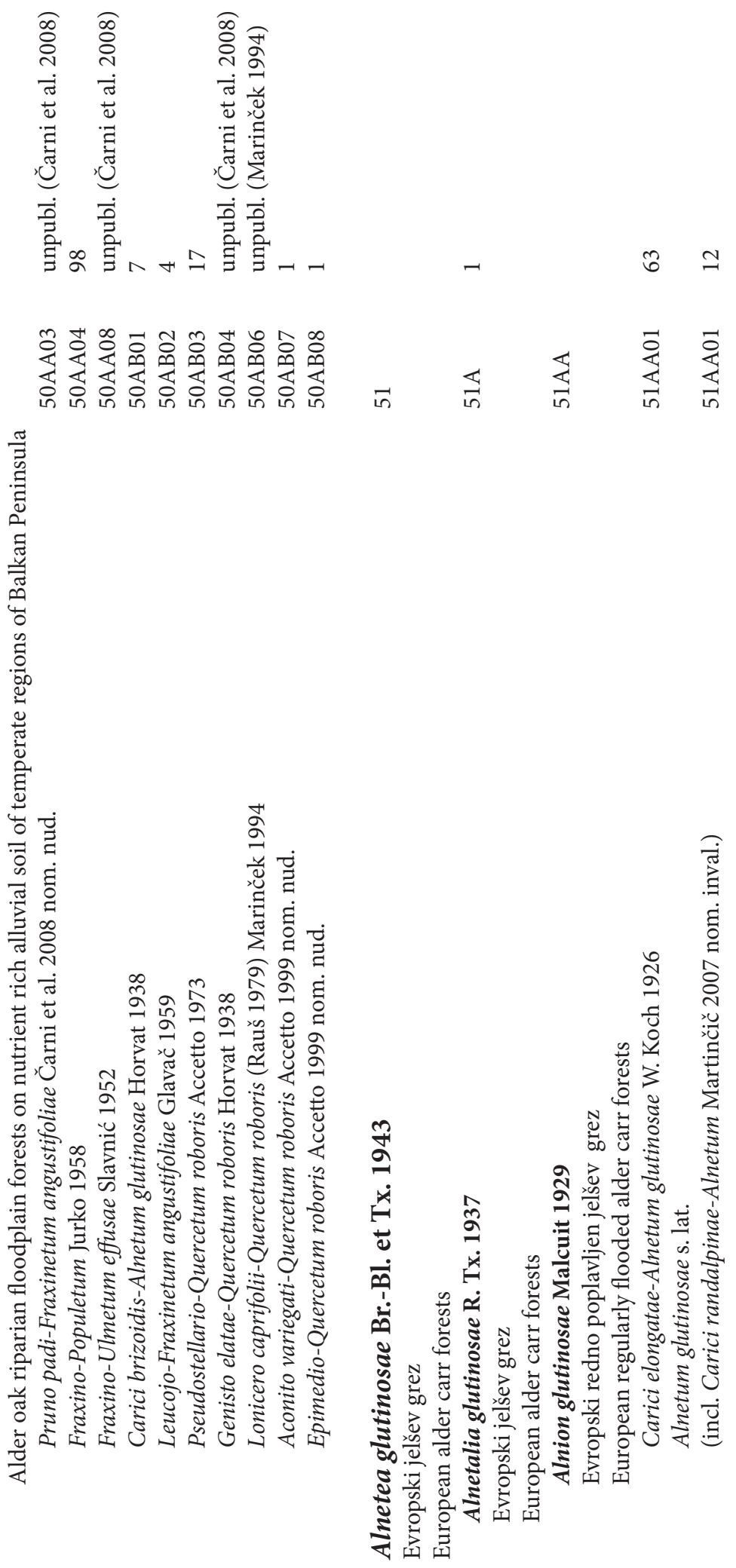